NIST Special Publication 250-83

Revision 1

\title{
Calibration of Hygrometers with the Hybrid Humidity Generator
}

\author{
C. W. Meyer \\ T. Herman \\ W. W. Miller
}

This publication is available free of charge from: https://doi.org/10.6028/NIST.SP.250-83r1
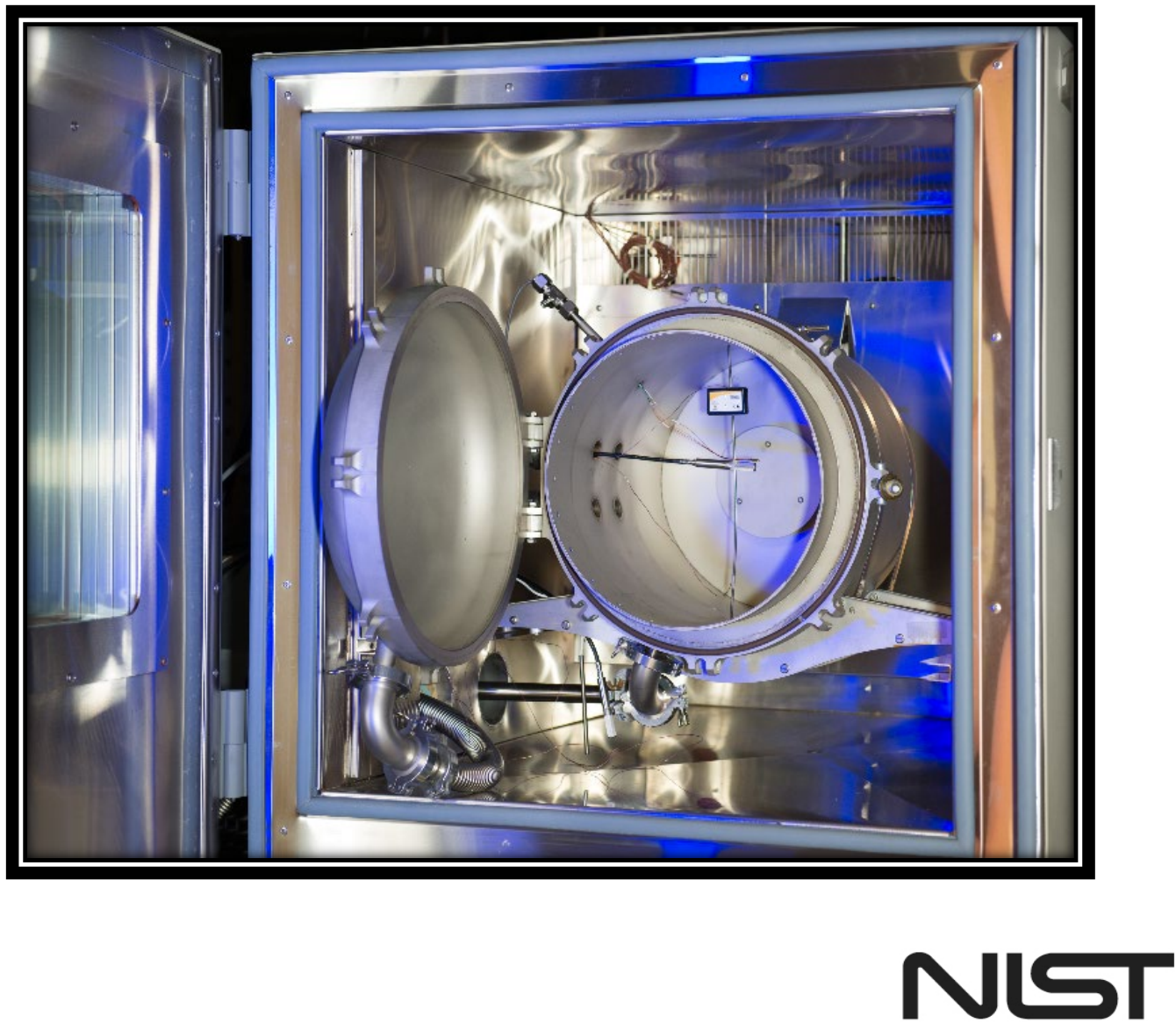

National Institute of Standards and Technology U.S. Department of Commerce 


\title{
Calibration of Hygrometers with the Hybrid Humidity Generator
}

\author{
C. W. Meyer \\ T. Herman \\ W. W. Miller \\ Thermodynamic Metrology Group \\ Sensor Science Division \\ Physical Measurement Laboratory
}

This publication is available free of charge from:

https://doi.org/10.6028/NIST.SP.250-83r1

September 2021

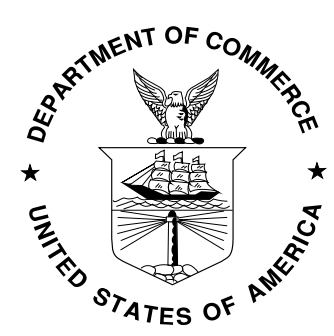

U.S. Department of Commerce

Gina M. Raimondo, Secretary

National Institute of Standards and Technology James K. Olthoff, Performing the Non-Exclusive Functions and Duties of the Under Secretary of Commerce for Standards and Technology \& Director, National Institute of Standards and Technology 
Certain commercial entities, equipment, or materials may be identified in this document in order to describe an experimental procedure or concept adequately. Such identification is not intended to imply recommendation or endorsement by the National Institute of Standards and Technology, nor is it intended to imply that the entities, materials, or equipment are necessarily the best available for the purpose.

National Institute of Standards and Technology Special Publication SP 250-83 Revision 1 Natl. Inst. Stand. Technol. Spec. Publ. 250-83 Rev. 1, 75 pages (September 2021)

CODEN: NSPUE2

This publication is available free of charge from: https://doi.org/10.6028/NIST.SP.250-83r1 


\begin{abstract}
We describe here the calibration of customer hygrometers using the NIST Hybrid Humidity Generator (HHG). This generator produces humidified air with water amount fractions (water mole fractions) ranging from $1.0 \times 10^{-7}$ to 0.57 using calibration gas flows up to 150 standard liters per minute. At ambient pressure these amount fractions correspond to dew/frost points ranging from $-90{ }^{\circ} \mathrm{C}$ to $+85{ }^{\circ} \mathrm{C}$. The HHG may be used to calibrate instruments measuring water amount fraction, such as cavity ring-down hygrometers. It may also be used to calibrate chilled-mirror hygrometers measuring dew/frost-point temperature when an additional pressure measurement is made at the inlet of the hygrometer. Finally, the HHG may be used to provide humidified air for the calibration of relative humidity sensors in a temperature-controlled test chamber; for this, an additional temperature measurement is made in the chamber. These sensors may be calibrated over the range $2 \%$ to $98 \% \mathrm{RH}$ for temperatures between $-34{ }^{\circ} \mathrm{C}$ and $85{ }^{\circ} \mathrm{C}$.

The HHG combines the two-pressure and divided-flow humidity generation methods (hence the name "hybrid"). The centerpiece of the HHG is a heat exchanger/saturator that is immersed in a temperature-controlled bath stable to within $1 \mathrm{mK}$. For dew/frost-point temperatures that are above $-10.3{ }^{\circ} \mathrm{C}$, the two-pressure method is employed. For frost points at or below $-10.3{ }^{\circ} \mathrm{C}$, the water-vapor/air mixture is produced by mixing metered streams of moist air produced by the twopressure method with purified, dry air.

In this special publication, we describe the design of the generator and its test chamber. We also describe a series of performance and validation tests on the HHG and its test chamber and use the results of these to construct an uncertainty budget for the generator when used in two-pressure mode and when used in the divided-flow mode. These tests include measurements of temperature gradients and pressure stability in the generator under various operating conditions, and comparison of the humidity generated by the HHG to that generated or measured by the other NIST humidity standards. For dew/frost-point temperatures, the uncertainty budget yields a total expanded uncertainty $(k=2)$ of less than $0.025^{\circ} \mathrm{C}$ for dew/frost-point temperatures above $-60{ }^{\circ} \mathrm{C}$. For amount fraction, the budget yields a total expanded relative uncertainty of less than $0.2 \%$ for amount fractions above $2 \times 10^{-5}$. For relative humidity in the test chamber, the budget yields a total expanded relative uncertainty of less than $0.3 \%$.
\end{abstract}

Key Words: humidity; generator; standards; saturator; calibration; hygrometer; water vapor, dew point, frost point, water amount fraction, water mole fraction, water mass ratio. 


\section{Calibration of Hygrometers with the Hybrid Humidity Generator}

Table of Contents

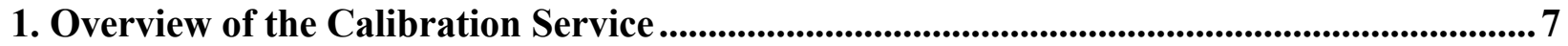

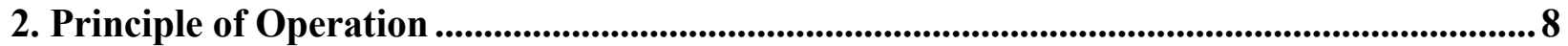

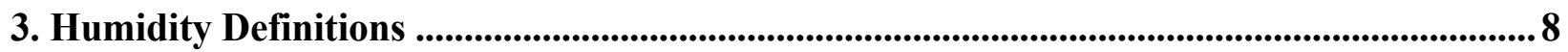

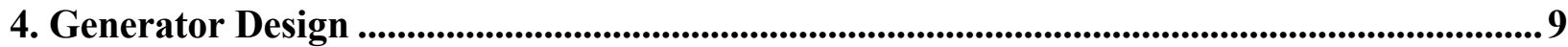

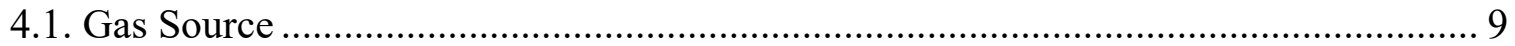

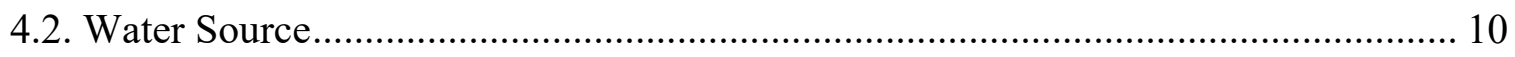

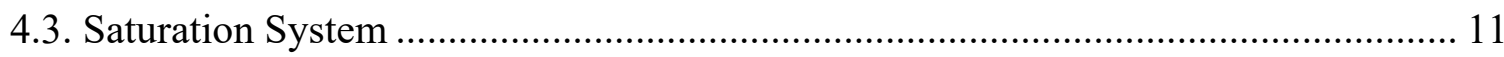

4.4. Implementation of the Two-Pressure Method ....................................................... 14

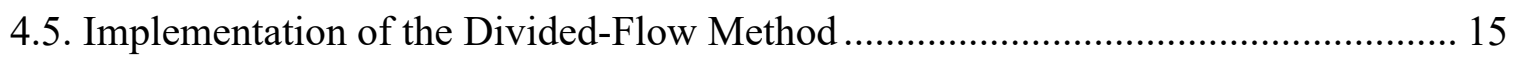

5. Performance and Validation Tests of the Generator .......................................................... 17

5.1. Temperature Uniformity and Stability in Final Saturator..................................... 17

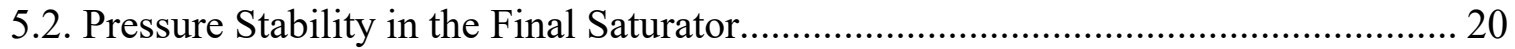

5.3. Self-consistency of the Generator in 2-P Mode.................................................. 21

5.4. Water Amount Fraction in the Dry Air in the Divided-Flow Method ....................... 22

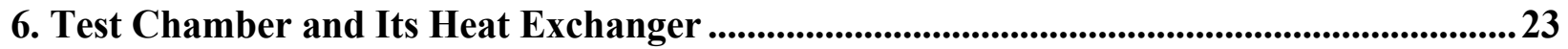

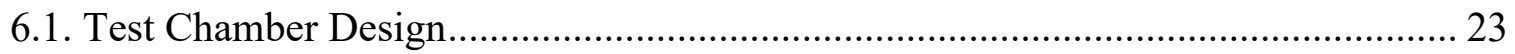

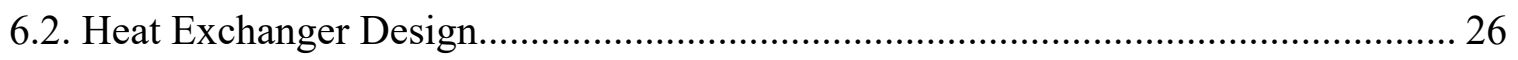

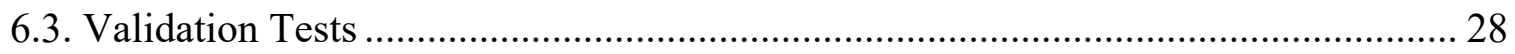

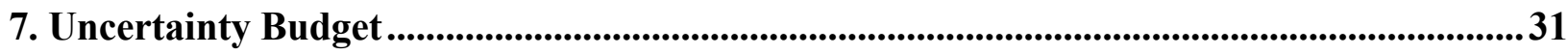

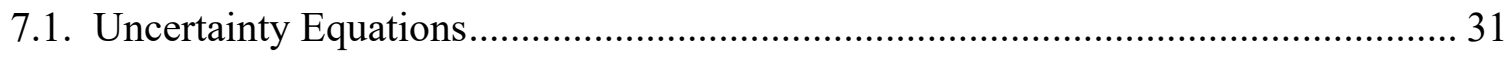

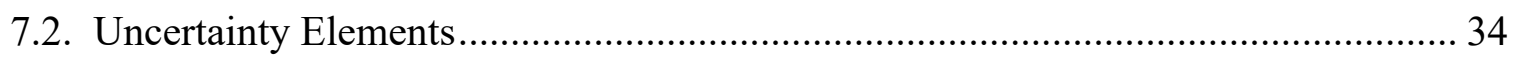

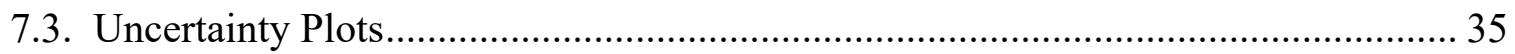

8. Comparisons with other Humidity Standards ................................................................... 43

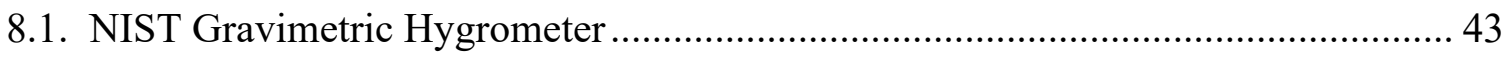

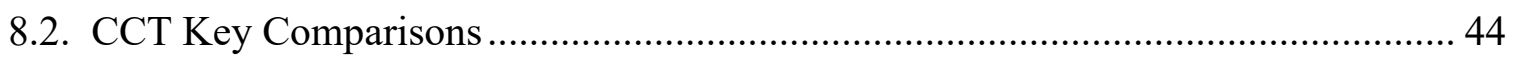

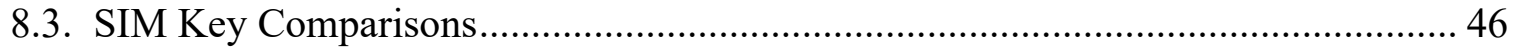

9. Calibration of Chilled-Mirror Hygrometers and Cavity Ringdown Spectrometers .......... 47

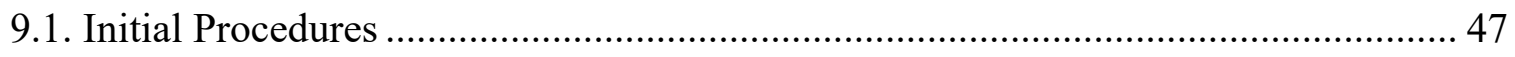

9.2. Connecting the Hygrometers to the Hybrid Generator ........................................ 47

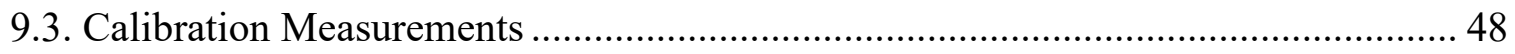

10. Calibration of Thermohygrometers and Dataloggers...................................................49

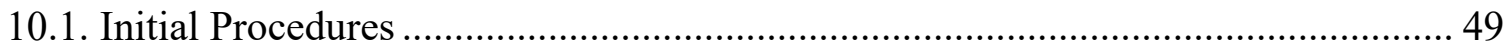

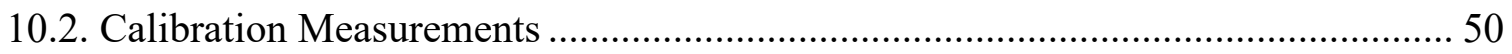

11. Quality Control ...............................................................................................................................51 


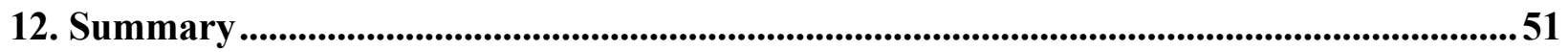

Acknowledgements...................................................................................................................................52

References ..........................................................................................................................................5

Appendix I. Derivation of the Uncertainty Equations for the Hybrid Generator ....................56

Appendix II. Uncertainty Element Subcomponents for the HHG and its Test Chamber ....64

Appendix III. Sample Calibration Reports .............................................................................................65 


\section{Overview of the Calibration Service}

The NIST Hybrid Humidity Generator (HHG) [1-3] provides calibration services for a variety of humidity-measuring instruments. It is operated by the Thermodynamic Metrology Group of the Sensor Science Division, which is part of the Physical Measurement Laboratory. Calibrations are performed by subjecting the instrument under test to air with an accurately known moisture content produced by the generator. The calibration system includes a test chamber (a chamber into which the humid air is directed and where the temperature and pressure are sufficiently constant and uniform), which is used for calibrating relative humidity sensors. The calibrations may be performed using humidity definitions of dew/frost point, relative humidity, water amount fraction (water mole fraction), or water mass ratio. Relative humidity calibrations can be performed on both relative humidity sensors and chilled-mirror hygrometers that have an external temperature probe. Relative humidity sensors are calibrated by placing them in the HHG's test chamber with humidified air flowing through it. Relative humidity calibrations for chilled-mirror hygrometers are performed by having the hygrometer measure the dew point of the air generated by the HHG while comparing the temperature measured by the hygrometer's external temperature probe with that of a reference thermometer. The instruments and ranges of calibration include but are not restricted to:

1. Chilled-Mirror Hygrometers, calibrated at customer-specified points over the dew/frost range of $-90{ }^{\circ} \mathrm{C}$ to $+85^{\circ} \mathrm{C}$, or alternatively over the relative-humidity range $2 \%$ to $98 \%$ for temperatures between $-34{ }^{\circ} \mathrm{C}$ and $85{ }^{\circ} \mathrm{C}$.

2. Temperature and Relative Humidity Sensors (Thermohygrometers), calibrated over the relative humidity range $2 \%$ to $98 \%$ for temperatures between $-34{ }^{\circ} \mathrm{C}$ and $85^{\circ} \mathrm{C}$.

3. Cavity Ring-Down Hygrometers, calibrated at customer-specified points over an amount fraction range of $1 \times 10^{-7}$ to the upper limit of the hygrometer.

Customers should consult the web address https://shop.nist.gov to find the most current information regarding calibration fees and technical contacts. The Thermodynamic Metrology Group follows the policies and procedures described in the NIST Calibration Services Users Guide, which can be found at these web addresses:

http://www.nist.gov/calibrations/policy.cfm

http://www.nist.gov/calibrations/domestic.cfm and

http://www.nist.gov/calibrations/foreign.cfm. These web pages give instructions for ordering a calibration for domestic and foreign customers. They discuss a) customer inquiries, b) prearrangements and scheduling, c) purchase orders, d) shipping, insurance, and risk of loss, and e) turnaround time. 


\section{Principle of Operation}

Generation of gas with an accurately known moisture content starts with saturating the gas with water at a known temperature and pressure. Controlled saturation is accomplished by flowing a stream of the gas over a layer of water with a constant, uniform temperature until the gas is in thermodynamic equilibrium with the water. Ideally, the pressure of the gas is constant and pressure gradients within the gas are negligible. The water amount fraction $x$ in the gas is then calculated using the equation

$$
x=\frac{e\left(T_{\mathrm{s}}\right)}{P_{\mathrm{s}}} f\left(T_{\mathrm{s}}, P_{\mathrm{s}}\right)
$$

Here, $T_{\mathrm{s}}$ and $P_{\mathrm{s}}$ are the temperature and pressure of the gas and water in the saturator, and $e\left(T_{\mathrm{s}}\right)$ is the water vapor pressure at $T_{\mathrm{s}}$, as calculated by [4]. The enhancement factor $f\left(T_{\mathrm{s}}, P_{\mathrm{s}}\right)$ reflects departures from ideal solution behaviour and non-ideal gas effects [5]. When $P_{\mathrm{s}}$ is approximately at ambient pressure, the generator is said to operate in one-pressure (1-P) mode.

At a given value of $T_{\mathrm{s}}$, two methods can be used to lower the humidity while still knowing its value accurately: the two-pressure (2-P) method and the divided-flow method. The HHG is capable of using these two methods separately or together (hence the name hybrid). The two-pressure method [6] involves saturating the gas at an elevated pressure and afterwards expanding the gas down to ambient pressure. The divided-flow method [6] involves diluting the saturated gas with dry gas using precisely metered streams of gas. Such a technique allows generation of arbitrarily low humidity values while operating the saturator at convenient temperatures. When performing hygrometer calibrations, the HHG operates in 1-P or 2-P mode for amount fractions greater than $2.5 \times 10^{-3}$ (a frost point of $-10.3^{\circ} \mathrm{C}$ ). The HHG uses the divided flow method for amount fractions at or less than this value.

\section{Humidity Definitions}

The HHG generates humidity by the definition of water amount fraction, but calibrations are also performed for other definitions, though they may require additional measurements.

The dew-point temperature $T_{\mathrm{DP}}$ is defined as the temperature (for a given amount fraction $x$ and gas pressure $P_{\mathrm{c}}$ ) at which liquid water and water vapor are in equilibrium. Here, the subscript "c" in $P_{\mathrm{c}}$ refers to the chamber in which the dew point is being determined, (although the gas, if air, is often in an open environment). Experimentally, determination of $T_{\mathrm{DP}}$ requires the additional measurement of $P_{\mathrm{c}}$. Once $P_{\mathrm{c}}$ has been determined, $T_{\mathrm{DP}}$ is obtained by iteratively solving the equation

$$
x=\frac{e\left(T_{\mathrm{DP}}\right)}{P_{\mathrm{c}}} f\left(T_{\mathrm{DP}}, P_{\mathrm{c}}\right) .
$$

While Eq. 2 is structurally similar to Eq. $1, T_{\mathrm{DP}}=T_{\mathrm{s}}$ only when $P_{\mathrm{c}}=P_{\mathrm{s}}$. Similarly, the frost-point temperature $T_{\mathrm{FP}}$ is given by 


$$
x=\frac{e_{\mathrm{i}}\left(T_{\mathrm{FP}}\right)}{P_{\mathrm{c}}} f\left(T_{\mathrm{FP}}, P_{\mathrm{c}}\right),
$$

where $e_{\mathrm{i}}$ is the saturated vapor pressure for ice, as calculated by [8,9].

Relative humidity $(R H)$ is defined by the World Meteorological Organization (WMO) to be [7]

$$
R H \equiv \frac{x}{x_{\mathrm{s}}}=\frac{e_{\mathrm{p}}}{e\left(T_{\mathrm{c}}\right) f\left(T_{\mathrm{c}}, P_{\mathrm{c}}\right)}=\frac{x P_{\mathrm{c}}}{e\left(T_{\mathrm{c}}\right) f\left(T_{\mathrm{c}}, P_{\mathrm{c}}\right)}
$$

where $x_{\mathrm{s}}$ is the water amount fraction at saturation, $e_{\mathrm{p}}$ is the partial pressure of the water vapor in the air and $T_{\mathrm{c}}$ is the air temperature in the chamber or location of interest. Experimentally, determination of $R H$ requires the additional measurements of $P_{\mathrm{c}}$ and $T_{\mathrm{c}}$. Chilled-mirror hygrometers that determine $R H$ do so by directly measuring $T_{\mathrm{DP}}$ using the chilled mirror, measuring $T_{\mathrm{c}}$ with an external thermometer, and calculating $R H$ using Eqs. 2-4 while assuming $f\left(T_{\mathrm{DP}}, P_{\mathrm{c}}\right) \cong f\left(T_{\mathrm{c}}, P_{\mathrm{c}}\right)$.

The water mass ratio $r$ is equal to the ratio of water mass to air mass in a given volume of gas, and is related to the amount fraction by

$$
r=\frac{m_{\mathrm{w}}}{m_{\mathrm{a}}} \frac{x}{1-x}=0.62196 \frac{x}{1-x},
$$

where $m_{\mathrm{w}}=18.015268 \mathrm{~g} / \mathrm{mol}[10]$ and $m_{\mathrm{a}}=28.96546 \mathrm{~g} / \mathrm{mol}$ [11] are the molar masses of water and air, respectively.

\section{Generator Design}

A schematic representation of the layout of the HHG is shown in Fig. 1 for a) the 2-P mode and b) the divided-flow mode. The system involves a dry gas source, a two-pressure saturation system, and (for divided-flow mode) a dilution system. The components of the HHG are described below.

\subsection{Gas Source}

The gas normally used in the HHG comes from the in-house supply of compressed air at NIST that has a pressure head of $550 \mathrm{kPa}$. Before entering the generator, the gas passes through a large regenerating gas dryer and $\mathrm{CO}_{2}$ scrubber; this reduces the water amount fraction to $1 \times 10^{-6}$ and removes $95 \%$ of the $\mathrm{CO}_{2}$. The $\mathrm{CO}_{2}$ removal prevents a reaction between it and the saturator water that forms carbonic acid. After purification, the gas passes through a $240 \mathrm{~L}$ ballast tank which serves to minimize pressure pulses produced by the gas dryer. Under special request, the HHG may use dry nitrogen boiled off from dewars of liquid nitrogen (chilled mirror and cavity ringdown spectrometers only). In this case, the gas does not pass through the filters, dryers, and ballast tank. 
Computer-controlled mass flow controllers regulate the gas flow; the maximum gas flow is $150 \mathrm{~L} / \mathrm{min}$.

\subsection{Water Source}

The water used in the HHG is produced by a commercial water distilling system. The water source for the system comes from the in-house supply of water at NIST. Before entering the distiller, the water goes through a small particle filter, a carbon filter, and a descaling filter. Once produced by the distiller, the water is held in a high-density linear polyethylene container of volume $140 \mathrm{~L}$, which rests above the pre-saturator (described below).

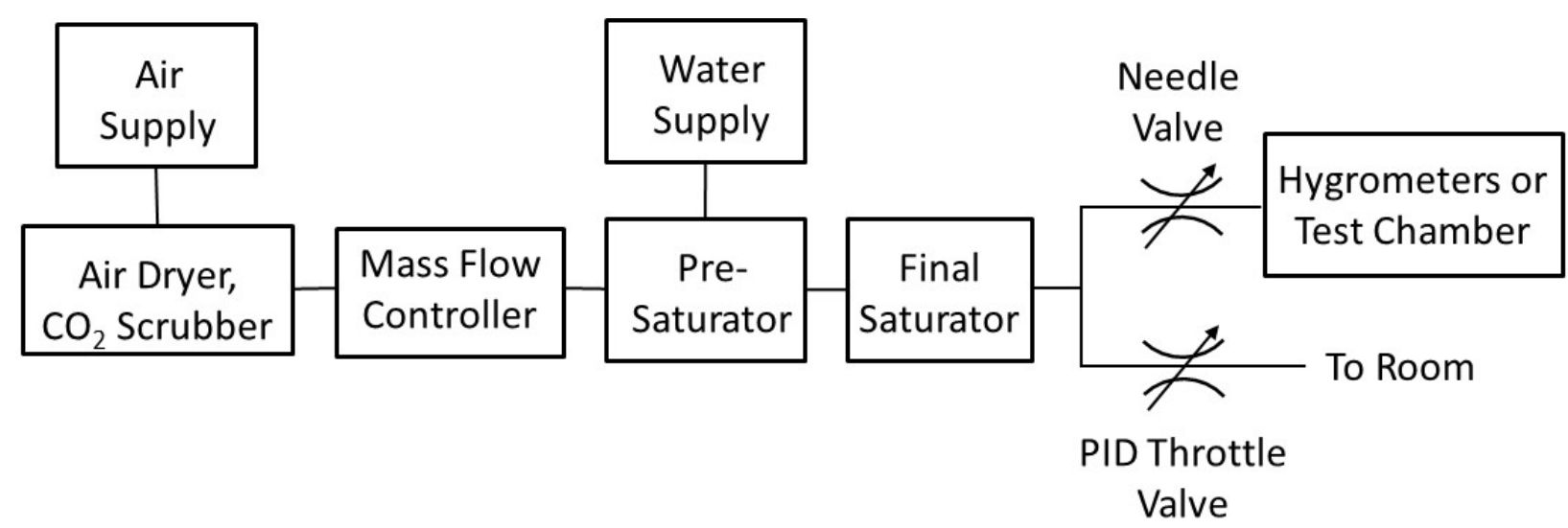

(a)

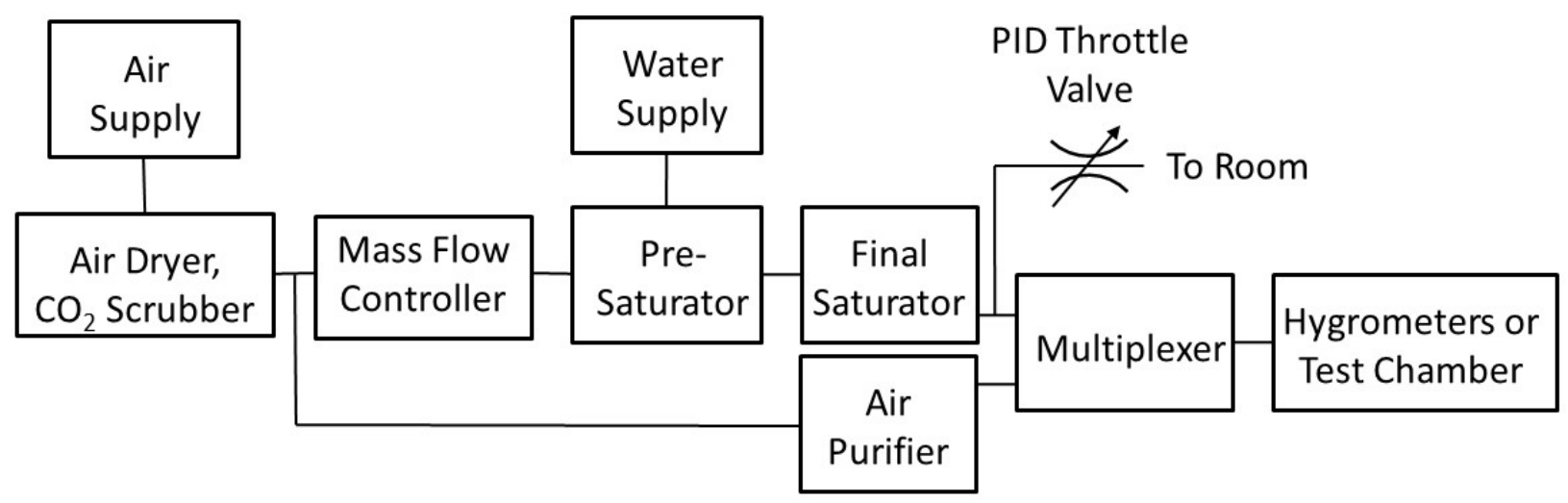

(b)

Figure 1. Schematic representation of the hybrid humidity generator (HHG) in a) two-pressure mode and b) divided-flow mode. The components used in these modes are all described in Section 4. 


\subsection{Saturation System}

The saturation system of the HHG consists of a pre-saturator and final saturator with a temperature-controlled tube connecting them. These parts are described below.

\subsubsection{Pre-saturator}

The pre-saturator accomplishes virtually all of the saturation, and the final saturator performs small adjustments to ensure that the generated humidity is constant and determinable with minimal uncertainty.

The purpose of the pre-saturator is to allow the HHG to generate high water amount fractions with low uncertainty. For a thermodynamic generator to accomplish this, the dry carrier gas must be humidified to a dew-point temperature nearly equal to the final saturator temperature before entering the saturator. Since water amount fractions in the HHG approach 0.57 , operation without a pre-saturator would cause excessive latent heat loading on the final saturation process. This would introduce large temperature gradients in the final saturator, resulting in large uncertainties in the water amount fraction in the gas.

A schematic diagram of the pre-saturator is shown in Fig. 2. It is a commercially made system that saturates the incoming gas by first passing the gas through its saturation chamber. In this chamber, the gas is sprayed with water at temperatures above the desired dew-point temperature. Afterwards the gas passes through the pre-saturator's heat exchanger (coil), which is controlled at approximately the desired dew-point temperature. The gas's excess moisture condenses inside this heat exchanger and flows down to the pre-saturator's water reservoir.

\subsubsection{Connecting Tube}

The pre-saturator and final saturator are connected using $2.5 \mathrm{~cm}$ diameter stainless steel tubing. When dew points higher than the ambient temperature are to be generated, the tubing is temperature-controlled to be about $30{ }^{\circ} \mathrm{C}$ higher than the desired dew point in order to prevent water condensation in the tubing. To ensure a uniform temperature of the inner tube, with no cold spots where water could condense, the connecting tube is surrounded by an outer aluminum "shell" tube of inner diameter $7.3 \mathrm{~cm}$ and outer diameter $7.6 \mathrm{~cm}$. Resistance heaters wound around this shell tube heat it to the desired temperature. Industrial process controllers with thermocouple sensors control the temperature of the shell tube. Heating of the connecting tube is accomplished by heat transfer through air from the outer tube. Heating the connecting tube in this way generates less temperature non-uniformities on the tube than if the resistance heaters were directly attached to the tube.

\subsubsection{Final Saturator}

The final saturator is composed of a heat exchanger and saturation chamber. Both systems rest inside a commercially made temperature-controlled bath of volume $167 \mathrm{~L}$ that is uniform to within $0.003{ }^{\circ} \mathrm{C}$ at $25^{\circ} \mathrm{C}$. The heat exchanger is located immediately above the saturation chamber in the 
bath. The gas first enters the heat exchanger, which conditions the gas to be at the temperature of the saturation chamber; this minimizes sensible heat loading on the chamber and also minimizes latent heat loading on it if the entering gas is oversaturated. In addition, the heat exchanger condenses out any moisture above the dew point of the saturation chamber; this condensed water is then directed down into the saturation chamber. The heat exchanger is made of $316 \mathrm{~L}$ stainless steel and is composed of two header tanks separated by an array of 116 parallel tubes with inner diameter $7.8 \mathrm{~mm}$ and length $48.5 \mathrm{~cm}$. The parallel tube design minimizes the pressure drop across the heat exchanger. The diameter of the tubes is sufficiently large to prevent them from being blocked by condensed water droplets. With the tube dimensions described and with a gas flow of $150 \mathrm{~L} / \mathrm{min}$, the gas flows through the parallel tubes for a period of about ten thermal time constants.

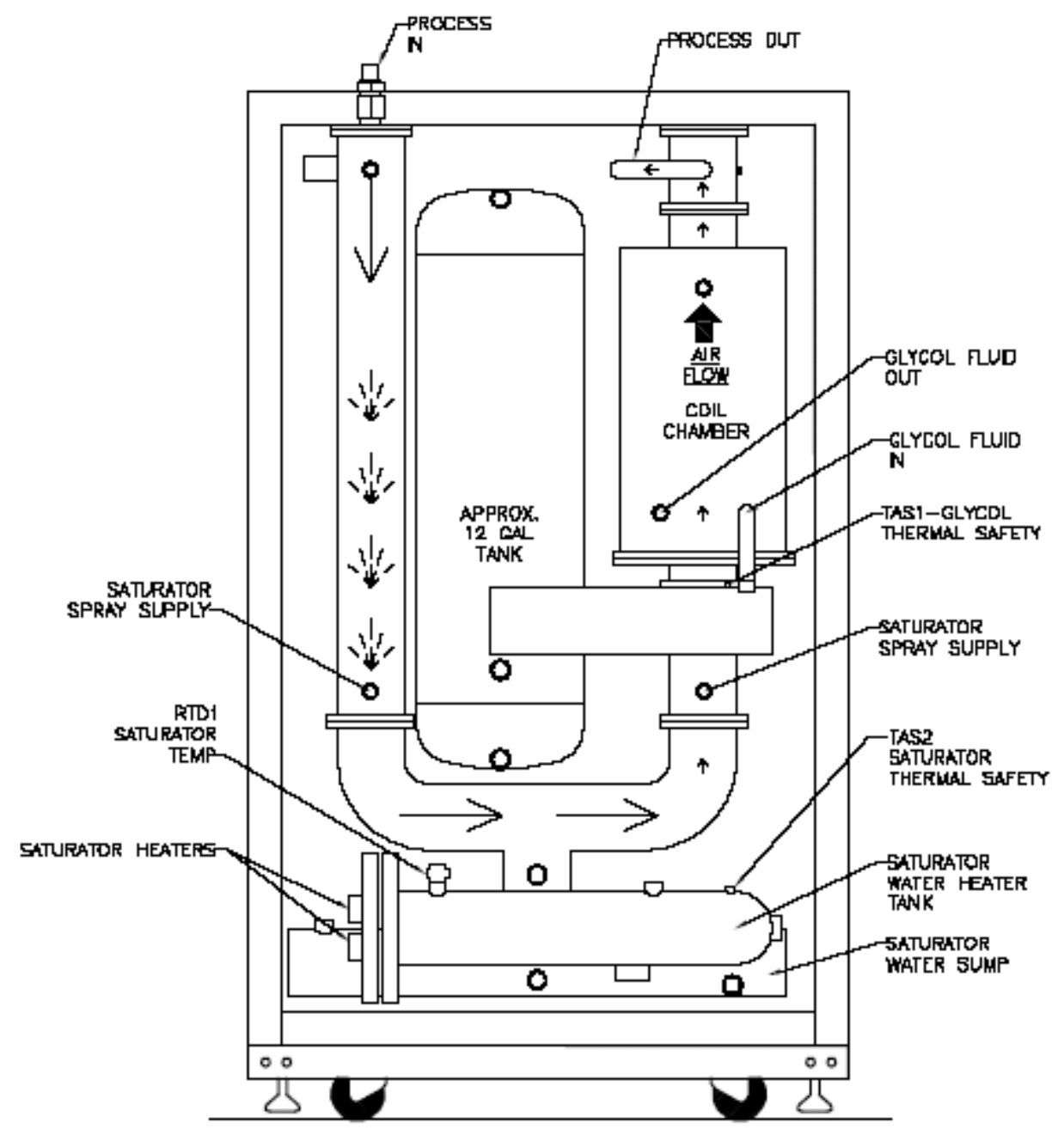

Figure 2. Schematic diagram of the pre-saturator of the HHG.

The gas exiting the heat exchanger flows into the saturation chamber below. The chamber is flat and roughly rectangular in shape. The saturation chamber is also made of $316 \mathrm{~L}$ stainless steel and contains a $2.2 \mathrm{~cm}$ layer of water and a $2.2 \mathrm{~cm}$ layer of gas above it. The chamber has a horizontal area of $0.28 \mathrm{~m}^{2}$, with total water and gas volumes of $6.16 \mathrm{~L}$ each. Stainless steel dividers inside 
the saturator partition the chamber into two channels of width $3.7 \mathrm{~cm}$ that follow a serpentine path, as shown in Fig. 3. Each channel covers half the area of the saturation chamber, as shown. The dividers are continuously welded along their lengths into the top plate of the chamber, allowing no gas flow over the dividers. Twisted vanes are welded to the dividers to improve mixing between the gas and water vapor while the gas is in the saturation chamber.

Inside the saturation chamber, a rectangular cross section rather than a circular cross-section is used because the former exhibits less sensitivity to water height changes than would a circular cross-section design. For a given water level, the rectangular section contains more water volume and has a smaller rate of change in airway cross-sectional area with water level, relative to a circular cross section. Therefore, increases in water volume in the chamber (from water condensation in the heat exchanger) are less likely to restrict the airway; this allows the generator to produce very high dew-point temperatures for significant time periods.

After the final saturator was constructed, the stainless steel inside was commercially passivated to ensure that the saturator would not contaminate the water stored in it. Since then, samples of water kept in the saturator for several months have been analyzed and show no noticeable increase in the level of impurities.

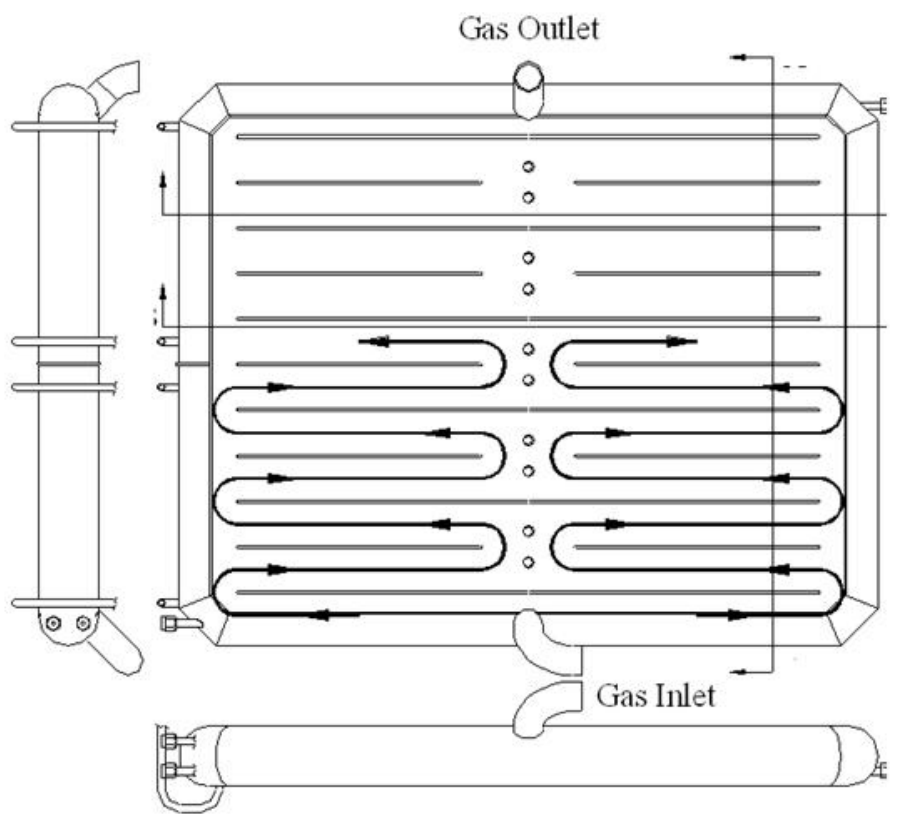

Figure 3. Schematic diagram of the saturation chamber.

The temperature of the final saturator is determined using a standard platinum resistance thermometer (SPRT) immersed in the temperature-controlled bath. The SPRT was calibrated on the International Temperature Scale of 1990 (ITS-90) by the NIST Thermodynamic Metrology Group. The resistance of the SPRT is measured using a computer-interfaced AC resistance bridge with a temperature-controlled $100 \Omega$ standard resistor as the reference resistor. A pressure transducer based on a silicon strain gauge, interfaced to a computer, measures the pressure in the saturator; the gauge is connected to a point in the saturator near the gas outlet using $1 / 4$ inch $(0.635 \mathrm{~cm})$ stainless-steel tubing. This tubing is at a sharp vertical slope in the region immediately 
above the saturator. Therefore, when the saturator temperature is greater than the ambient temperature, any condensation occurring in the tubing is directed down to the saturator; this ensures that the transducer is never exposed to condensed water and always properly measures the pressure inside the saturator. Chamber pressure measurements (for dew point and relative humidity determination) are also made with a pressure transducer based on a silicon strain gauge. Both transducers are periodically calibrated by the NIST Thermodynamic Metrology Group.

The entire heat-exchanger/final-saturator system is shown in Fig. 4. A horizontal plate on top of the heat exchanger supports the system inside the temperature-controlled bath and also serves as the top cover to the bath. Two sets of water fill tubes and exit tubes can be seen in the figure, one for each channel. The fill tubes are used to fill the saturation chamber with water. The exit tubes are used to withdraw water that is above the fill level; this is accomplished by briefly increasing the pressure of the saturator above ambient and then opening the valve to the exit tubes. When viewed from above, the saturator and heat exchanger nearly fill the bath chamber, and almost touch a baffle plate attached to the two bath stirrers (see figure). This configuration promotes optimal circulation of water within the bath with minimal dead-zones. Such a design minimizes temperature non-uniformity in the bath.

\subsection{Implementation of the Two-Pressure Method}

The two-pressure method [6] involves saturating the gas at an elevated pressure and afterwards expanding the gas down to ambient pressure. The advantage of this technique is that a range of humidity values can be generated using one saturator temperature. This is useful for two reasons. First, it is much faster for an operator to change the saturator pressure than to change the saturator temperature. Second, the low humidity limit of the generator is lowered, since the amount fraction is inversely proportional to the saturator pressure.
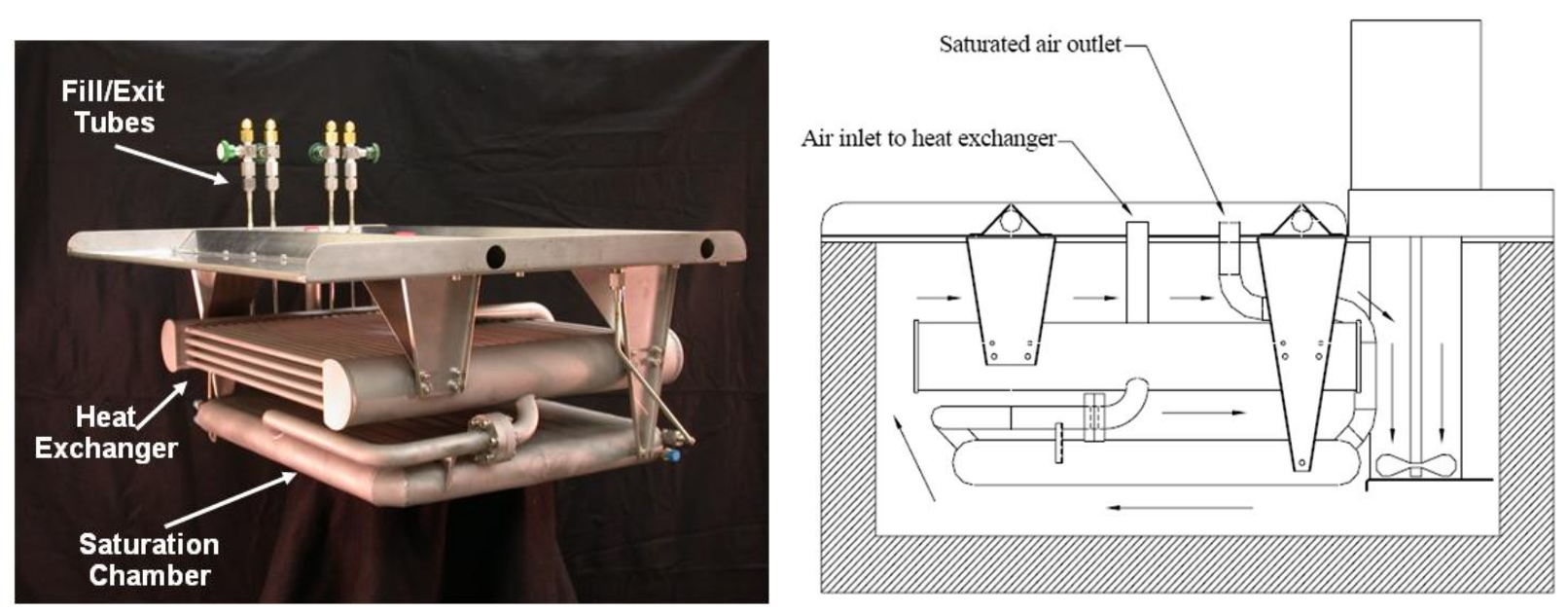

Figure 4. The final saturator. Photograph of the saturator, showing the heat exchanger and saturation chamber (left), and schematic diagram of the saturator in the temperature-controlled bath, showing direction of water flow in the bath (right). 
The HHG employs the two-pressure method by first using the $550 \mathrm{kPa}$ pressure head of the gas source to raise the pressure in the saturator to the desired value, flowing the gas with a rate of $30 \mathrm{~L} / \mathrm{min}$. It then uses an expansion valve at the exit of the saturation chamber to control the pressure. The expansion valve consists of a throttle valve with a high-speed motor/gear assembly. A PID controller that senses the pressure using the strain gauge mentioned above sets the opening of the throttle. The valve is located immediately above the temperature-controlled bath and is connected to the gas outlet from the saturator. Figure 5 shows a photograph of the laboratory layout of the pre-saturator, saturator, connector tube, and throttle valve. Most of the humidified gas exits the saturator through the throttle valve. However, when dew/frost-point or amountfraction calibrations are performed, $3 \mathrm{~L} / \mathrm{min}$ to $5 \mathrm{~L} / \mathrm{min}$ of the humidified gas passes through a second expansion valve (a needle valve) attached to the saturator tubing immediately before the throttle valve (see Fig. 1a). In this case, the gas passing through the needle valve is used for calibration of customer hygrometers.

\subsection{Implementation of the Divided-Flow Method}

The divided-flow method [7] involves diluting the saturated gas with dry gas using precisely metered streams of gas. The amount fraction after dilution is

$$
x=\frac{\dot{n}_{\mathrm{s}} x_{\mathrm{s}}+\dot{n}_{\mathrm{p}} x_{\mathrm{p}}}{\dot{N}}
$$

where $\dot{n}_{\mathrm{s}}$ and $\dot{n}_{\mathrm{p}}$ are the molar flows of the saturated gas and pure gas, respectively, and $\dot{N}$ is the total molar flow. Also, $x_{\mathrm{s}}$ is the amount fraction of water in the saturated gas and $x_{\mathrm{p}}$ is the residual amount fraction of water in the pure gas; the value of $x_{\mathrm{p}}$ is assumed to be zero and its uncertainty is determined both from the efficiency of the gas purifier and from water outgassing from the tube walls of the manifold. Such a technique allows generation of arbitrarily low humidity values while operating the saturator at convenient temperatures. When generating low humidity, this method has two principal advantages. First, the temperature-controlled bath may be operated with water, which is much safer and less expensive than liquids with lower freezing temperatures. Second, the technique avoids the large temperature gradients in the generator bath that often exist at low temperatures; these gradients add large uncertainties to the uncertainty of the generated humidity. 


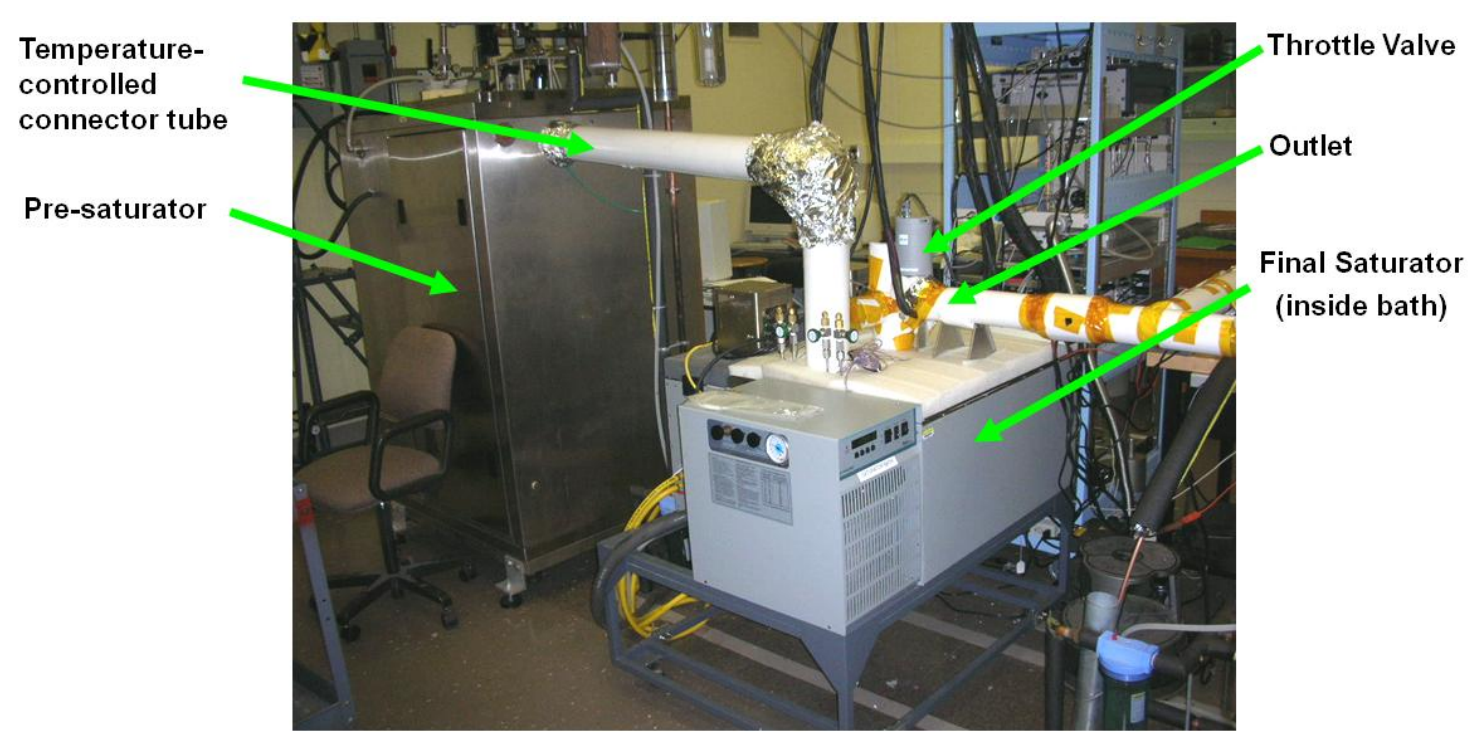

Figure 5. Laboratory configuration of several components of the HHG.

The HHG employs the divided-flow method using a gas multiplexer. The multiplexer contains seven flow-metering banks. Each bank consists of a commercially made mass-flow controller and a commercially made flow meter (a laminar-flow element) that measures the standard volume flow. The maximum flow for the meters are $10 \mathrm{~cm}^{3} / \mathrm{min}, 100 \mathrm{~cm}^{3} / \mathrm{min}, 1 \mathrm{~L} / \mathrm{min}, 10 \mathrm{~L} / \mathrm{min}$, $30 \mathrm{~L} / \mathrm{min}, 100 \mathrm{~L} / \mathrm{min}$, and $100 \mathrm{~L} / \mathrm{min}$. The upstream side of each flow bank is connected in parallel to both the saturated gas supply and a purified gas supply. When the divided-flow method is used, both the saturated gas supply (and hence the saturator) and the purified gas are kept at a pressure of approximately $300 \mathrm{kPa}$. The purified gas comes from the original gas source described in section 2.1, but it is additionally dried using a molecular sieve; the sieve is specified to reduce the water amount fraction of the gas to below $1 \times 10^{-9}$. The downstream side of each flow bank connects to a common outlet manifold. Pneumatic valves controlled by a computer select whether dry gas, wet gas, or no gas flows through each bank. For those banks with flow, the computercontrolled mass-flow controllers adjust the flow to provide the dilution nominally specified. The flow meters measure the flow of the saturated gas $\dot{v}_{\mathrm{s}}$ and the flow of the dry gas $\dot{v}_{\mathrm{p}}$ and provide this information to the computer. The two flows are added to obtain the total flow $\dot{V}$. The flow meters are periodically calibrated for pure air by the NIST Fluid Metrology Group using upstream pressures of $300 \mathrm{kPa}$ to replicate the conditions under which they are used. When measuring the air flow of the saturated gas (with $x=0.0022$ ), it is assumed that the change to the flow-meter calibration due to the saturation is negligible. It is also assumed that $\dot{n}_{\mathrm{s}} / \dot{N}=\dot{v}_{\mathrm{s}} / \dot{V}$ and $\dot{n}_{\mathrm{p}} / \dot{N}=\dot{v}_{\mathrm{p}} / \dot{V}$. Combining the above assumptions has been shown to cause an error of less than $3.5 \times 10^{-4} \dot{n}_{\mathrm{s}}$, which is below the calibration uncertainties for the flow meters. Figure 6 shows a photograph of the multiplexer. 


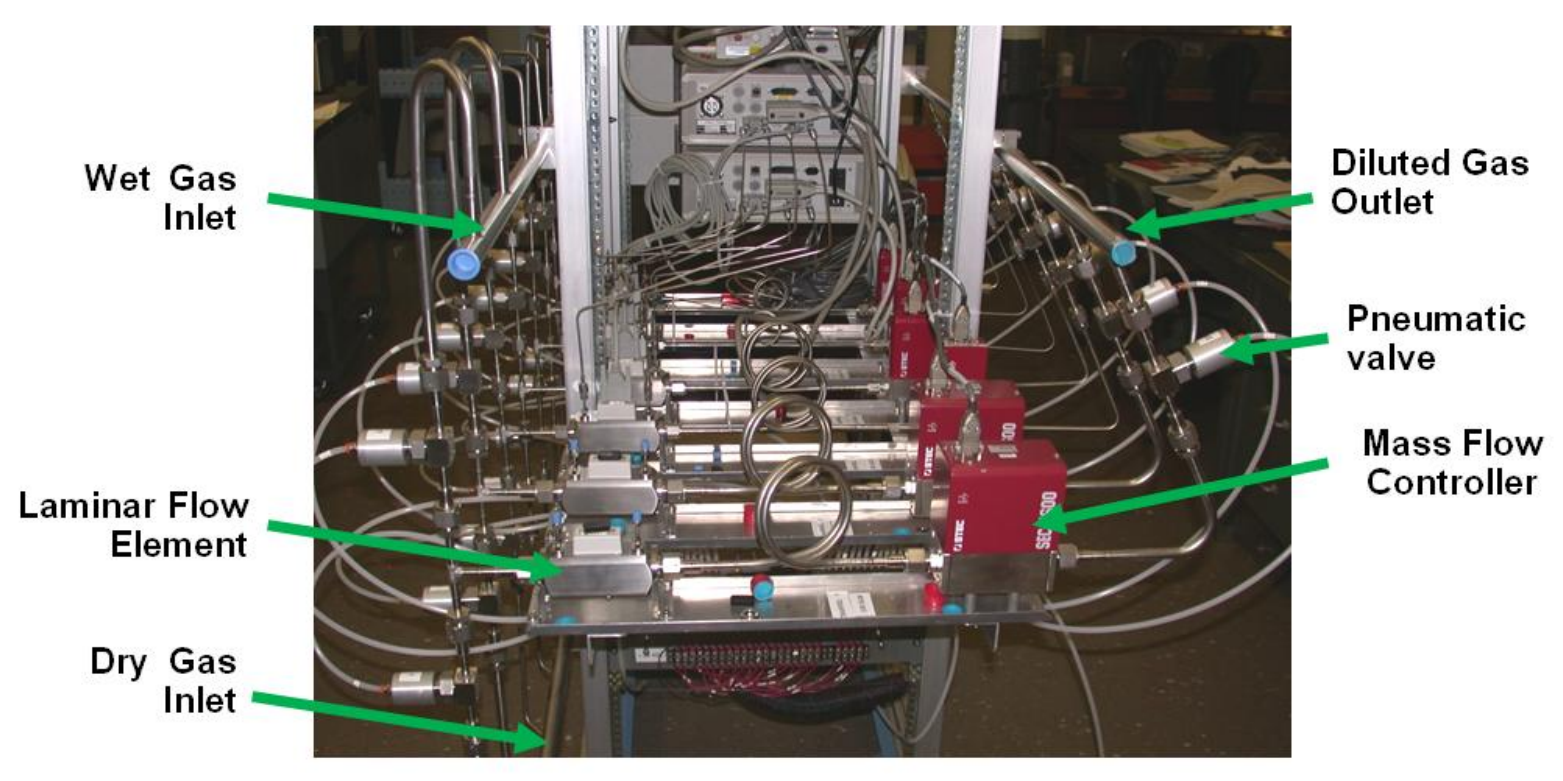

Figure 6. Photograph of the multiplexer, which is used when operating the HHG in divided-flow mode.

\section{Performance and Validation Tests of the Generator}

Performance tests were made on the HHG in two-pressure mode to determine components of an uncertainty budget for the generator. Specifically, we measured temperature gradients and temperature stability in the saturator bath, and temperature gradients and pressure stability inside the saturation chamber.

\subsection{Temperature Uniformity and Stability in Final Saturator}

We measured temperature non-uniformities in the bath with five type $\mathrm{K}$ thermocouples used in differential mode, measured with an $8 \frac{1}{2}$ digit multimeter through a scanner with low thermal emfs. We attached the reference junction of each thermocouple to the exit point from the saturator chamber and placed the measuring junction in thermal contact with the location of interest. The locations examined were the entrance to the heat exchanger, the exit from the heat exchanger, the entrance to the saturation chamber, the bath below the saturation chamber, and the bath above the saturation chamber.

Figure 7 shows the temperature non-uniformities measured. In a) they are shown as a function of bath temperature with no gas flow. Between $0{ }^{\circ} \mathrm{C}$ and $40{ }^{\circ} \mathrm{C}$, the non-uniformities are within the resolution of the measurements. At $60{ }^{\circ} \mathrm{C}$ non-uniformities become observable and at $85{ }^{\circ} \mathrm{C}$ they reach $16 \mathrm{mK}$. However, the largest non-uniformities are vertical, with the top of the bath being cooler than the bottom, and it has been found that the largest temperature variation (at the top of the bath by the entrance to the heat-exchanger) is strongly dependent on the bath fill level. In b) they are shown at $84{ }^{\circ} \mathrm{C}$ as a function of gas flow when the pre-saturator temperature is $85^{\circ} \mathrm{C}$. Here, the non-uniformities are plotted as a function of time; before $1800 \mathrm{~s}$ the flow is zero, and 

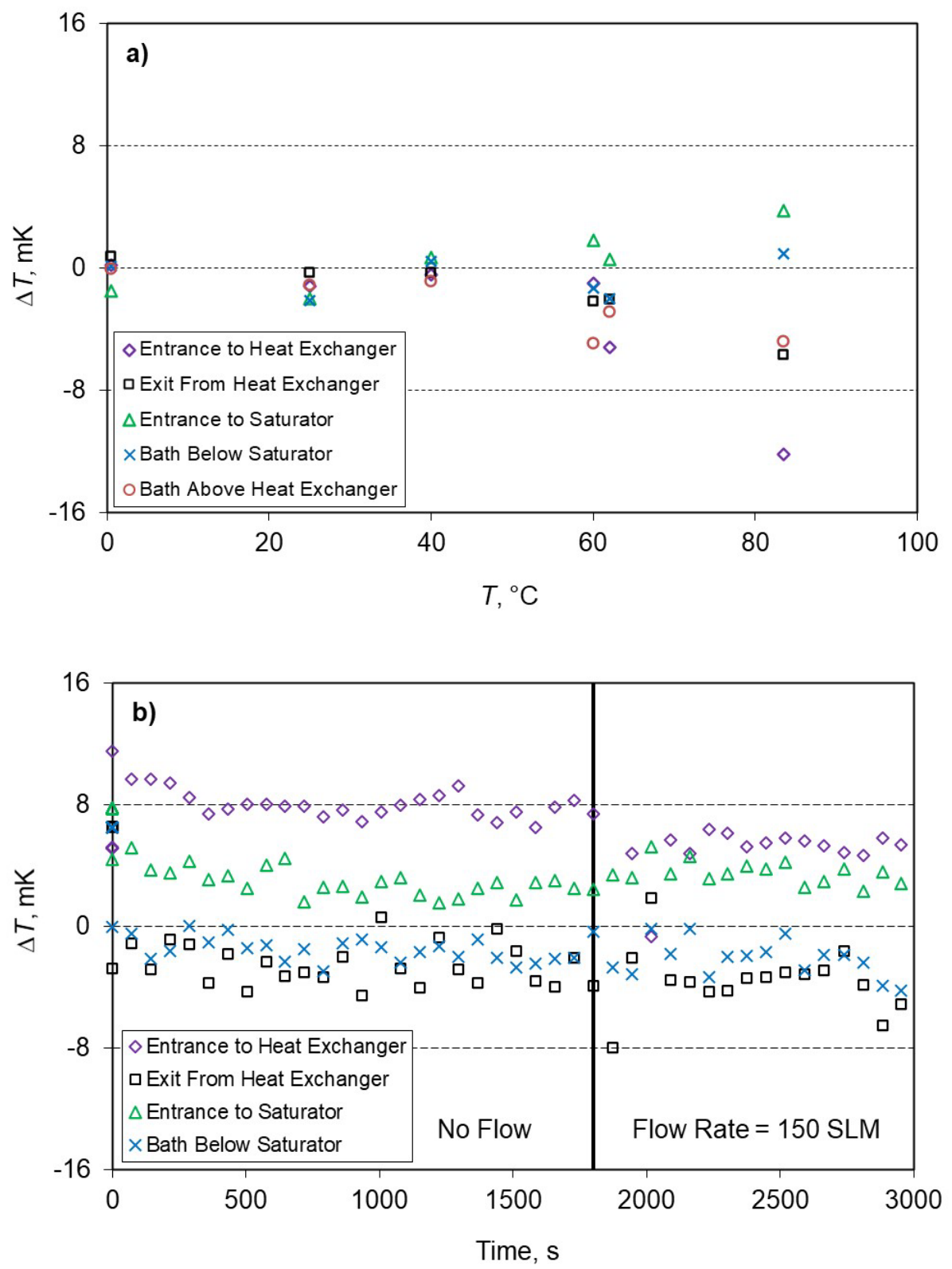

Figure 7. Temperature non-uniformities in the bath containing the final saturator, as measured by differential type $\mathrm{K}$ thermocouples attached to the outside of the saturator. The plots display temperature differences between the designated location and the exit point from the saturation chamber. In a), the non-uniformities are shown as a function of bath temperature when no gas flows through the generator. In $b$ ), the effect of gas flow on the non-uniformities is shown for a temperature of $84^{\circ} \mathrm{C}$. The non-uniformities are shown as a function of time, with no flow before $1800 \mathrm{~s}$ and $150 \mathrm{~L} / \mathrm{min}$ after $1800 \mathrm{~s}$. Here, the saturator is at ambient pressure and the pre-saturator is generating a dew point of $85^{\circ} \mathrm{C}$. 
after $1800 \mathrm{~s}$ the flow is $150 \mathrm{~L} / \mathrm{min}$. No significant difference in the non-uniformities is seen for these two flows. Note that the non-uniformity at the entrance to the heat exchanger is noticeably smaller in b) than in a); we attribute this to a higher bath fill level in b). In b), the non-uniformity in the bath above the heat exchanger is not shown because the corresponding thermocouple was not functioning when the measurements were made. As a result of these studies, we have concluded that during humidity calibrations the fill level of the bath should always be approximately $2.5 \mathrm{~cm}$ below the top lid of the bath container. When using the HHG, it is standard operating procedure to ensure beforehand that the bath is at the correct level.

We also measured the thermal effects of pre-saturated gas flowing through the saturator. The measurements were made using two metal-sheathed, type $T$ thermocouples that are mounted with measuring junctions near the saturator entrance. The junction of the first thermocouple is immersed in the water and that of the second is located in the gas stream. Figure 8 shows the temperature difference between the thermocouple junctions when gas flows through the generator and when no gas flows through (with no flow, we assume both thermocouples are at the bath temperature). For this plot, the bath temperature is $22^{\circ} \mathrm{C}$, the gas flow is $50 \mathrm{~L} / \mathrm{min}$, and the differences are plotted as a function of pre-saturator dew point. When the pre-saturator dew point is considerably less than the bath temperature, temperature non-uniformities occur due to evaporative cooling of the water in the chamber. With a dew point $8{ }^{\circ} \mathrm{C}$ below the bath temperature, the non-uniformity is over $0.1{ }^{\circ} \mathrm{C}$. However, no non-uniformities are resolvable when the dew point is above the bath temperature; in this case the excess moisture condenses in the heat exchanger and the gas is at thermal equilibrium with the saturation chamber by the time it enters the chamber. These measurements demonstrate the importance of setting the pre-saturator heat-exchanger temperature above rather than below the bath temperature. When using the HHG, it is standard operating procedure to set the pre-saturator heat exchanger temperature to $0.3^{\circ} \mathrm{C}$ above the bath temperature.

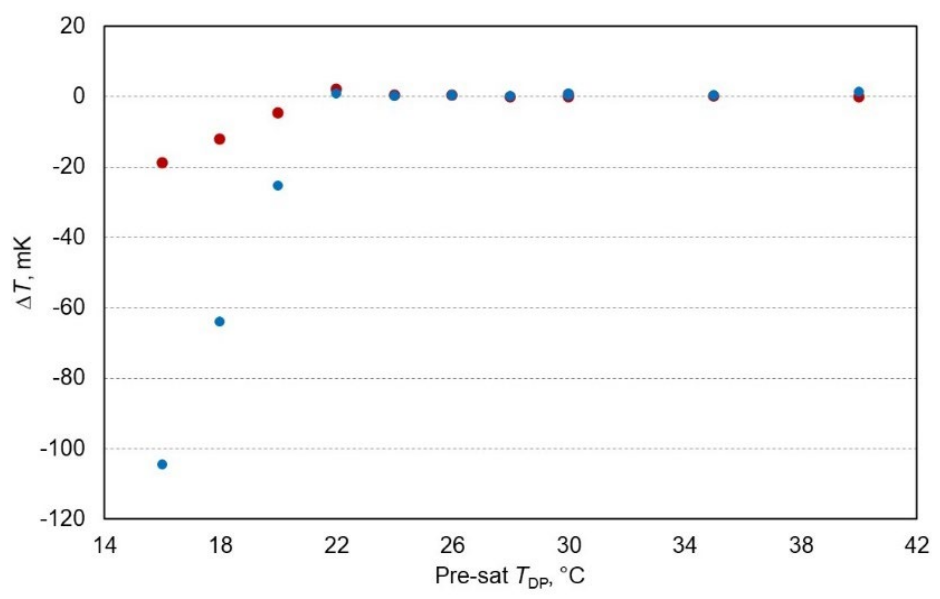

Figure 8. Temperature deviations from the bath temperature inside the saturation chamber at the entrance to the chamber when gas is flowing through it. The flow is $50 \mathrm{~L} / \mathrm{min}$ and the bath temperature is $22{ }^{\circ} \mathrm{C}$. The deviations are plotted as a function of pre-saturator dew point. The blue and red circles are from type $\mathrm{T}$ thermocouples (used in absolute mode) placed in the water and gas, respectively. Here, $\Delta T=T_{\text {flow }}-T_{\text {no flow, }}$ where $T_{\text {flow }}$ and $T_{\text {no flow }}$ are the measured temperatures with and without gas flow, respectively. $T_{\text {no flow }}$ is assumed to be the bath temperature. 
In addition, we measured the stability of the bath over $1200 \mathrm{~s}$ at a series of bath temperatures. Figure 9 shows the results. At $20^{\circ} \mathrm{C}$ the standard deviation was at a minimum, at $0.2 \mathrm{mK}$. As the bath temperature was lowered, the standard deviation reached $0.9 \mathrm{mK}$ at $0.5^{\circ} \mathrm{C}$ and, as it was raised, the standard deviation reached $1.1 \mathrm{mK}$ at $85^{\circ} \mathrm{C}$.

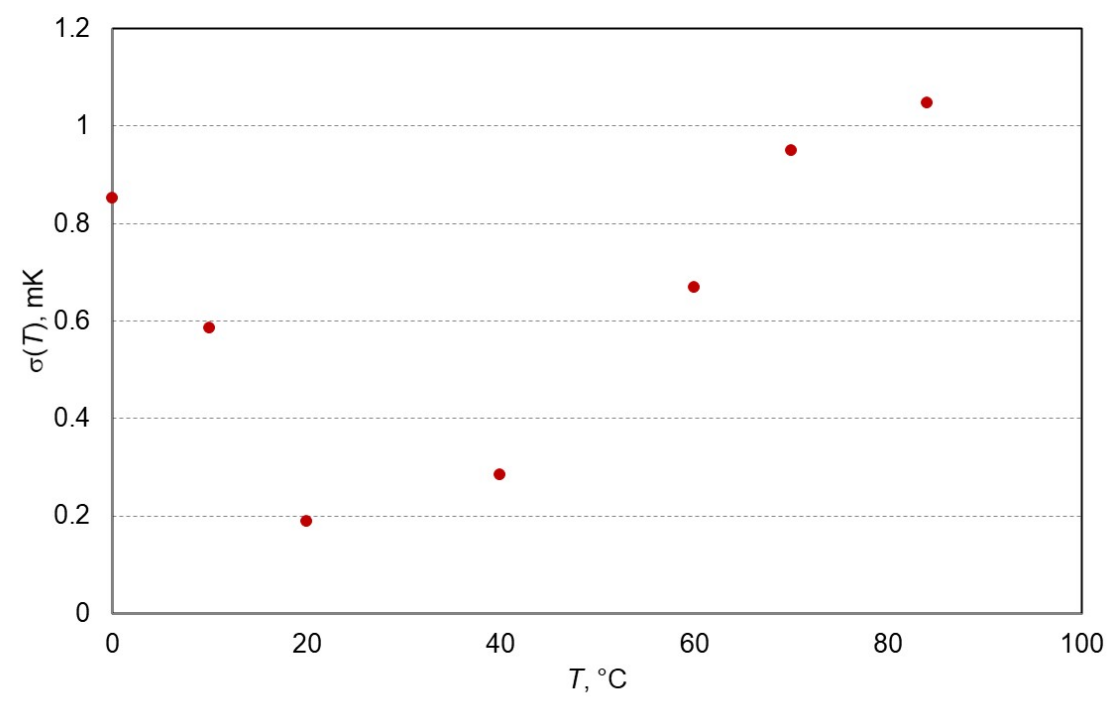

Figure 9. Standard deviation of the temperature fluctuations in the bath containing the final saturator as a function of bath temperature, as measured by an SPRT.

\subsection{Pressure Stability in the Final Saturator}

For measuring pressure fluctuations in the saturation chamber, we first optimized the PID settings of the pressure controller. We then measured the pressure variations at the optimum settings. At a saturator temperature of $20{ }^{\circ} \mathrm{C}$ and with a variety of pressures and flows up to $150 \mathrm{~L} / \mathrm{min}$, the standard deviation was less than $15 \mathrm{~Pa}$. An example is shown in Fig. 10, where the flow was $100 \mathrm{~L} / \mathrm{min}$, and the standard deviation of the pressure fluctuations was $9 \mathrm{~Pa}$. Unfortunately, since pressure is controlled by adjustments of gas flow out of the saturation chamber through the throttle valve, optimal pressure control results in noticeable gas-flow fluctuations. Gas flow fluctuations can cause mirror-temperature instabilities for chilled-mirror hygrometers, preventing them from achieving optimal resolution. Therefore, for dew/frost-point and amount fraction calibrations, the gas used for calibrating the hygrometers passes through a second expansion valve (see section 4.4) and therefore does not exhibit the flow fluctuations found in the gas exiting the throttle valve. 


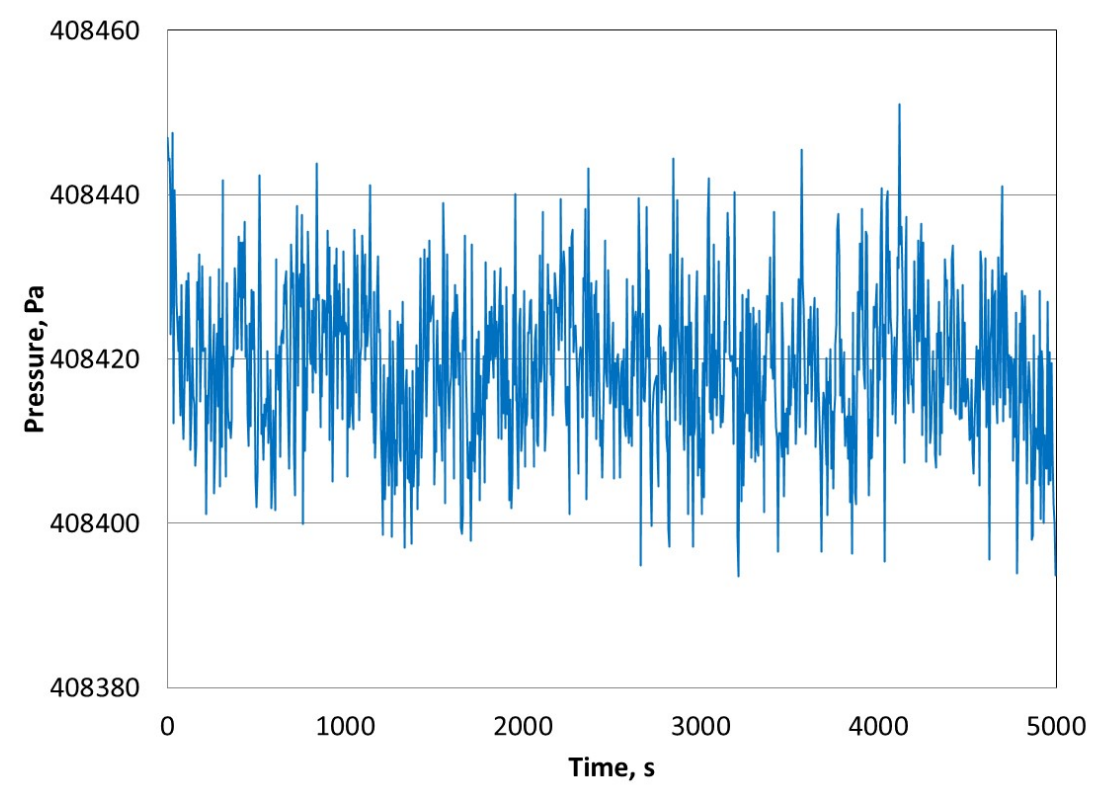

Figure 10. Pressure fluctuations in the saturator when the flow is $150 \mathrm{~L} / \mathrm{min}$. The standard deviation of the fluctuations is $9 \mathrm{~Pa}$.

\subsection{Self-consistency of the Generator in 2-P Mode}

For the self-consistency tests, we generated dew points with eight different saturator temperatures and saturator pressures ranging from $500 \mathrm{kPa}$ to ambient. By varying the degree of pressure expansion, the same dew point may be generated over a range of saturator temperatures. Selfconsistency of the generator output was tested by using a chilled-mirror hygrometer as a transfer standard. We performed a 4-wire resistance measurement of the hygrometer's platinum resistance thermometer (PRT), which is in thermal contact with its mirror. The hygrometer dew-point temperature, as determined by the PRT, was then calculated with the Callendar-van Dusen equation [12], using $100 \Omega$ as the assumed PRT resistance at $0{ }^{\circ} \mathrm{C}$. The flow through the generator was $30 \mathrm{~L} / \mathrm{min}$, and $0.5 \mathrm{~L} / \mathrm{min}$ of this flow was directed through the hygrometer. The difference between the hygrometer-measured dew-point temperature and the generated dew-point temperature, $\Delta T_{\mathrm{DP}}$, was then plotted for each dew point of the set. Figure 11 shows $\Delta T_{\mathrm{DP}}$ as a function of dew-point temperature. The overlap between the dew points generated at different saturator temperatures, indicated with different symbols, shows the degree of self-consistency of the HHG. The dew-point values agree with each other to within $20 \mathrm{mK}$. 


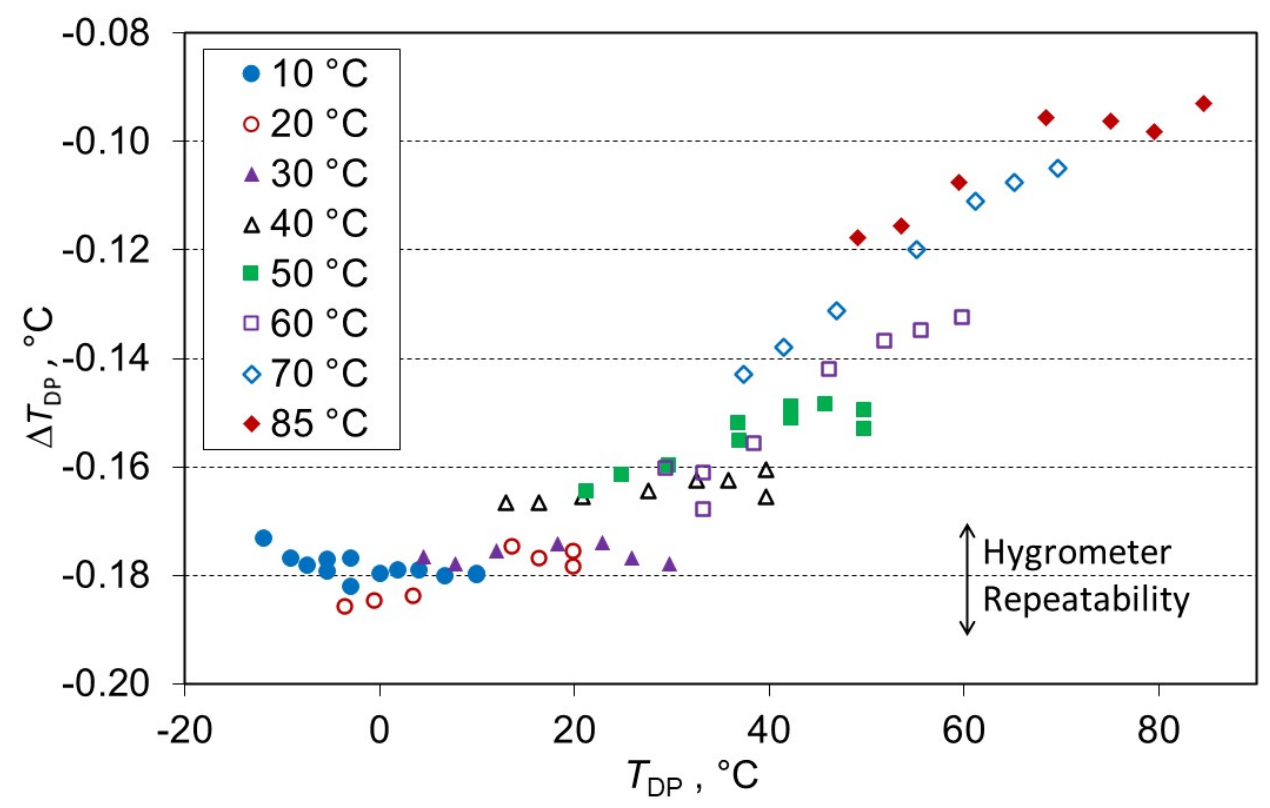

Figure 11. Comparison of dew points generated by the HHG using different saturator temperatures. The comparisons were made using an uncalibrated chilled-mirror hygrometer as a transfer standard. Here $\Delta T_{\mathrm{DP}}$ is the measured dew point minus the generated dew point. Measurements with the saturator at different temperatures are plotted with different symbols. The hygrometer repeatability $(k=1)$ is also shown.

\subsection{Water Amount Fraction in the Dry Air in the Divided-Flow Method}

As stated in section 4.2, the dry air used in the divided-flow method is conditioned by passing it through a molecular sieve. The specifications of the sieve state that the water amount fraction of the air exiting the sieve is $x_{\mathrm{p}}<1 \mathrm{nmol} / \mathrm{mol}$. To test this specification, we performed measurements of the water amount fraction generated by the HHG using a commercial cavity ringdown spectrometer (CRDS) hygrometer over the range $0<x<8 \mathrm{nmol} / \mathrm{mol}$. The hygrometer was specified to have a resolution of $0.1 \mathrm{nmol} / \mathrm{mol}$ with a lower detection limit (LDL) of $0.3 \mathrm{nmol} / \mathrm{mol}$. The LDL represents the uncertainty of the measurement over this range. The dry gas flow used was $150 \mathrm{~L} / \mathrm{min}$ and that of the wet gas $(x=2.2 \mathrm{mmol} / \mathrm{mol})$ ranged from zero to $6.4 \times 10^{-4} \mathrm{~L} / \mathrm{min}$. The results of the measurements are shown as the solid circles in Fig. 12(a). Linear regression was used to fit a line to the data, as shown in the figure, and the residuals to the fit are shown in Fig. 12(b). According to Eq. 6, the $y$-intercept indicates a value of $x_{\mathrm{p}}=1.4 \mathrm{nmol} / \mathrm{mol}$ with an uncertainty $(k=2)$ of $u\left(x_{\mathrm{p}}\right)=0.3 \mathrm{nmol} / \mathrm{mol}$. This value is nearly consistent with the specifications for the molecular sieve. Based on these results, we have opted to assume that $x_{\mathrm{p}}=0$ in our calculations of the humidity generated by the HHG and assign a standard uncertainty of $u\left(x_{\mathrm{p}}\right)=1 \mathrm{nmol} / \mathrm{mol}$ in the uncertainty budget of the HHG. 

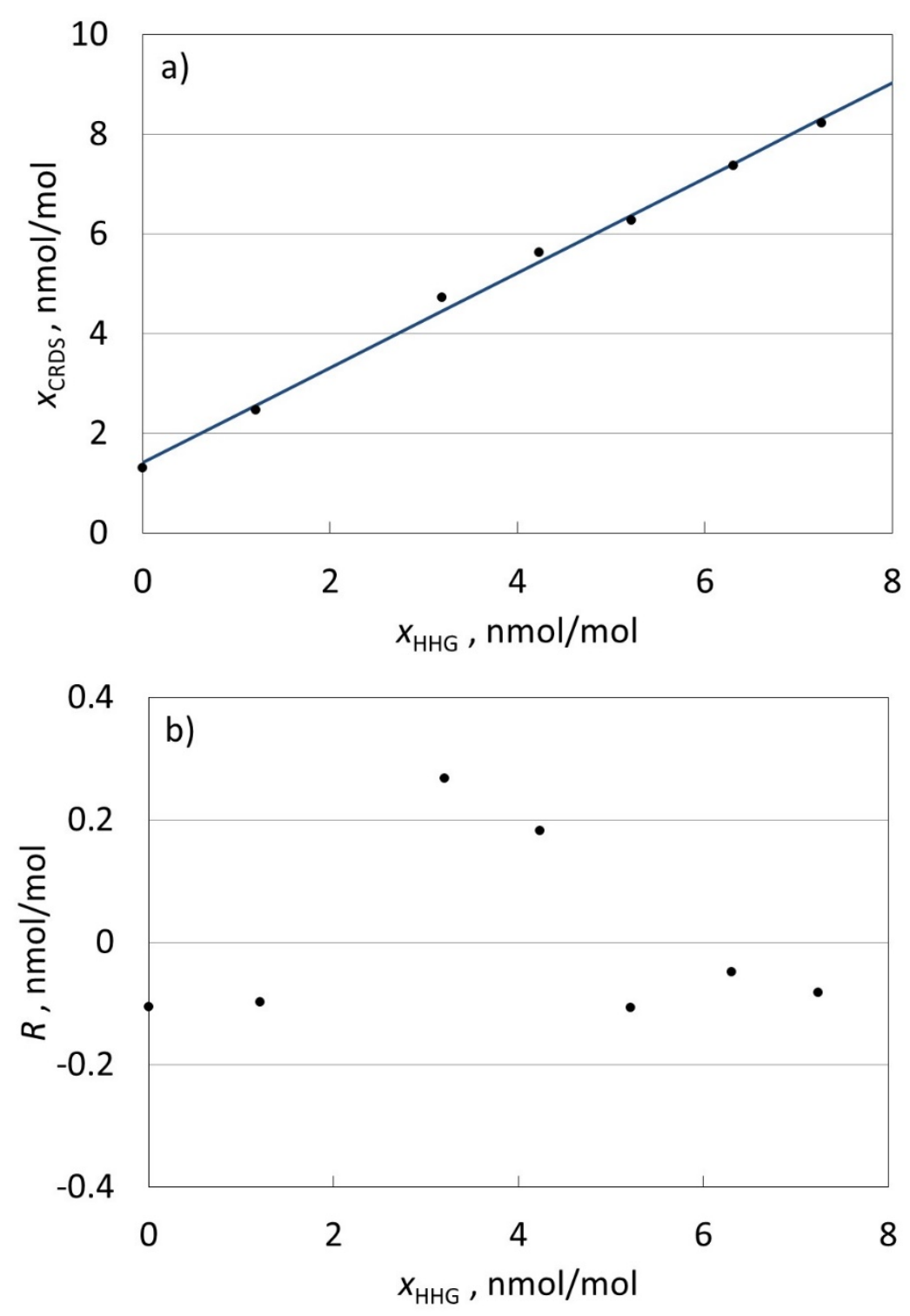

Figure 12. a) Water amount fraction measured by a commercial cavity ring down spectrometer as a function of water amount fraction calculated to be generated by the HHG when using the divided flow method over the range $0<x<8 \times 10^{-9}$. The line is a linear regression fit to the data, with $y=0.951 x+1.421$. b) Residuals $R$ from the fit to the data.

\section{Test Chamber and Its Heat Exchanger}

\subsection{Test Chamber Design}

The HHG test chamber is an accessory used for the calibration of temperature and relative humidity sensors (thermohygrometers). It is used for providing a stable, uniform temperature and 
pressure for the gas and humidity sensors during calibration; this is necessary because relative humidity is a function of temperature and pressure as well as water amount fraction. The test chamber is mounted inside a commercial environmental chamber using brackets. Semi-transparent diagrams of the test chamber are shown in Fig. 13, and a photograph of it inside the environmental chamber is shown in Fig. 14.

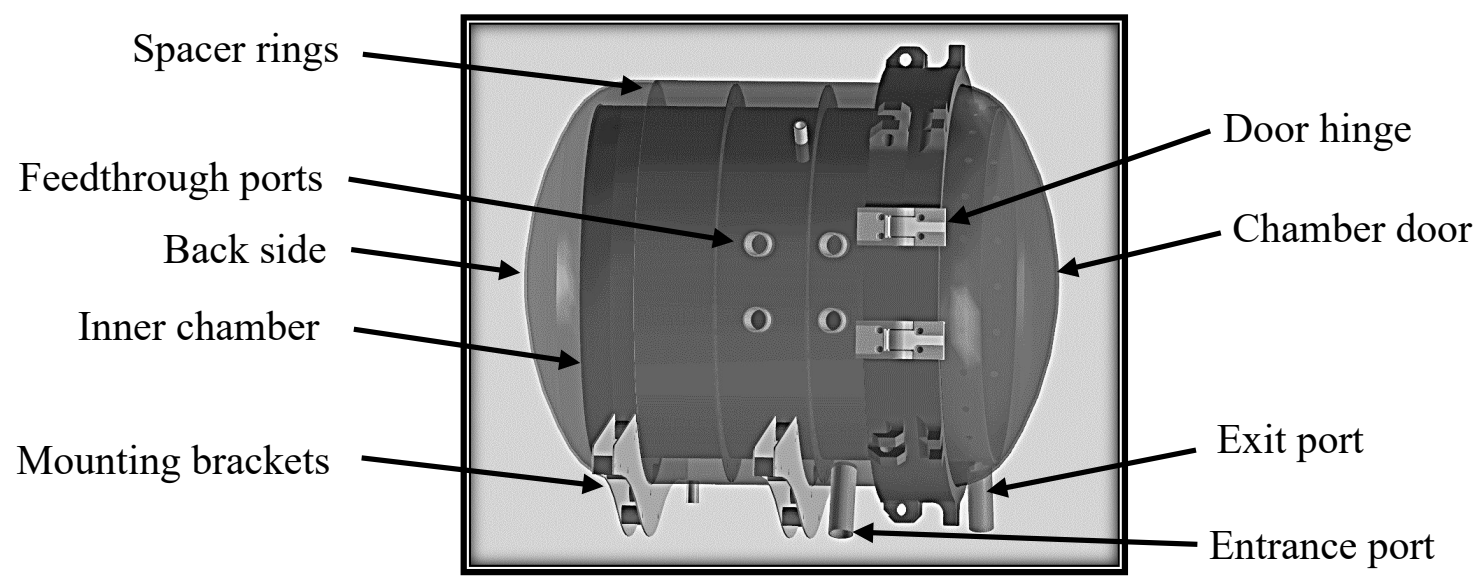

(a) Side View

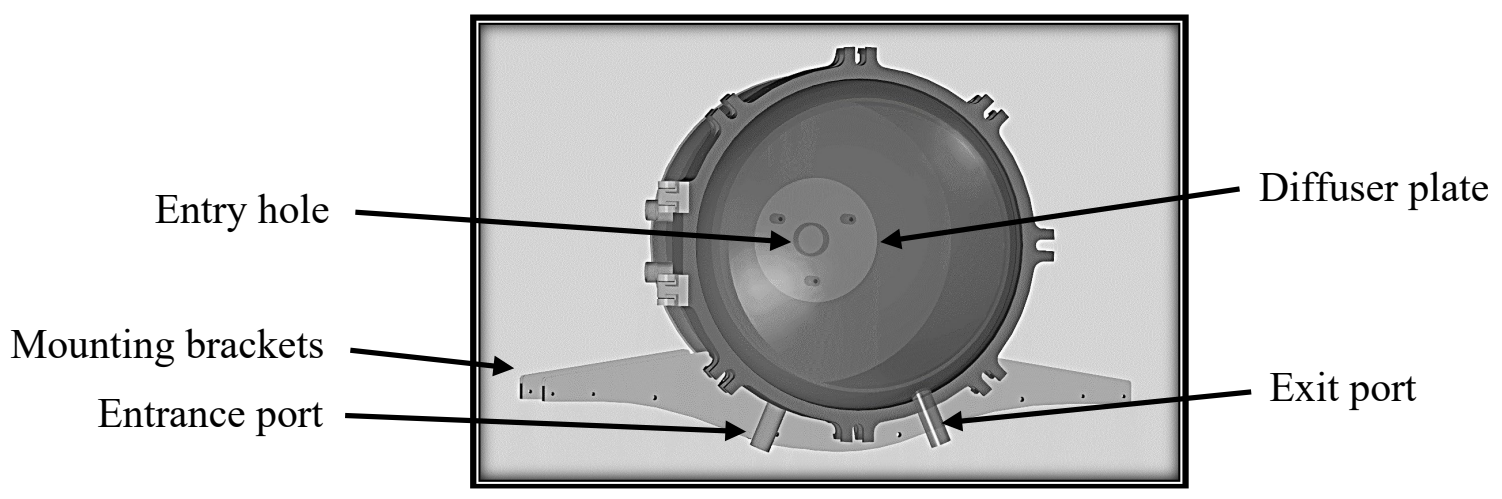

(b) Front View

Figure 13. Diagrams of test chamber, showing a) side view and b) front view

The test chamber is made of $316 \mathrm{~L}$ stainless steel and has a cylindrical geometry with the axis oriented horizontally. It is composed of an inner chamber resting inside an outer shell, with the two parts separated by spacer rings. The rings contain diffuser holes that allow air to flow through the annulus between the parts. The outer diameter of the outer shell is $40.6 \mathrm{~cm}$ and the wall thickness is $0.16 \mathrm{~cm}$. The ends of the shell are domed and the length of the shell along the axis is $48.3 \mathrm{~cm}$. The inner diameter of the chamber is $35.2 \mathrm{~cm}$ and the axial length is $41.0 \mathrm{~cm}$, providing a volume of approximately $40 \mathrm{~L}$. The chamber is open on the front side and closed on its back side with a flat circular plate. The wall thickness of the inner chamber is $0.16 \mathrm{~cm}$. The inner chamber 

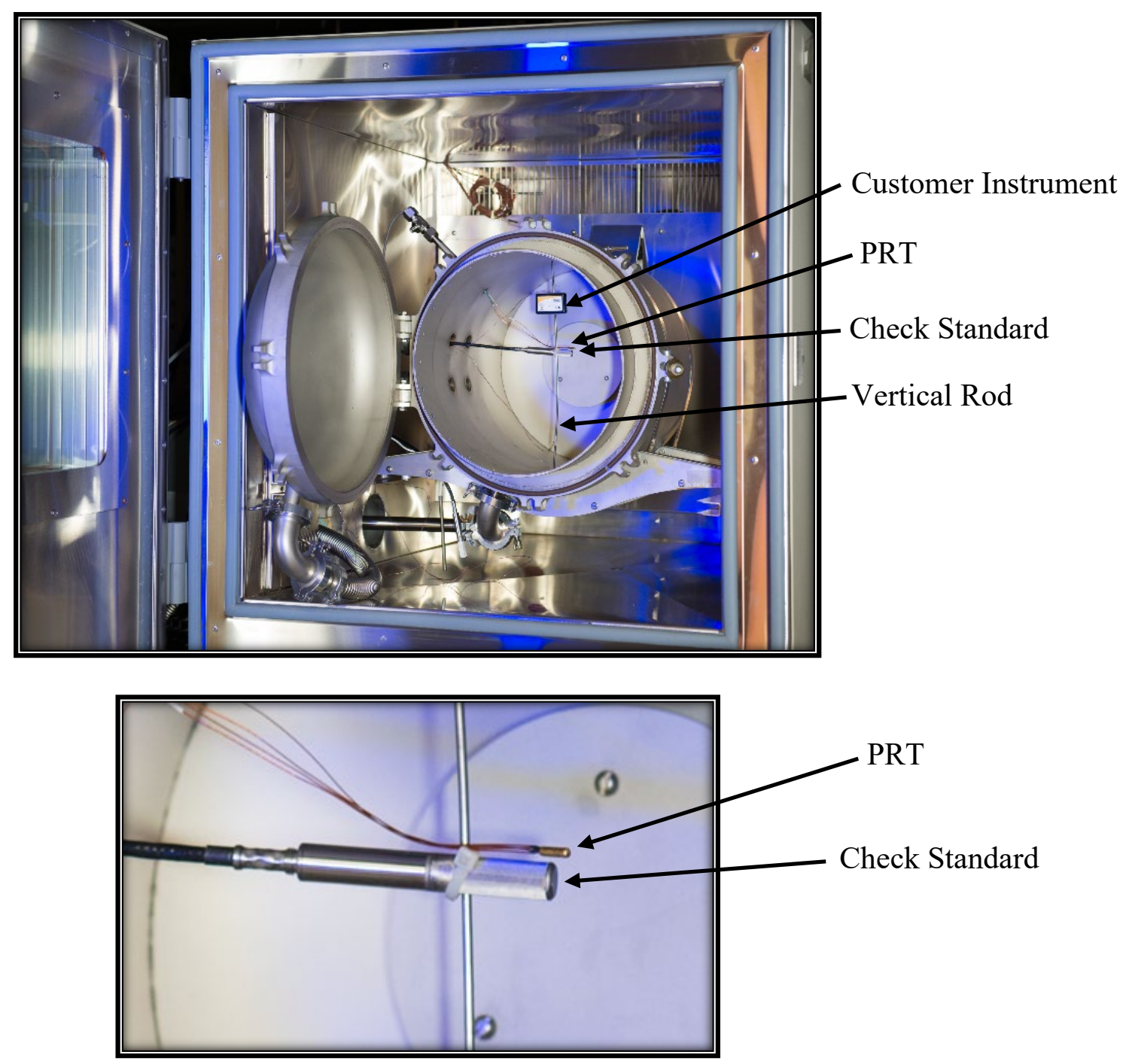

Figure 14. Top: photograph of the test chamber mounted inside the environmental chamber. Bottom: blowup of the top photo, showing the chamber PRT and check standard.

and outer shell are joined at the front of the shell with a ring, sealing the annulus there. However, the inner chamber protrudes out $7.6 \mathrm{~cm}$ from the sealing ring. The door to the chamber is domeshaped and is sealed to the chamber/shell with an O-ring. The door opens using a hinge and can be latched closed using $1 / 2$ "-20 hinged bolts at seven equally spaced locations along the periphery of the door. When the door is closed, the front edge of the inner chamber butts against the inside of the door, forming an annular cavity between the outside of the inner chamber and the door. A collection of 20 diffuser holes of diameter $0.64 \mathrm{~cm}$ are placed at equally spaced positions along the periphery of the inner chamber, $1.9 \mathrm{~cm}$ from the front.

The humidified air enters the annulus of the test chamber through a port at the bottom. The air travels to a domed cavity between the back sides of the chamber and shell. From this region, the air passes through a hole of diameter $3.8 \mathrm{~cm}$ in the center of the back side of the chamber. After 
passing through the hole, the air is immediately directed radially outward by a diffuser plate of diameter $15.2 \mathrm{~cm}$. The air then travels axially from the back of the chamber to the front. The air exits the inner chamber radially through the diffuser holes at the front of the chamber into the annular cavity between the chamber and door. The air exits the annular cavity through a port in the bottom of the chamber door. The design of the test chamber encourages laminar flow of the air through its interior. With the maximum flow rate possible with the generator, $150 \mathrm{~L} / \mathrm{min}$, the air in the $\sim 40 \mathrm{~L}$ chamber is displaced approximately once every $16 \mathrm{~s}$. With the axial chamber length of $41 \mathrm{~cm}$, the velocity of the passing air corresponding to this displacement is $2.6 \mathrm{~cm} / \mathrm{s}$. The Reynolds number (Re) of this flow for a kinematic viscosity of $1.6 \times 10^{-5} \mathrm{~m}^{2} / \mathrm{s}$ (air at $20^{\circ} \mathrm{C}$ ) in a circular container of diameter $35 \mathrm{~cm}$ is then $\mathrm{Re} \cong 560$, well below the laminar-turbulent threshold of 2300 .

Commercial platinum resistance thermometers (PRTs) are mounted inside the test chamber and inside the environmental chamber (but outside the test chamber) for the purpose of monitoring the temperature in those locations. The test chamber PRT is cylindrical in shape and has a diameter of $0.25 \mathrm{~cm}$ and a length of $1.5 \mathrm{~cm}$. It is placed in the center of the chamber by attaching it using cable ties to a $0.16 \mathrm{~cm}$ vertical rod that is placed at approximately the axial midpoint of the chamber, as shown in Fig. 14. The test chamber PRT has been calibrated by the NIST Thermodynamic Metrology Group and serves as the reference thermometer for determining the chamber temperature during calibrations. The temperature inside the environmental chamber is specified to be stable and uniform to within $0.5{ }^{\circ} \mathrm{C}$. The thermal mass of the test chamber walls further stabilizes the temperature inside of the chamber. It will be shown in section 6.3 that inside the central part of the test chamber the temperature is stable and uniform to within $\pm 10 \mathrm{mK}$. When calibrating customer thermohygrometers, they are placed as close as possible to the reference thermometer without blocking them from the air flow.

\subsection{Heat Exchanger Design}

The humidified air exiting the HHG is conditioned to the temperature of the test chamber before it enters the chamber. The conditioning is performed using a counterflow heat exchanger. Semitransparent diagrams of this heat exchanger are shown in Fig. 15. The heat exchanger is made of 316L stainless steel and uses a commercial heat-exchange fluid (labeled HEF in figure). The heatexchange fluid is circulated into the exchanger from a commercial dynamic temperature-control system. The outside of the exchanger consists of an outer-shell tube of diameter $10 \mathrm{~cm}$ and length $153 \mathrm{~cm}$ that is bounded on each end by a circular plate. Immediately inside each of the two tube ends is a cylindrical chamber of diameter $10 \mathrm{~cm}$ and length $6 \mathrm{~cm}$; one is an air-entrance chamber and the other is an air exit chamber. Between these two chambers are 48 open heat-exchange thinwall tubes of diameter $0.63 \mathrm{~cm}$, length $140 \mathrm{~cm}$, and wall thickness $0.09 \mathrm{~cm}$. The heat-exchange tubes are all parallel to the outer-shell tube and are mounted in holes in the inside walls of the chambers. The tubes are evenly spaced in a hexagonal lattice using 6 circular mounting plates (shown in Fig. 16) spaced at $28 \mathrm{~cm}$ intervals. Each mounting plate contains small holes of diameter $0.2 \mathrm{~cm}$ to allow the heat-exchange fluid to flow through. The fluid flows into the large tube through a port located just inside the air exit chamber and exits through a port located just inside the air entrance chamber. The air enters the heat exchanger through an entrance port attached to the air entrance chamber, passes through the heat-exchange tubes into the air exit chamber, and the exits through an exit port. PRTs are mounted in ports attached to the ends of the outer-shell tube for the 
purpose of monitoring the temperature in the air-entrance and air-exit chambers. Two other PRTs are mounted in ports adjacent to the heat-exchange-fluid-entrance and heat-exchange-fluid-exit ports for the purpose of monitoring the temperature in those locations. The counterflow design ensures that the temperature of the air exiting the heat exchanger is approximately equal to the temperature of the heat-exchange fluid entering the heat exchanger. By controlling the heatexchange fluid temperature to be that of the test chamber, the temperature non-uniformities in the test chamber can be kept to within $0.01{ }^{\circ} \mathrm{C}$ even when flowing humidified air through it at $150 \mathrm{~L} / \mathrm{min}$.

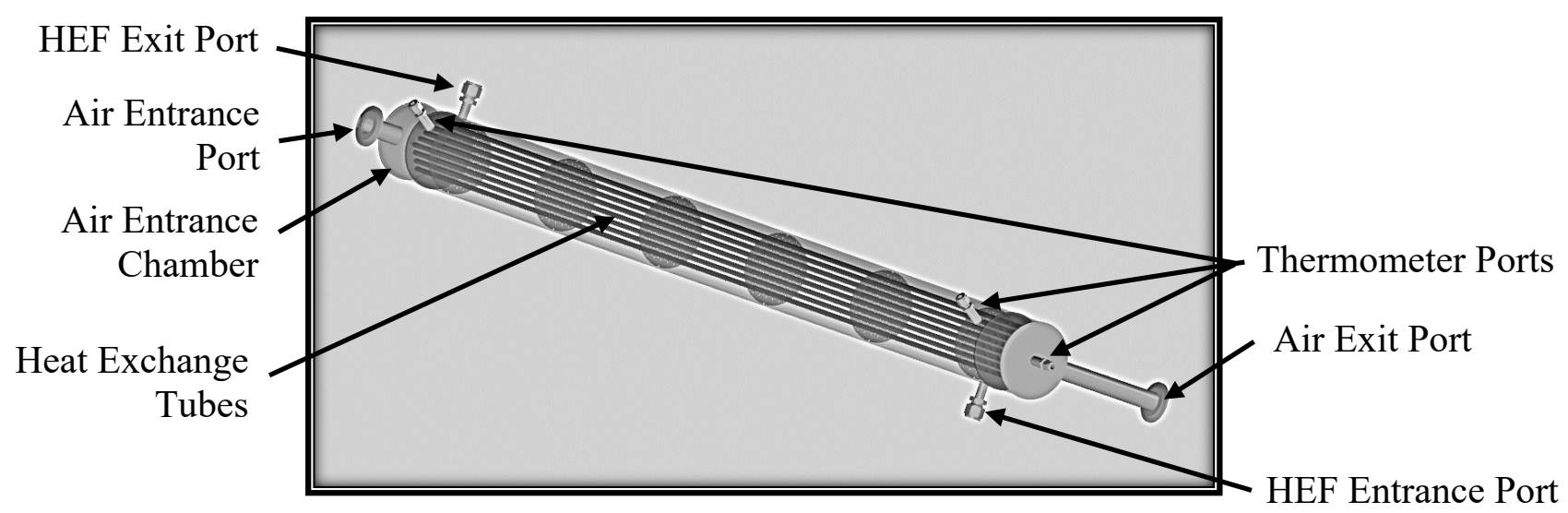

(a) Side View

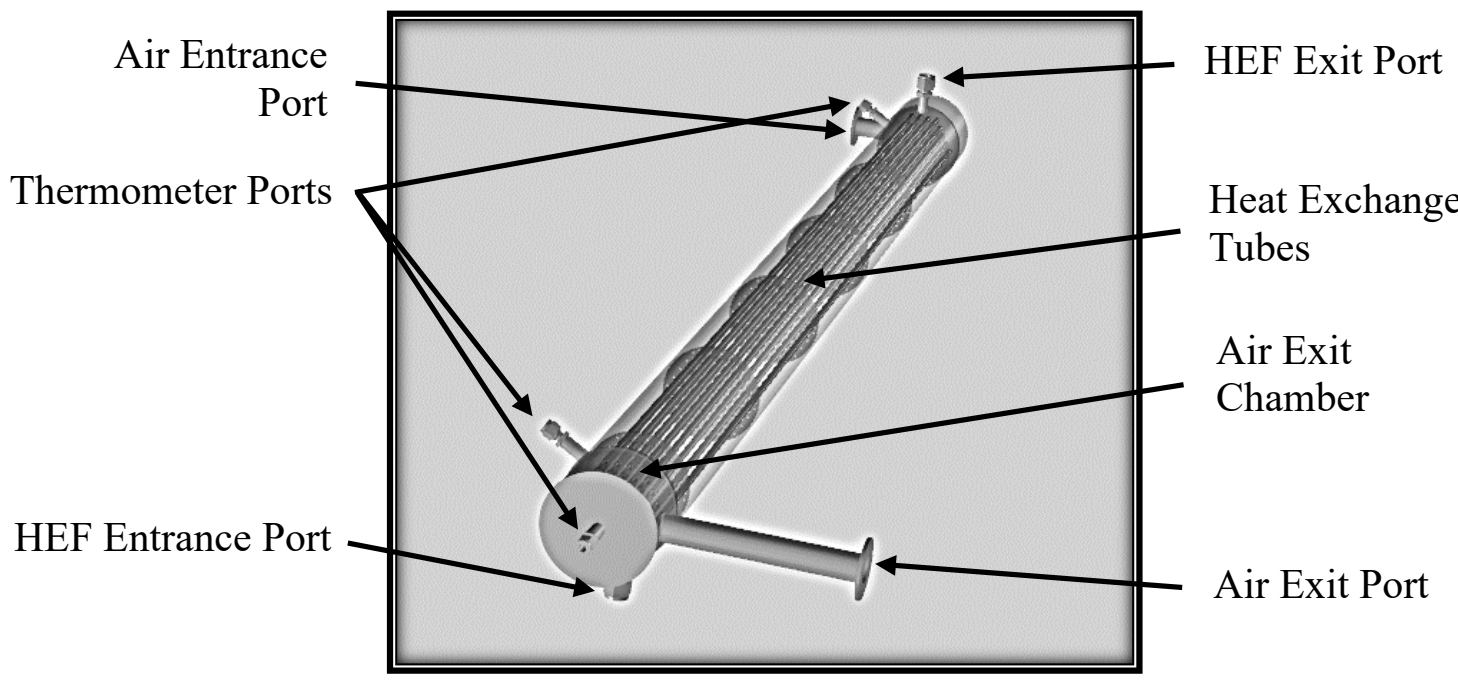

(b) Front View

Figure 15. Diagrams of the heat exchanger, showing a) side view and b) front view 


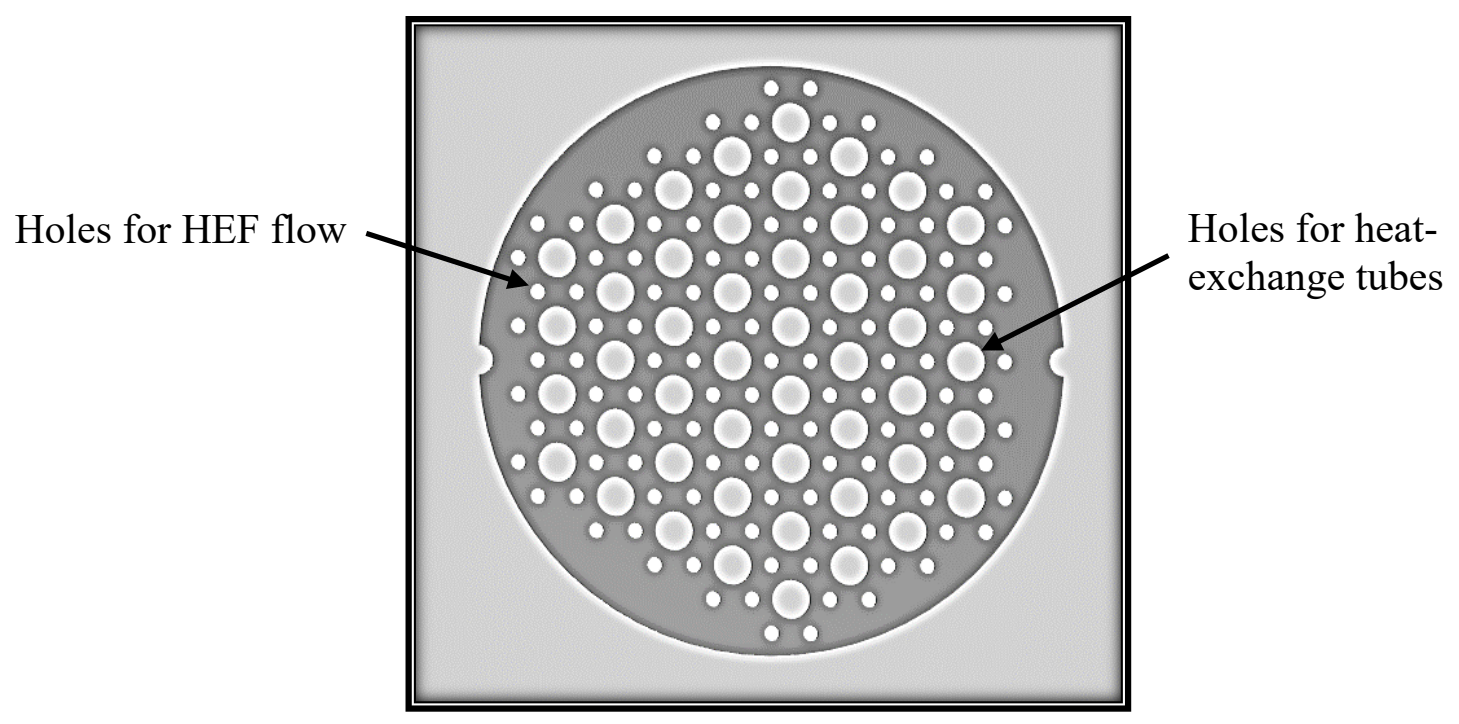

Figure 16. Diagram of a mounting plate in the heat exchanger

Both the environmental chamber and heat exchanger can be controlled at temperatures between $-34{ }^{\circ} \mathrm{C}$ and $190{ }^{\circ} \mathrm{C}$. This allows calibration of thermohygrometers over the relative humidity range $2 \%$ to $98 \%$ for temperatures between $-34{ }^{\circ} \mathrm{C}$ and $85{ }^{\circ} \mathrm{C}$, as well as well as over more limited relative-humidity ranges between $85^{\circ} \mathrm{C}$ and $190^{\circ} \mathrm{C}$.

\subsection{Validation Tests}

The test chamber was examined for both temperature stability and non-uniformity. Figure 17 shows plots of the temperature as a function of time inside the test chamber once a steady-state temperature has been achieved (typically after several hours). These plots reveal the temperature stability inside the chamber over a period of $7000 \mathrm{~s}$ at temperatures of approximately $-40{ }^{\circ} \mathrm{C}$, $20^{\circ} \mathrm{C}$, and $80^{\circ} \mathrm{C}$, when $150 \mathrm{~L} / \mathrm{min}$ of air flows through the chamber. The peak-to-peak variation of the temperature is approximately $5 \mathrm{mK}$. Figure 18 shows the temperature uniformity inside the test chamber when $150 \mathrm{~L} / \mathrm{min}$ of air flows through the chamber, through measurements of the temperature difference between the two junctions of a differential thermocouple. The junctions were attached to the rod shown in Fig. 14 and placed $15 \mathrm{~cm}$ from the center of the rod, separating them from each other by $30 \mathrm{~cm}$. The rod was placed in four different positions in the chamber. In all positions, the center of the rod was approximately in the center of the test chamber. In one case, the rod was placed vertically (as in Fig. 14). In a second case, it was placed horizontally, perpendicular to the chamber axis. In a third case, the rod was placed along the axis of the chamber. In the final case, radial temperature variations were measured by placing one of the thermocouple junctions in the center of the rod and the other junction $15 \mathrm{~cm}$ away; the rod was placed vertically and azimuthal symmetry was assumed for this arrangement. The temperature-difference measurements were made at five different temperatures: $-40{ }^{\circ} \mathrm{C}, 0{ }^{\circ} \mathrm{C}, 20^{\circ} \mathrm{C}, 50^{\circ} \mathrm{C}$, and $80^{\circ} \mathrm{C}$. The vertical, horizontal, and radial temperature differences were all within $12 \mathrm{mK}$. The axial temperature differences were the largest, increasing from $2 \mathrm{mK}$ at $80^{\circ} \mathrm{C}$ to $30 \mathrm{mK}$ at $-40{ }^{\circ} \mathrm{C}$. Based on the results of Figs. 17-18, and considering the close placement of customer thermohygrometers to the reference thermometer, we estimate the chamber temperature standard uncertainty due to stability and uniformity to be $10 \mathrm{mK}$. 

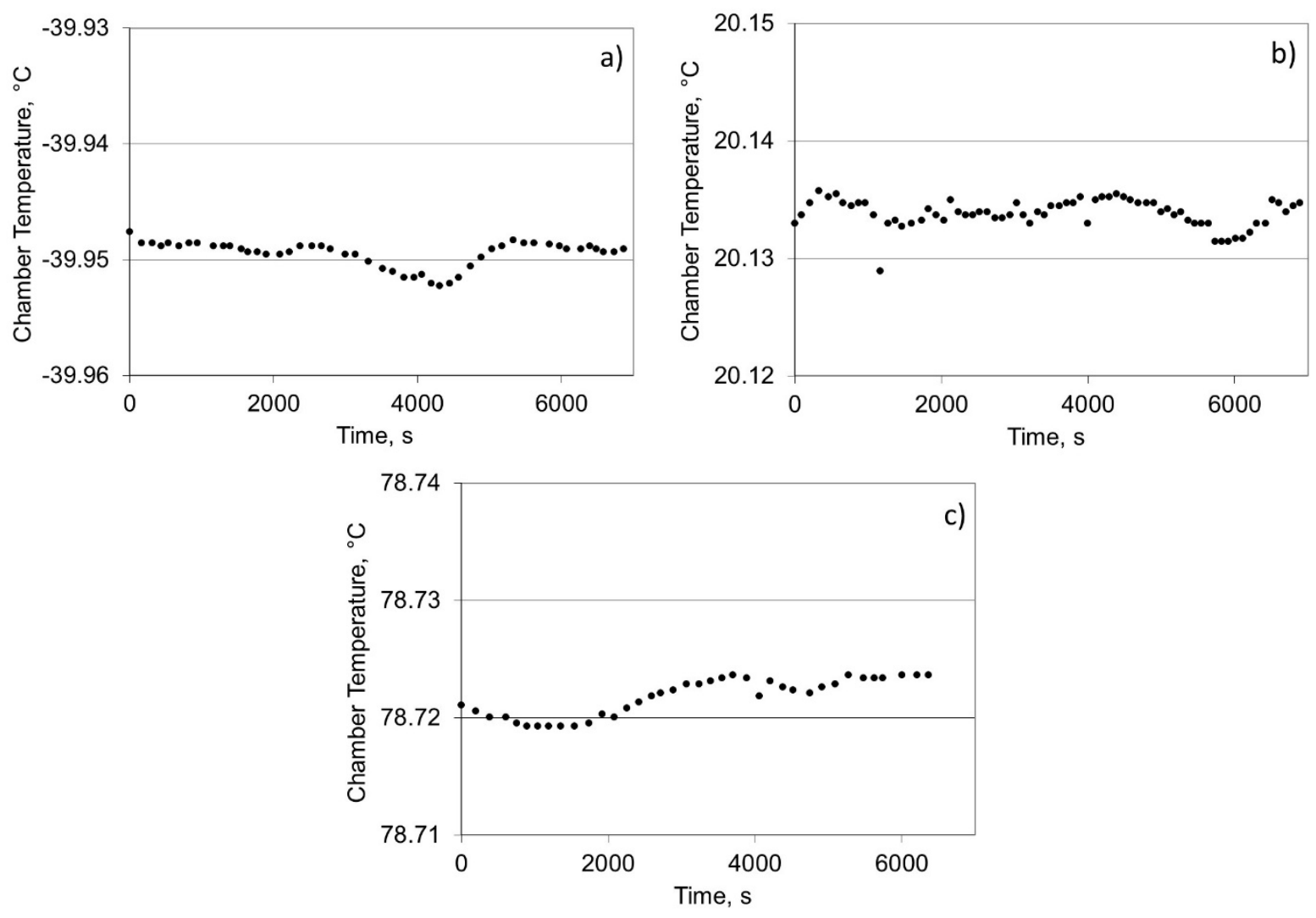

Figure 17 . Temperature stability in test chamber near a) $-40{ }^{\circ} \mathrm{C}$, b) $20^{\circ} \mathrm{C}$, and c) $80^{\circ} \mathrm{C}$

Figure 19 shows the stability of the relative humidity inside the test chamber at $23{ }^{\circ} \mathrm{C}$ at three different values of generated relative humidity: $80 \%, 20 \%$, and $5 \%$, with a flow rate of $150 \mathrm{~L} / \mathrm{min}$. The standard deviation of the RH values is $0.014 \%, 0.022 \%$, and $0.002 \%$ for the RH values of $80 \%, 20 \%$, and $5 \%$, respectively. 


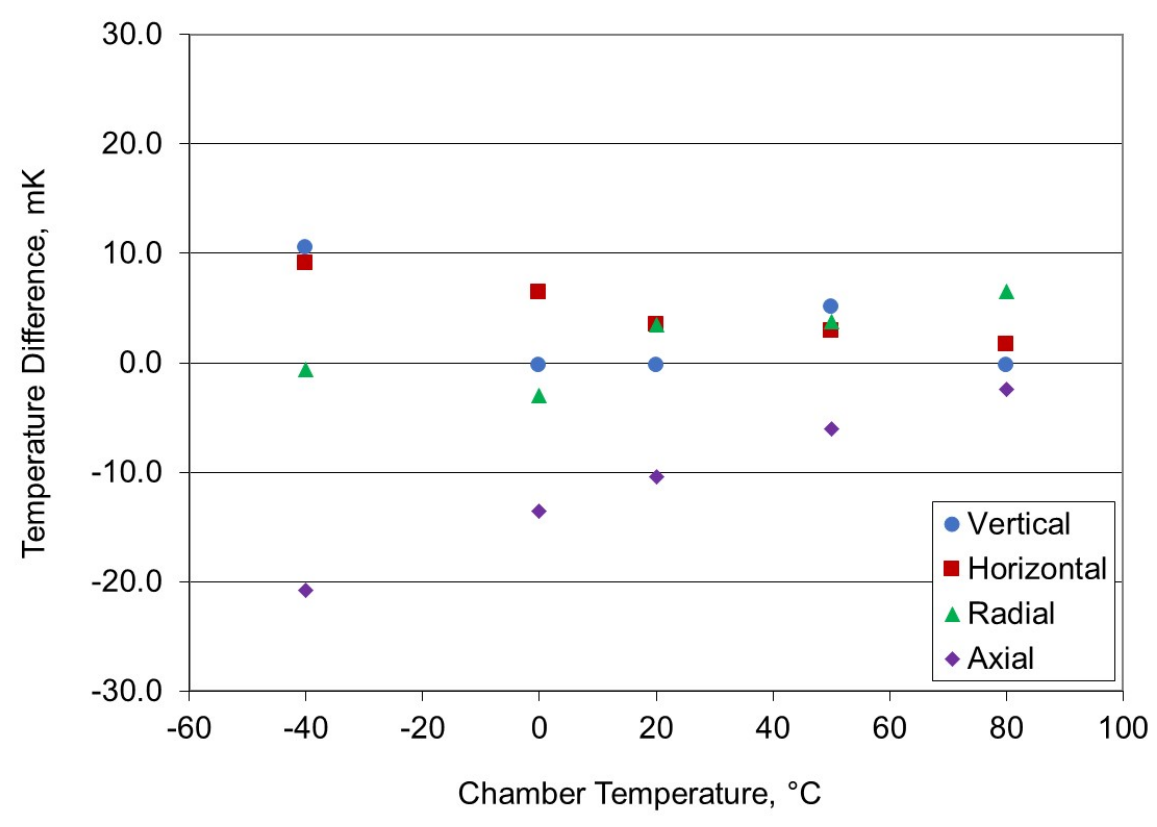

Figure 18. Temperature difference between two locations in test chamber (see text for location description) separated by $30 \mathrm{~cm}$, measured using differential thermocouples
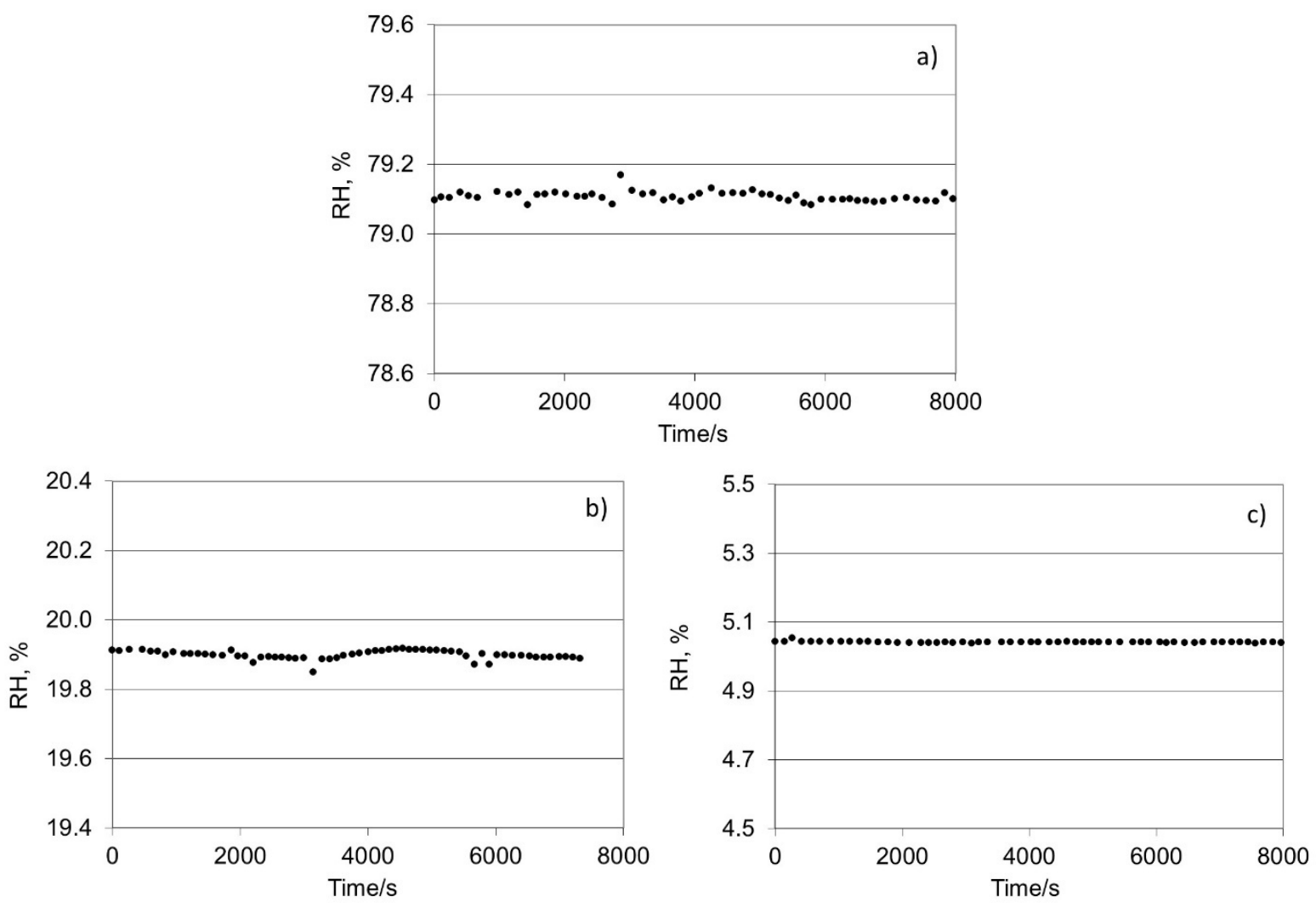

Figure 19. Stability of relative humidity in test chamber 


\section{Uncertainty Budget}

Based on these performance tests as well as measurement equipment specifications, we have constructed uncertainty budgets for the humidity generated by the HHG. There are budgets for the three expressions of humidity (water amount fraction, dew/frost-point temperature, and relative humidity) under two conditions: two-pressure generator without dilution and two pressure with dilution. The total uncertainties associated with these budgets are based on the guidelines for the expression of uncertainty in measurement $[13,14]$. The equations relating the total uncertainties to the uncertainty components are listed below and derived in Appendix I.

The total uncertainty for humidity generated by the hybrid generator is presented here for four different humidity definitions: water amount fraction, dew/frost-point temperature, relative humidity, and water mass ratio. For each of these four definitions, we present the uncertainty for the cases of humidity generated in 1-P mode, 2-P mode, and divided-flow mode. In the equations below, $u(X)$ is the standard uncertainty of the quantity $X$.

\subsection{Uncertainty Equations}

\subsubsection{Water Amount Fraction Generated in 1-P or 2-P Mode}

Here, the total standard relative uncertainty for the water amount fraction, $u_{\mathrm{r}}(x)$, is expressed as

$$
u_{\mathrm{r}}(x)^{2}=\left[\frac{u(x)}{x}\right]^{2}=\left(\frac{1}{e_{\mathrm{s}}} \frac{d e_{\mathrm{s}}}{d T_{\mathrm{s}}}\right)^{2} u\left(T_{\mathrm{s}}\right)^{2}+\frac{u\left(P_{\mathrm{s}}\right)^{2}}{P_{\mathrm{s}}^{2}}+\frac{u\left(e_{\mathrm{s}}^{\text {calc }}\right)^{2}}{e_{\mathrm{s}}}+\frac{u\left(f_{\mathrm{s}}^{\text {calc }}\right)^{2}}{f_{\mathrm{s}}} .
$$

The four relevant uncertainties are $u\left(T_{\mathrm{s}}\right), u\left(P_{\mathrm{s}}\right), u\left(e_{\mathrm{s}}^{\text {calc }}\right)$, and $u\left(f_{\mathrm{s}}^{\text {calc }}\right)$. Here, $u\left(e_{\mathrm{s}}^{\text {calc }}\right)$ and $u\left(f_{\mathrm{s}}^{\text {calc }}\right)$ are the uncertainties of the calculated values of $e\left(T_{\mathrm{s}}\right)$ and $f_{\mathrm{s}}\left(T_{\mathrm{s}}, P_{\mathrm{s}}\right)$, respectively, due to the imperfect knowledge of these physical relations.

\subsubsection{Dew-point Temperature Generated in 1-P or 2-P Mode}

For this case, the total standard uncertainty of the dew-point temperature $T_{\mathrm{DP}}$ or frost-point temperature $T_{\mathrm{FP}}$ of the gas in a test chamber with pressure $P_{\mathrm{c}}$ and temperature $T_{\mathrm{c}}=T_{\mathrm{DP}}$ or $T_{\mathrm{c}}=T_{\mathrm{FP}}$ is expressed as

$$
u\left(T_{\mathrm{DP}}\right)^{2}=\left(\frac{e_{\mathrm{c}}}{\left[d e_{\mathrm{c}} / d T_{\mathrm{DP}}\right]}\right)^{2}\left[\left(\frac{1}{e_{\mathrm{s}}} \frac{d e_{\mathrm{s}}}{d T_{\mathrm{s}}}\right)^{2} u\left(T_{\mathrm{s}}\right)^{2}+\frac{u\left(P_{\mathrm{s}}\right)^{2}}{P_{\mathrm{s}}^{2}}+\frac{u\left(P_{\mathrm{c}}\right)^{2}}{P_{\mathrm{c}}^{2}}+u_{\mathrm{r}}\left(\Delta e^{\text {calc }}\right)^{2}+u_{\mathrm{r}}\left(\Delta f^{\text {calc }}\right)^{2}\right]
$$

The five relevant uncertainties are $u\left(T_{\mathrm{s}}\right), u\left(P_{\mathrm{s}}\right), u\left(P_{\mathrm{c}}\right), u_{\mathrm{r}}\left(\Delta e^{\text {calc }}\right)$, and $u_{\mathrm{r}}\left(\Delta f^{\text {calc }}\right)$. When the generator is used in 1-P mode $\left(P_{\mathrm{s}} \cong P_{\mathrm{c}}\right)$,

$$
u_{\mathrm{r}}\left(\Delta e^{\text {calc }}\right)=u_{\mathrm{r}}\left(\Delta f^{\text {calc }}\right)=0 .
$$


When the generator is used in 2-P mode $\left(P_{\mathrm{s}} \neq P_{\mathrm{c}}\right)$,

$$
\begin{gathered}
u_{\mathrm{r}}\left(\Delta e^{\text {calc }}\right)^{2} \equiv \frac{u\left(e_{\mathrm{s}}^{\text {calc }}\right)^{2}}{e_{\mathrm{s}}^{2}}+\frac{u\left(e_{\mathrm{c}}^{\text {calc }}\right)^{2}}{e_{\mathrm{c}}^{2}}, \\
u_{\mathrm{r}}\left(\Delta f^{\text {calc }}\right)^{2} \equiv \frac{u\left(f_{\mathrm{s}}^{\mathrm{calc}}\right)^{2}}{f_{\mathrm{s}}^{2}}+\frac{u\left(f_{\mathrm{c}}^{\mathrm{calc}}\right)^{2}}{f_{\mathrm{c}}^{2}} .
\end{gathered}
$$

Here, $u\left(e_{\mathrm{s}}^{\text {calc }}\right), u\left(e_{\mathrm{c}}^{\text {calc }}\right), u\left(f_{\mathrm{s}}^{\text {calc }}\right)$, and $u\left(f_{\mathrm{c}}^{\text {calc }}\right)$ are the uncertainties of the calculated values of, $e\left(T_{\mathrm{s}}\right), e\left(T_{\mathrm{c}}\right), f\left(T_{\mathrm{s}}, P_{\mathrm{s}}\right)$, and $f\left(T_{\mathrm{c},} P_{\mathrm{c}}\right)$, respectively, due to the imperfect knowledge of these physical relations. In Eqs. 10-11, note that the subscript "r" in $u_{\mathrm{r}}\left(\Delta e^{\text {calc }}\right)$ and $u_{\mathrm{r}}\left(\Delta f^{\text {calc }}\right)$ is used to show that they are relative uncertainties and therefore dimensionless.

\subsubsection{Relative Humidity Generated in 1-P or 2-P Mode}

The total standard relative uncertainty for the relative humidity, $u_{\mathrm{r}}(R H)$, of the gas in the test chamber with temperature $T_{\mathrm{c}}$ and pressure $P_{\mathrm{c}}$ is expressed as

$$
\begin{aligned}
u_{r}(R H)^{2}=\left[\frac{u(R H)}{R H}\right]^{2}= & {\left[\left(\frac{1}{e_{\mathrm{s}}} \frac{d e_{\mathrm{s}}}{d T_{\mathrm{s}}}\right)^{2} u\left(T_{\mathrm{s}}\right)^{2}+\frac{1}{P_{\mathrm{s}}^{2}} u\left(P_{\mathrm{s}}\right)^{2}+\left(\frac{1}{e_{\mathrm{c}}} \frac{d e_{\mathrm{c}}}{d T_{\mathrm{c}}}\right)^{2} u\left(T_{\mathrm{c}}\right)^{2}+\frac{1}{P_{\mathrm{c}}^{2}} u\left(P_{\mathrm{c}}\right)^{2}\right.} \\
& \left.+u_{\mathrm{r}}\left(\Delta e^{\text {calc }}\right)+u_{\mathrm{r}}\left(\Delta f^{\text {calc }}\right)\right]
\end{aligned}
$$

The six relevant uncertainties are $u\left(T_{\mathrm{s}}\right), u\left(P_{\mathrm{s}}\right), u\left(T_{\mathrm{c}}\right), u\left(P_{\mathrm{c}}\right), u_{\mathrm{r}}\left(\Delta e^{\text {calc }}\right)$, and $u_{\mathrm{r}}\left(\Delta f^{\text {calc }}\right)$. Here, $u_{\mathrm{r}}\left(\Delta e^{\text {calc }}\right)$ and $u_{\mathrm{r}}\left(\Delta f^{\text {calc }}\right)$ are given by Eqs. 9 for 1-P mode and Eqs. 10-11 for 2-P mode.

\subsubsection{Water Amount Fraction Generated in Divided-flow Mode}

For this case, the total standard relative uncertainty for the water amount fraction, $u_{\mathrm{r}}(x)$ is expressed as

$$
\begin{aligned}
u_{\mathrm{r}}(x)^{2}=\left[\frac{u(x)}{x}\right]^{2} \cong & \left(\frac{1}{e_{\mathrm{s}}} \frac{d e_{\mathrm{s}}}{d T_{\mathrm{s}}}\right)^{2} u\left(T_{\mathrm{s}}\right)^{2}+\frac{u\left(P_{\mathrm{s}}\right)^{2}}{P_{\mathrm{s}}^{2}}+\frac{u\left(e_{\mathrm{s}}^{\mathrm{calc}}\right)^{2}}{e_{\mathrm{s}}^{2}}+\frac{u\left(f_{\mathrm{s}}^{\text {calc }}\right)^{2}}{f_{\mathrm{s}}} \\
& +\frac{u\left(\dot{n}_{\mathrm{p}}\right)^{2}}{\dot{N}^{2}}+\left(\frac{x_{\mathrm{s}}}{x}-1\right)^{2}\left(\frac{u\left(x_{\mathrm{p}}\right)^{2}}{x_{\mathrm{s}}^{2}}+\frac{u\left(\dot{n}_{\mathrm{s}}\right)^{2}}{\dot{N}^{2}}\right)
\end{aligned}
$$

The seven relevant uncertainties are $u\left(T_{\mathrm{s}}\right), u\left(P_{\mathrm{s}}\right), u\left(e_{\mathrm{s}}^{\text {calc }}\right), u\left(f_{\mathrm{s}}^{\text {calc }}\right), u\left(x_{\mathrm{p}}\right), u\left(\dot{n}_{\mathrm{s}}\right)$, and $u\left(\dot{n}_{\mathrm{p}}\right)$. 


\subsubsection{Frost-point Temperature Generated in Divided-flow Mode}

In the hybrid generator, the divided flow method will only be used for generating frost points. Here, the total standard uncertainty of the frost-point temperature $T_{\mathrm{DP}}$ of the gas in the test chamber is

$$
\begin{aligned}
u\left(T_{\mathrm{FP}}\right)^{2}= & \frac{e_{\mathrm{c}}}{\left[d e_{\mathrm{c}} / d T_{\mathrm{c}}\right]^{2}}\left[\left(\frac{1}{e_{\mathrm{s}}} \frac{d e_{\mathrm{s}}}{d T_{\mathrm{s}}}\right)^{2} u\left(T_{\mathrm{s}}\right)^{2}+\frac{u\left(P_{\mathrm{s}}\right)^{2}}{P_{\mathrm{s}}^{2}}+\frac{u\left(P_{\mathrm{c}}\right)^{2}}{P_{\mathrm{c}}^{2}}+u_{\mathrm{r}}\left(\Delta e^{\text {calc }}\right)^{2}+u_{\mathrm{r}}\left(\Delta f^{\text {calc }}\right)^{2}\right. \\
& \left.+\left(\frac{x_{\mathrm{s}}}{x}-1\right)^{2}\left(\frac{u\left(x_{\mathrm{p}}\right)^{2}}{x_{\mathrm{s}}^{2}}+\frac{u\left(\dot{n}_{\mathrm{s}}\right)^{2}}{\dot{N}^{2}}\right)+\frac{u\left(\dot{n}_{\mathrm{p}}\right)^{2}}{\dot{N}^{2}}\right]
\end{aligned}
$$

The eight relevant uncertainty elements are $u\left(T_{\mathrm{s}}\right), u\left(P_{\mathrm{s}}\right), u\left(x_{\mathrm{p}}\right), u\left(\dot{n}_{\mathrm{s}}\right), u\left(\dot{n}_{\mathrm{p}}\right), u\left(P_{\mathrm{c}}\right), u_{\mathrm{r}}\left(\Delta e^{\text {calc }}\right)$, and $u_{\mathrm{r}}\left(\Delta f^{\text {calc }}\right)$. Here, $u_{\mathrm{r}}\left(\Delta e^{\text {calc }}\right)$ and $u_{\mathrm{r}}\left(\Delta f^{\text {calc }}\right)$ are defined in Eqs. 10-11.

\subsubsection{Relative Humidity Generated in Divided-flow Mode}

Here, the total standard relative uncertainty of the relative humidity of the gas in the test chamber is

$$
\begin{aligned}
u_{\mathrm{r}}(R H)=\left[\frac{u(R H)}{R H}\right]^{2}= & {\left[\left(\frac{1}{e_{\mathrm{s}}} \frac{d e_{\mathrm{s}}}{d T_{\mathrm{s}}}\right)^{2} u\left(T_{\mathrm{s}}\right)^{2}+\frac{u\left(P_{\mathrm{s}}\right)^{2}}{P_{\mathrm{s}}^{2}}+\left(\frac{1}{e_{\mathrm{c}}} \frac{d e_{\mathrm{c}}}{d T_{\mathrm{c}}}\right)^{2} u\left(T_{\mathrm{c}}\right)^{2}+\frac{u\left(P_{\mathrm{c}}\right)^{2}}{P_{\mathrm{c}}^{2}}\right.} \\
& \left.+u_{\mathrm{r}}\left(\Delta e^{\text {calc }}\right)+u_{\mathrm{r}}\left(\Delta f^{\text {calc }}\right)+\left(\frac{x_{\mathrm{s}}}{x}-1\right)^{2}\left(\frac{u\left(x_{\mathrm{p}}\right)^{2}}{x_{\mathrm{s}}^{2}}+\frac{u\left(\dot{n}_{\mathrm{s}}\right)^{2}}{\dot{N}^{2}}\right)+\frac{u\left(\dot{n}_{\mathrm{p}}\right)^{2}}{\dot{N}^{2}}\right]
\end{aligned}
$$

The nine relevant uncertainty elements are $u\left(T_{\mathrm{s}}\right), u\left(P_{\mathrm{s}}\right), u\left(T_{\mathrm{c}}\right), u\left(P_{\mathrm{c}}\right)$, $u_{\mathrm{r}}\left(\Delta e^{\text {calc }}\right), u_{\mathrm{r}}\left(\Delta f^{\text {calc }}\right), u\left(x_{\mathrm{p}}\right), u\left(\dot{n}_{\mathrm{s}}\right)$, and $u\left(\dot{n}_{\mathrm{p}}\right)$, where $u_{\mathrm{r}}\left(\Delta e^{\text {calc }}\right)$ and $u_{\mathrm{r}}\left(\Delta f^{\text {calc }}\right)$ are given by Eqs. $10-11$.

\subsubsection{Water Mass Ratio}

The total standard uncertainty for mass ratio is related to that for the amount fraction by

$$
u(r)=0.62196 \frac{1}{(1-x)^{2}} u(x),
$$


or, in terms of relative uncertainty $u_{\mathrm{r}}(\mathrm{r})$,

$$
u_{\mathrm{r}}(r)=\frac{u(r)}{r}=\frac{1}{(1-x)} u_{\mathrm{r}}(x)
$$

Here, $u_{\mathrm{r}}(x)$ is given by Eq. 7 when the generator is used in 1-P or 2-P mode, and by Eq. 13 when the generator is used in divided-flow mode.

\subsection{Uncertainty Elements}

Shown in Table 1 is a list of all the relevant uncertainty elements mentioned above and their standard uncertainty values. The subcomponents of the uncertainty elements $T_{\mathrm{s}}, P_{\mathrm{s}}$, and $P_{\mathrm{c}}$ are given in Appendix II. For calibration of a chilled-mirror hygrometer with an external thermometer, the value for the uncertainty of $T_{\mathrm{c}}$ is based on the typical uncertainty for the calibration of external temperature probes at NIST [15]. For calibration of relative humidity sensors in the HHG test chamber, the uncertainty of $T_{\mathrm{c}}$ additionally contains a component for temperature differences between the sensor and the chamber standard thermometer. In Table 1, the uncertainty for the calculation of $e(T)$ is obtained from Fig. 6.4 of [16] for $T \geq 0.01{ }^{\circ} \mathrm{C}$ and from Eq. 5a of [9] for $T<0.01{ }^{\circ} \mathrm{C}$ (note that Eq. 5a provides an expanded uncertainty that must be divided by 2 ). The uncertainties for the calculations of $f_{\mathrm{s}}$ and $f_{\mathrm{c}}$ are presented as a fit to the uncertainty data of Table 9 in [17]; because there is no data below $-50^{\circ} \mathrm{C}$, we extrapolated the curve determined from the available data to obtain the uncertainty formula listed in Table 1. In obtaining the formula, the "maximum percentage uncertainties" from [17] were divided by $\sqrt{3}$ to obtain the standard uncertainty. The values for $u\left(f_{\mathrm{s}}^{\text {calc }}\right)$ and $u\left(f_{\mathrm{c}}^{\text {calc }}\right)$ decrease with temperature and increase with pressure; they are quite significant for some operating conditions. By comparison, the uncertainties of $e_{\mathrm{s}}^{\text {calc }}$ and $e_{\mathrm{c}}^{\text {calc }}$ are negligible.

An additional uncertainty element is that due to moisture diffusion through the vertical pressure sensing tube of the final saturator. When the saturator temperature is above ambient, moisture will condense inside the tube in the ambient-temperature region and drip down to the saturator. As the air in that region dries from the condensation, additional moisture will diffuse through the tube from the saturator to the ambient-temperature region. This creates a diffusion-driven moisture flow which can lower the water amount fraction of the air exiting the saturator. We have calculated the depletion and determined it to be less than $0.002 \%$ for the intended gas flows through the generator (over $20 \mathrm{~L} / \mathrm{min}$ ). This amount is negligible compared to other uncertainties, and as a result we are not including it in Table 1.

The table does not include uncertainties from measurement repeatability of the particular hygrometer under calibration. In the calibration reports, however, the total uncertainty for the calibration of the hygrometer is reported, with the uncertainty due to hygrometer repeatability determined as described in the hygrometer specifications. If repeatability is not provided in the manufacturer specifications, the repeatability of similar instruments is used. 
Table 1. Uncertainty elements for the Hybrid Humidity Generator and their uncertainties. Here, $u(X)$ is the standard uncertainty for element $X$. The elements with subscript "c" refer to the environment in which the humidity is to be determined. The element $T_{\mathrm{c}}$ is only relevant for chilled-mirror hygrometers with an external thermometer for determination of relative humidity or for thermohygrometers calibrated inside the test chamber. Note that the values for $T_{\mathrm{s}}$ in the expressions for $u\left(f_{\mathrm{s}}^{\text {calc }}\right)$ and $u\left(f_{\mathrm{c}}^{\text {calc }}\right)$ are in units of Kelvin.

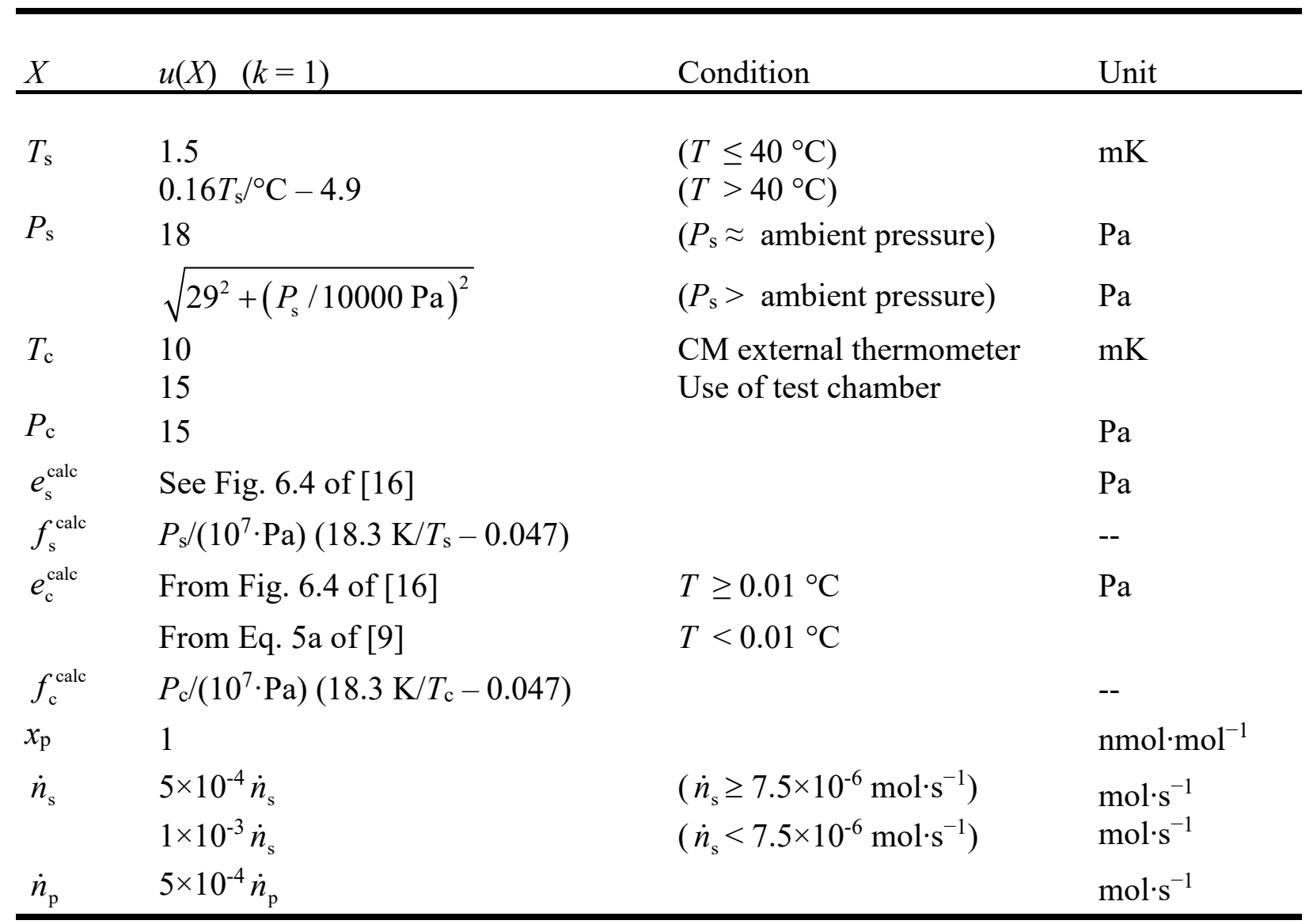

\subsection{Uncertainty Plots}

Figure 20 shows the total expanded uncertainty for humidity generated by the HHG when the generator is operated in 1-P mode. The uncertainty is shown for the a) water amount fraction (relative uncertainty) and b) dew point. Here, the total expanded uncertainty is given by $U(x)=$ $k u(x)$, where the coverage factor is $k=2$. The expanded relative uncertainty is given by $U_{\mathrm{r}}(x)=$ $U(x) / x$. In the figure, the black curve represents the total uncertainty, while the other curves represent the contributions to the total uncertainty from individual uncertainty components. In Fig. 20(b), the uncertainty contributions from $e_{\mathrm{s}}^{\text {calc }}$ and $e_{\mathrm{c}}^{\text {calc }}$ are zero, because these uncertainties cancel out when the generator is used in 1-P mode; the uncertainty contributions for $f_{\mathrm{s}}^{\text {calc }}$ and $f_{\mathrm{c}}^{\text {calc }}$ 
are zero for the same reason. Also in this plot, the curve designated as " $P$ " represents the contributions from both $P_{\mathrm{s}}$ and $P_{\mathrm{c}}$. The figure shows that for the 1-P mode, the dominant uncertainty is from pressure measurement and stability, except for saturator temperatures above $60{ }^{\circ} \mathrm{C}$; in this case uncertainties due to temperature non-uniformities in the bath dominate. Figures 21(a) and 21(b) show similar plots for the case when the generator is operated in 2-P mode with $P_{\mathrm{s}}=500 \mathrm{kPa}$. In Fig. $21(\mathrm{~b})$, the discontinuity at $0{ }^{\circ} \mathrm{C}$ is due to the assumption of frost-point generation below this temperature. This figure shows that when the saturator is operated in this way, the uncertainties in $f_{\mathrm{s}}^{\text {calc }}$ and $f_{\mathrm{c}}^{\text {calc }}$ usually dominate.

Figure 22 shows the expanded uncertainty generated by the HHG when it is used in divided-flow mode. The uncertainties plotted are (a) the water amount fraction (relative uncertainty) and (b) the frost-point temperature. For these plots, the saturator parameters are $P_{\mathrm{s}}=300 \mathrm{kPa}$ and $T_{\mathrm{s}}=0.5^{\circ} \mathrm{C}$. In the plots, " $n$ " refers to the combined contribution to the total from $\dot{n}_{\mathrm{s}}$ and $\dot{n}_{\mathrm{p}}$. In Fig 22(a), $U_{\mathrm{r}}(x)$ is relatively constant for $x>2 \times 10^{-6}$. At the highest value of $x$ shown in the plot, $\dot{n}_{\mathrm{p}}=0$ and so $U_{\mathrm{r}}(x)$ is only due to the saturator. As $x$ decreases to $2 \times 10^{-6}, U_{\mathrm{r}}(x)$ increases slightly due to the rising significance of $u\left(\dot{n}_{\mathrm{s}}\right)$ and $u\left(\dot{n}_{\mathrm{p}}\right)$. As $x$ decreases below $2 \times 10^{-6}, u\left(x_{\mathrm{p}}\right) / x$ dominates $U_{\mathrm{r}}(x)$, increasing its value to nearly $2 \%$ at $x=1 \times 10^{-7}$. In (b), the total expanded uncertainty is $U\left(T_{\mathrm{FP}}\right)=k u\left(T_{\mathrm{FP}}\right)$. For $-70{ }^{\circ} \mathrm{C} \leq T_{\mathrm{FP}} \leq-12{ }^{\circ} \mathrm{C}, U\left(T_{\mathrm{FP}}\right)$ ranges from $16 \mathrm{mK}$ to $25 \mathrm{mK}$, decreasing with temperature. As $T_{\mathrm{FP}}$ decreases below $-70{ }^{\circ} \mathrm{C}, U\left(T_{\mathrm{FP}}\right)$ rises rapidly up to $120 \mathrm{mK}$ at $-90{ }^{\circ} \mathrm{C}$ due to the increasing influence of $u\left(x_{\mathrm{p}}\right)$.

Figure 23 shows the expanded relative uncertainty $U_{\mathrm{r}}(R H)=U(R H) / R H$ for relative humidity calibrations of a chilled-mirror hygrometer with an external temperature probe, using humid gas generated by the HHG and flowing to an environment with temperature $T_{\mathrm{c}}=20^{\circ} \mathrm{C}$ and pressure $100 \mathrm{kPa}$. Here, $U_{\mathrm{r}}(R H)$ includes the uncertainty of the humidity produced by the generator and the uncertainty of the calibration of the hygrometer's external temperature probe. In plots a) and b), the generator is operated in 2-P mode; the plots show the uncertainty for two saturator temperatures: a) $T_{\mathrm{s}}=20^{\circ} \mathrm{C}$ and b) $T_{\mathrm{s}}=1{ }^{\circ} \mathrm{C}$, which generate different relative humidity ranges. In plot c), the generator is operated in divided-flow mode.

Figure 24 shows the expanded relative uncertainty $U_{\mathrm{r}}(R H)=U(R H) / R H$ for relative humidity calibrations of a thermohygrometer, using humid gas generated by the HHG and flowing to the test chamber with temperature $T_{\mathrm{c}}=20^{\circ} \mathrm{C}$ and pressure $100 \mathrm{kPa}$. Here, $U_{\mathrm{r}}(R H)$ includes the uncertainty of the humidity produced by the generator and the uncertainty of the temperature in the chamber at the point of the thermohygrometer. In plots a) and b), the generator is operated in 2-P mode; the plots show the uncertainty for two saturator temperatures: a) $T_{\mathrm{s}}=20{ }^{\circ} \mathrm{C}$ and b) $T_{\mathrm{s}}=$ $1{ }^{\circ} \mathrm{C}$, which generate different relative humidity ranges. In plot $\mathrm{c}$ ), the generator is operated in divided-flow mode. The primary difference between the plots in Figs. 23 and 24 is that for Fig. 23 $u\left(T_{\mathrm{c}}\right)=0.01{ }^{\circ} \mathrm{C}$ and for Fig. $24 u\left(T_{\mathrm{c}}\right)=0.015^{\circ} \mathrm{C}$.

Figure 25 shows the total expanded relative uncertainty for mass ratio, $U_{\mathrm{r}}(r)=U(r) / r$, generated by the HHG when the generator is operated in a) 1-P mode and b) $2-\mathrm{P}$ mode with $P_{\mathrm{s}}=500 \mathrm{kPa}$. In the plots, the black curve represents the total uncertainty, while the other curves represent the contributions to the total uncertainty from individual uncertainty components. 

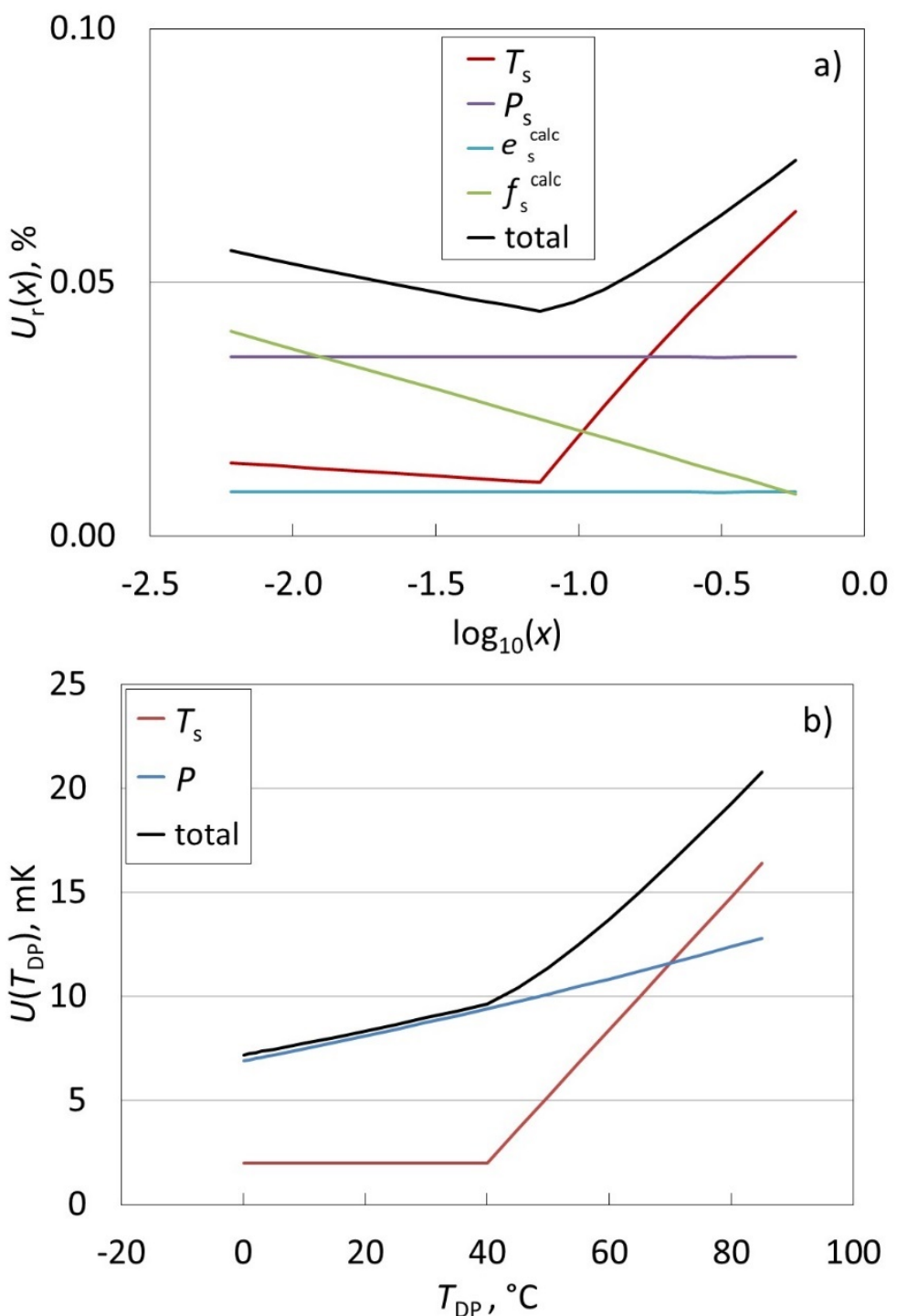

Figure 20. Total expanded uncertainty $U$ for the (a) water amount fraction and (b) dewpoint temperature generated by the HHG saturator when used in 1-P mode. The black curve represents the total uncertainty, while the other curves show the contributions from individual uncertainty elements. In a), the expanded uncertainty is expressed as a relative uncertainty $U_{\mathrm{r}}(x)=U(x) / x=k u(x) / x$, where $k=2$ and $u(x)$ is the standard uncertainty for $x$. In b), the total expanded uncertainty is $U\left(T_{\mathrm{DP}}\right)=k u\left(T_{\mathrm{DP}}\right)$. In $\left.\mathrm{b}\right), P$ represents the combined contributions from both $P_{\mathrm{s}}$ and $P_{\mathrm{c}}$. 

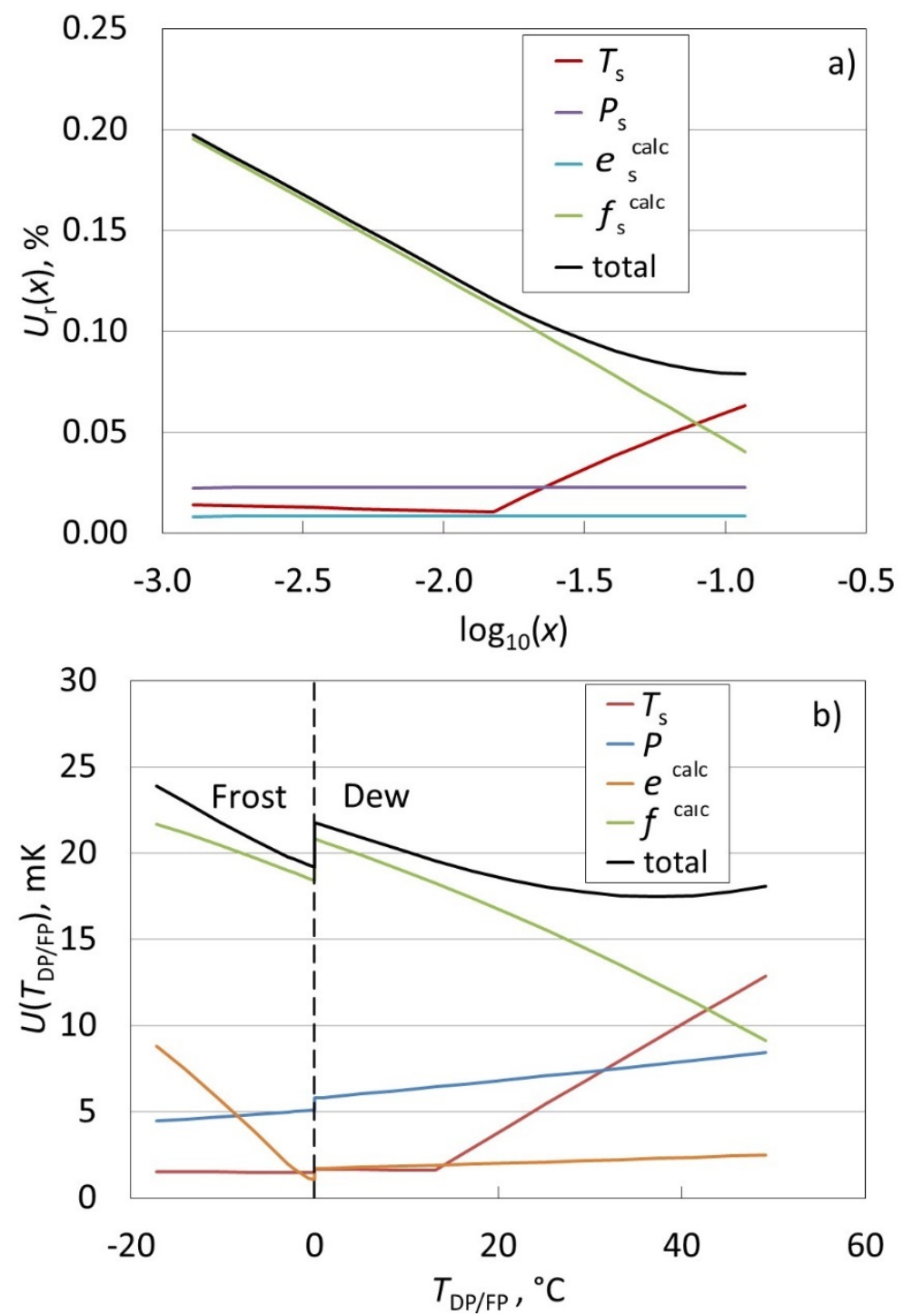

Figure 21. Total expanded uncertainty $U$ for the (a) water amount fraction and (b) dew/frost-point temperature generated by the HHG saturator when used in 2-P mode with $P_{\mathrm{s}}=500 \mathrm{kPa}$. The black curve represents the total uncertainty, while the other curves show the contributions from individual uncertainty elements. In a), the expanded uncertainty is expressed as a relative uncertainty $U_{\mathrm{r}}(x)=U(x) / x=k u(x) / x$, where $k=2$ and $u(x)$ is the standard uncertainty for $x$. In b), the total expanded uncertainty is $U\left(T_{\mathrm{DP}}\right)=$ $k u\left(T_{\mathrm{DP}}\right)$. In $\left.\mathrm{b}\right), P, e^{\text {calc }}$, and $f^{\text {calc }}$ each represent the combined contributions of their quantity from both the saturator and chamber (hygrometer). 

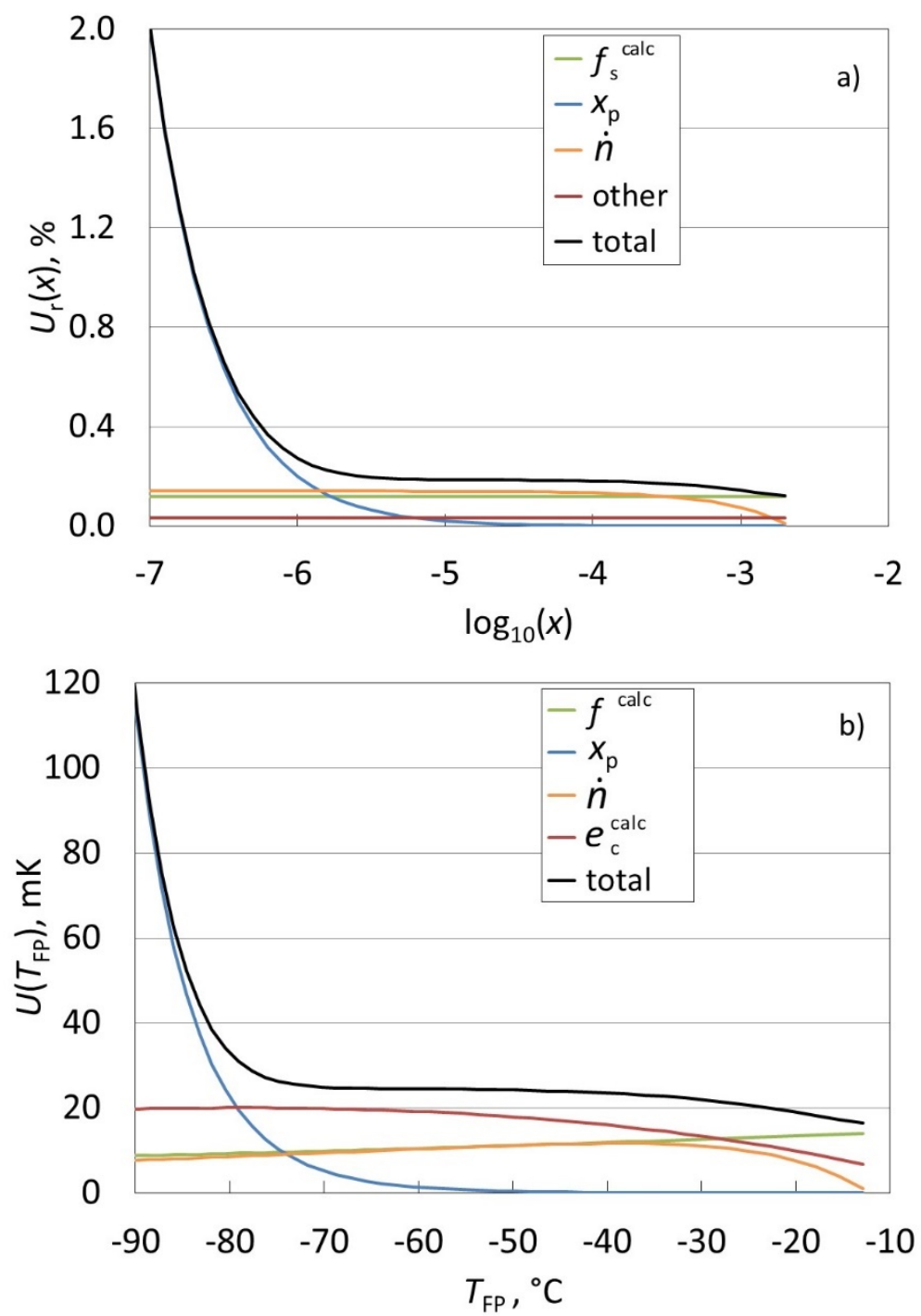

Figure 22. Total expanded uncertainty for the a) water amount fraction (relative uncertainty) and b) frost-point temperature generated by the HHG when it is used in divided-flow mode with a saturator pressure of $P_{\mathrm{s}}=300 \mathrm{kPa}$. Here, f $f^{\mathrm{calc}}$ represents the combined uncertainty contributions from both the saturator and chamber (hygrometer), and $\dot{n}$ represents the combined uncertainty contributions from the wet gas and dry gas. 

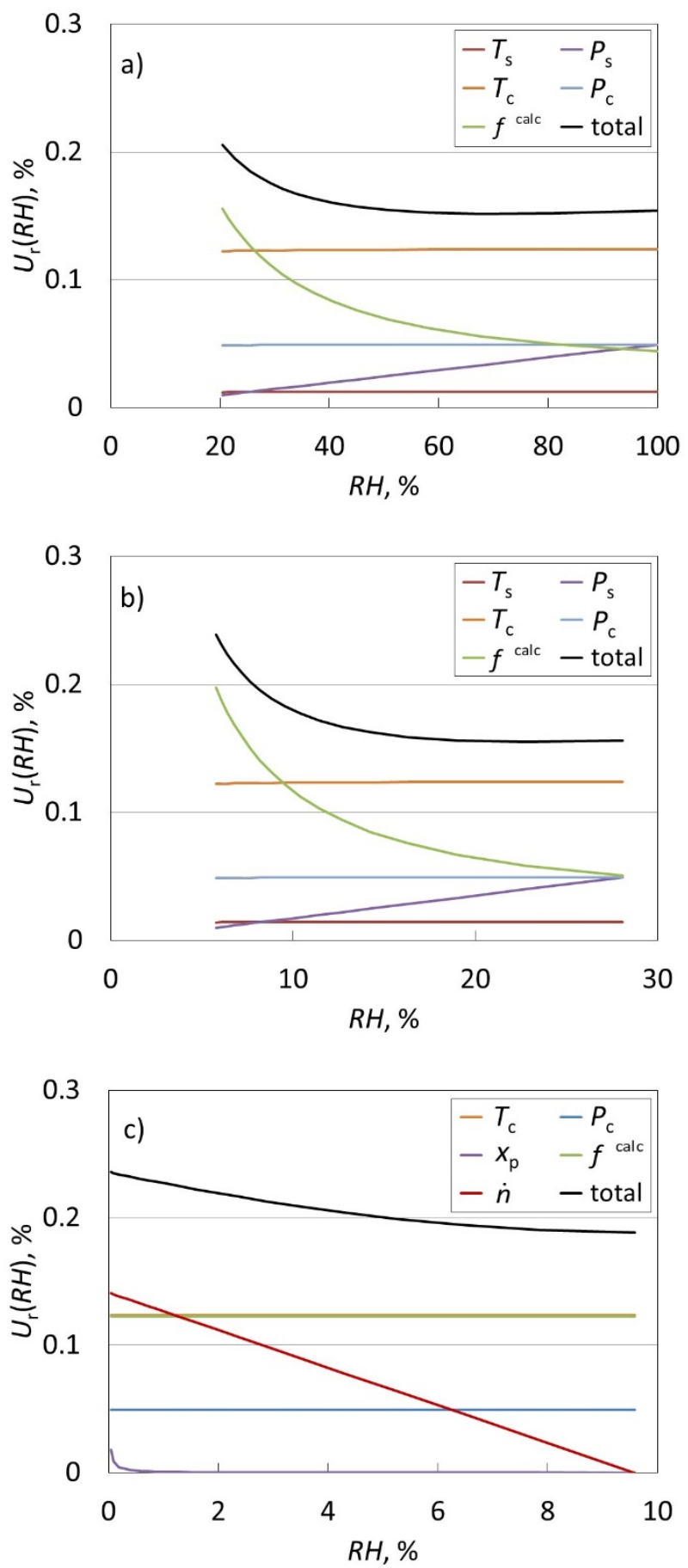

Figure 23. Total expanded relative uncertainty $U_{\mathrm{r}}(R H)$ for the relative humidity calibrations of a chilled-mirror hygrometer with and external temperature probe, using humid gas generated by the HHG to an environment of temperature $T_{\mathrm{c}}=20^{\circ} \mathrm{C}$ and pressure $P_{\mathrm{c}}=100 \mathrm{kPa}$. Here, $U_{\mathrm{r}}(R H)$ includes the uncertainty for the calibration of the hygrometer's external temperature probe. In plots a) and b), the generator is used in 2-P mode, and the saturator temperature is a) $20{ }^{\circ} \mathrm{C}$ and b) $1{ }^{\circ} \mathrm{C}$; the relative humidity is varied by changing the saturator pressure. In c), the generator is used in divided-flow mode. 

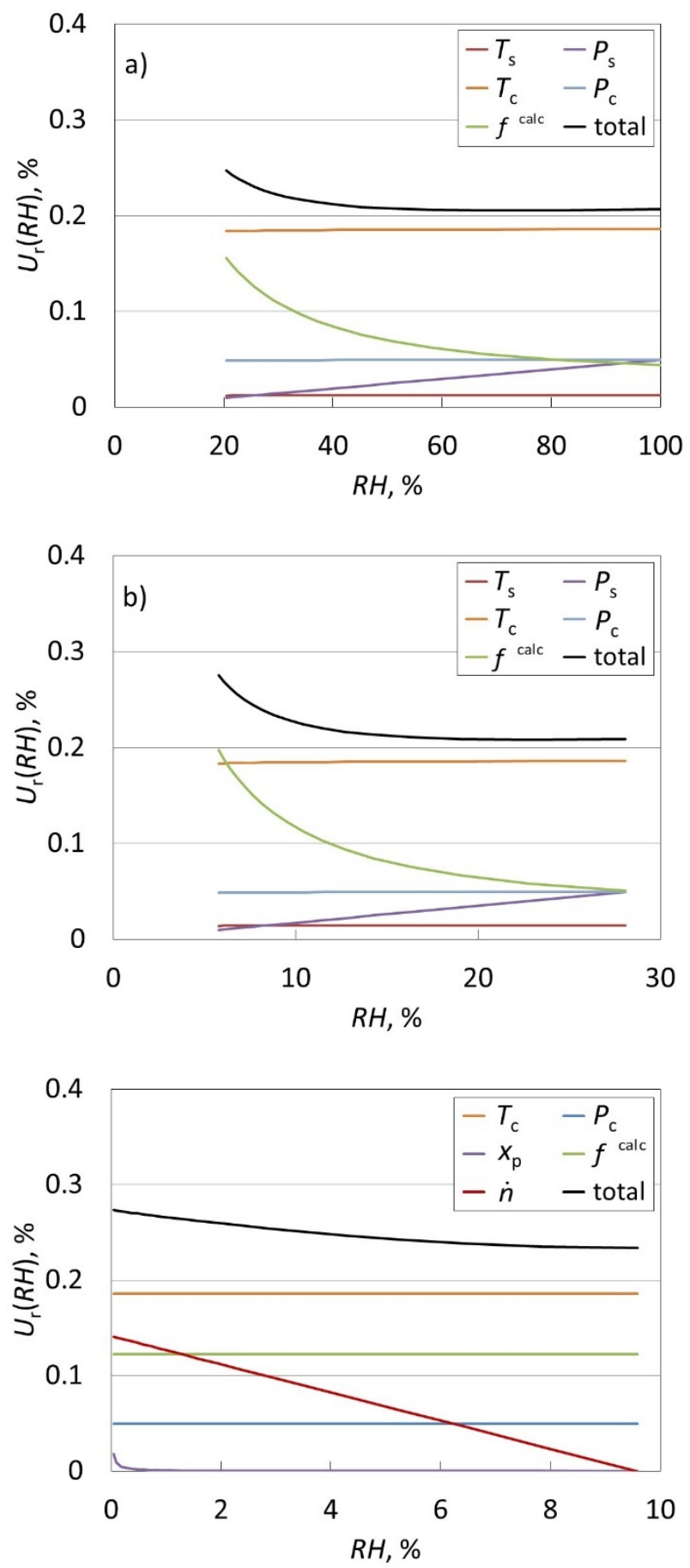

Figure 24. Total expanded relative uncertainty $U_{\mathrm{r}}(R H)$ for the relative humidity calibrations of a thermohygrometer, using humid gas generated by the HHG to the test chamber with temperature $T_{\mathrm{c}}=20^{\circ} \mathrm{C}$ and pressure $P_{\mathrm{c}}=100 \mathrm{kPa}$. Here, $U_{\mathrm{r}}(R H)$ includes the uncertainty for the temperature of the chamber at the location of the thermohygrometer. In plots $\mathrm{a}$ ) and $\mathrm{b}$ ), the generator is used in 2-P mode, and the saturator temperature is a) $20^{\circ} \mathrm{C}$ and b) $1{ }^{\circ} \mathrm{C}$; the relative humidity is varied by changing the saturator pressure. In $\mathrm{c}$ ), the generator is used in dividedflow mode. 

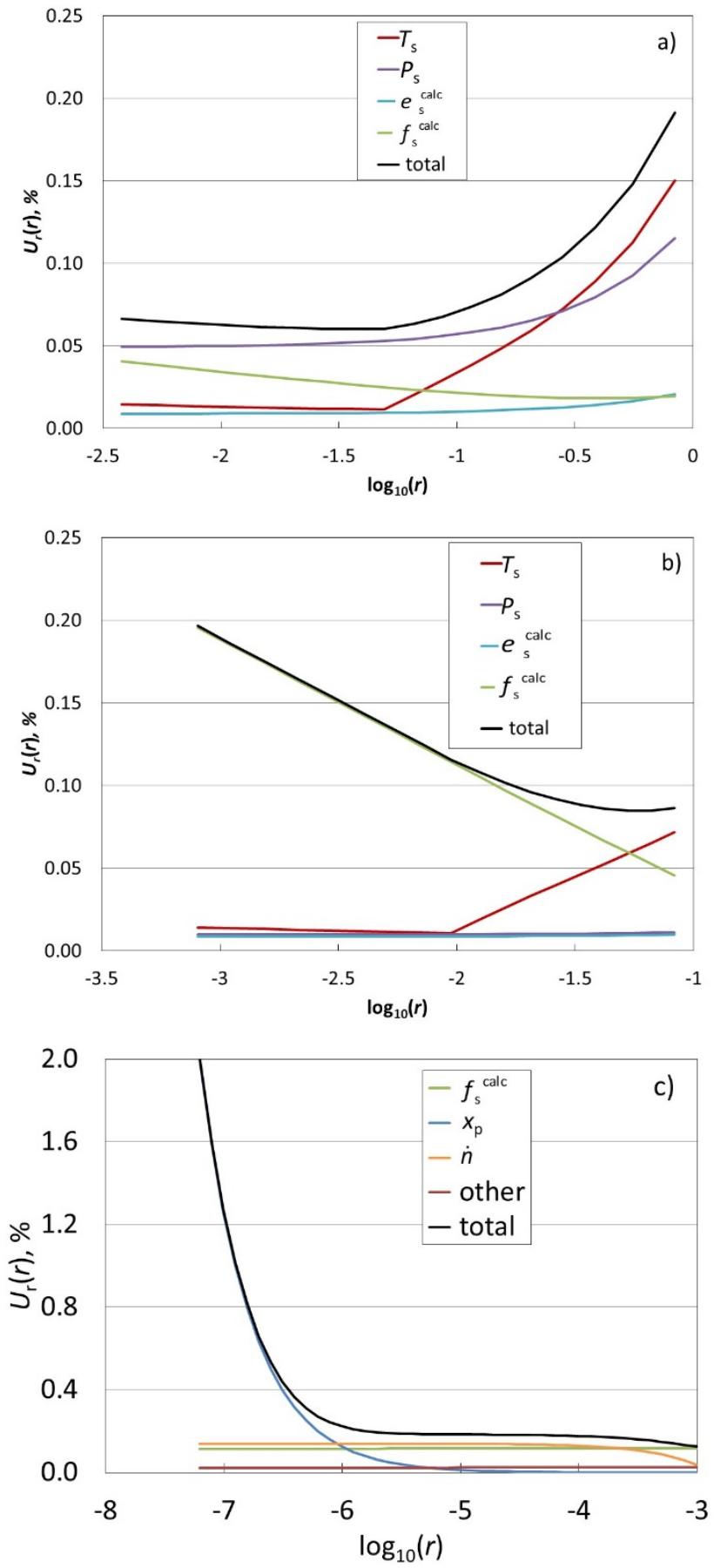

Figure 25. Total expanded relative uncertainty $U_{\mathrm{r}}(r)$ for the mass ratio $r$ generated by the HHG. In the plots the generator is used in a) 1-P mode, b) 2-P mode with $P_{\mathrm{s}}=500 \mathrm{kPa}$, and c) in divided-flow mode. 


\section{Comparisons with other Humidity Standards}

\subsection{NIST Gravimetric Hygrometer}

We have performed comparisons between the humidity generated by the HHG and that measured by the NIST gravimetric hygrometer $[18,19]$. The gravimetric hygrometer is a primary standard for humidity measurement. It determines the mass ratio of water to air in a humid gas sample by separating out the water from the gas and subsequently determining the masses of the water and dry air. The results of the comparison are shown in Figure 26, which plots $\Delta x / x$, where $\Delta x \equiv x_{\mathrm{GH}}-x_{\mathrm{HHG}}$; here, $x_{\mathrm{GH}}$ is the water amount fraction measured by the gravimetric hygrometer and $x_{\mathrm{HHG}}$ is that generated using the HHG. Here, the saturator pressure was $\approx 200 \mathrm{kPa}$ for all points except for those where $\log _{10}(x)=-2.7$. In this case, the saturator pressure was $300 \mathrm{kPa}$ and the saturator temperature was $1{ }^{\circ} \mathrm{C}$; these are the saturator parameters used when the HHG is operated in divided-flow mode.

The expanded uncertainty $(k=2)$ of the amount fraction measurements by the gravimetric hygrometer is estimated to be $0.20 \%$ over the range of humidity in the plot. For the hybrid generator using the above parameters, the expanded uncertainty is estimated to be less than $0.08 \%$, so the combined expanded relative uncertainty of the $\mathrm{HHG}$ and gravimetric hygrometer is estimated to be $U_{\mathrm{r}}(x) \approx 0.22 \%$.

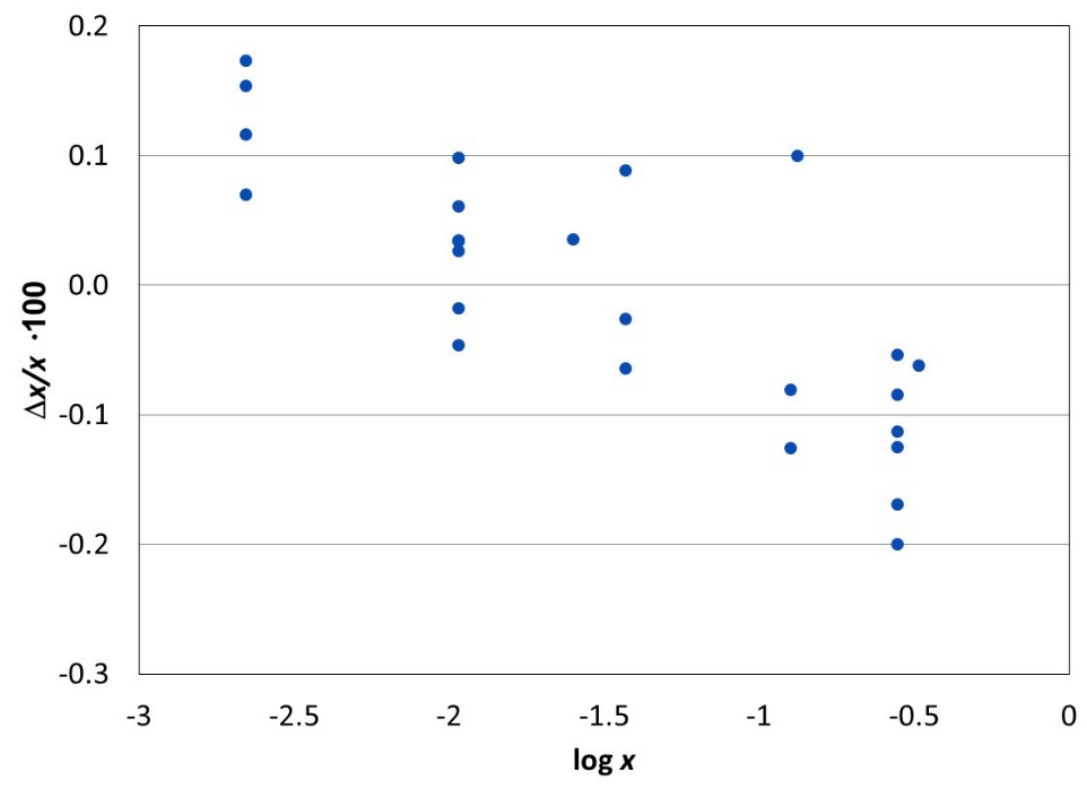

Figure 26. Comparison of water amount fraction $x$ measured by the NIST gravimetric hygrometer with that generated by the HHG. Here, $\Delta x \equiv x_{\mathrm{GH}}-x_{\mathrm{HHG}}$, where $x_{\mathrm{GH}}$ is the amount fraction measured by the gravimetric hygrometer and $x_{\mathrm{HHG}}$ is that generated using the HHG. The combined expanded $(k=2)$ relative uncertainties of the gravimetric hygrometer and generator are $U_{\mathrm{r}}(x) \approx 0.22 \%$. 
The values of $\Delta x / x$ are all within $0.2 \%$ and the averages of the points taken at one value of $x$ are all within $0.12 \%$. This is within the combined uncertainties of the HHG and gravimetric hygrometer, showing agreement between the two systems.

\subsection{CCT Key Comparisons}

Under the Mutual Recognition Arrangement (MRA) [20] it was agreed that the metrological equivalence of national measurement standards would be determined by a set of key comparisons chosen and organized by the consultative committees of the International Committee for Weights and Measures (CIPM) working closely with the Regional Metrology Organizations (RMOs).

In 2001 the Consultative Committee for Thermometry (CCT) of the CIPM arranged for a multilateral key comparison of dew/frost-point standards, named CCT-K6 [21], with the National Physical Laboratory (NPL, UK) to be its pilot and the National Measurement Institute of Japan (NMIJ, Japan) to be its co-pilot. The assigned participants were the National Metrology Institutes (NMIs) of the UK, Japan, the United States, Finland, Spain, Italy, China, Singapore, Russia, and the Netherlands. The comparison points were $20{ }^{\circ} \mathrm{C}, 1{ }^{\circ} \mathrm{C},-10{ }^{\circ} \mathrm{C},-30{ }^{\circ} \mathrm{C}$, and $-50{ }^{\circ} \mathrm{C}$. The comparison measurements were performed between 2002 and 2009. As the NMI of the United States, NIST participated in the comparison, performing its measurements in 2007 . It used the HHG as its standard at the points $20^{\circ} \mathrm{C}, 1^{\circ} \mathrm{C}$, and $-10^{\circ} \mathrm{C}$. At the time of these measurements, the divided-flow system for the HHG was not yet operational, so NIST used its Low Frostpoint Generator (LFPG) [22] (now decommissioned) as its standard at the points $-30{ }^{\circ} \mathrm{C}$ and $-50{ }^{\circ} \mathrm{C}$.

The comparison measurements by all participants were performed using two chilled-mirror hygrometers supplied by the pilots, called transfer standards. Each NMI used its primary standard generator to produce humid air with a dew/frost-point $T_{\mathrm{DP} / \mathrm{FP}}^{\mathrm{g}}$. It then used the transfer standards to obtain the measured dew/frost-point $T_{\mathrm{DP} / \mathrm{FP}}^{\mathrm{m}}$. The difference between the two, $\Delta T_{\mathrm{DP} / \mathrm{FP}}$, given by

$$
\Delta T_{\mathrm{DP} / \mathrm{FP}}=T_{\mathrm{DP} / \mathrm{FP}}^{\mathrm{g}}-T_{\mathrm{DP} / \mathrm{FP}}^{\mathrm{m}}
$$

was the quantity used to compare the dew/frost-point standards of the participants in the key comparison.

One of the achievements of CCT-K6 was the creation of key comparison reference values (KCRVs) for $\Delta T_{\mathrm{DP} / \mathrm{FP}}$ at the comparison points [21], [ $\left.\Delta T_{\mathrm{DP} / \mathrm{FP}}\right]_{\mathrm{KCRV}}$. These KCRVs are considered to be international consensus values for dew/frost-point standards at these points. They are also reference values with which all NMIs can establish degrees of equivalence. If NMI standards have established degrees of equivalence (DoE's) to the KCRVs, they can establish DoE's with each other without performing direct comparison measurements. By participating in CCT-K6, the HHG has established DoE's to the CCT-K6 KCRVs. For a given NMI, the DoE $D_{\mathrm{NMI} / K C R V}$ at a dew/frostpoint temperature $T_{\mathrm{DP} / \mathrm{FP}}$, is given by

$$
D_{\mathrm{NMI} / \mathrm{KCRV}}\left(T_{\mathrm{DP} / \mathrm{FP}}\right) \equiv\left[\Delta T_{\mathrm{DP} / \mathrm{FP}}\right]_{\mathrm{NMI}}-\left[\Delta T_{\mathrm{DP} / \mathrm{FP}}\right]_{\mathrm{KCRV}} \cdot
$$


In Table 2, the DoE's between the HHG dew/frost-point standards and the KCRVs are shown, along with their expanded $(k=2)$ uncertainties (obtained from Tables 7.3 and 7.4 in [21]). The DoE values are well within their expanded $(k=2)$ uncertainties.

Table 2. Degree of equivalence between $T_{\mathrm{DP} / \mathrm{FP}}$ realized by NIST and the KCRV, $D_{\mathrm{NIST} / \mathrm{KCRV}}$, and its expanded uncertainty $(k=2), U\left(D_{\mathrm{NIST} / \mathrm{KCRV}}\right)$, at $T_{\mathrm{DP} / \mathrm{FP}}$ values of $20^{\circ} \mathrm{C}$, $1{ }^{\circ} \mathrm{C}$, and $-10^{\circ} \mathrm{C}$, as given by Tables 7.3 and 7.4 in [21].

\begin{tabular}{|c|c|c|}
\hline $\begin{array}{c}\text { Nominal } \\
T_{\mathrm{DP} / \mathrm{FP}} \\
\left({ }^{\circ} \mathrm{C}\right)\end{array}$ & $\begin{array}{c}D_{\mathrm{NIST} / \mathrm{KCRV}} \\
\left({ }^{\circ} \mathrm{C}\right)\end{array}$ & $\begin{array}{c}U\left(D_{\mathrm{NIST} / \mathrm{KCRV}}\right) \\
\left({ }^{\circ} \mathrm{C}\right)\end{array}$ \\
\hline 20 & -0.006 & 0.050 \\
\hline 1 & -0.011 & 0.060 \\
\hline-10 & -0.039 & 0.043 \\
\hline
\end{tabular}

Because the HHG wasn't involved with the 2007 comparison measurements at $-30{ }^{\circ} \mathrm{C}$ and $-50{ }^{\circ} \mathrm{C}$ for CCT-K6, NIST later used the HHG to perform a bilateral comparison with the National Metrology Institute of Japan, of the National Institute of Advanced Industrial Science and Technology (NMIJ/AIST, Japan), designated CCT-K6.2, at these two frost points as well as at $-70{ }^{\circ} \mathrm{C}$ and $-80{ }^{\circ} \mathrm{C}$ [23]. The measurements were performed between December 2015 and November 2016. The results of the comparison directly established the DoE between NIST HHG and NMIJ/AIST frost-point standards at these points. They also indirectly established the DoE between the NIST HHG frost-point standards and the CCT-K6 KCRVs at these points, since NMIJ provided linkage through its participation in that key comparison. In Table 3, the DoE's between the HHG dew/frost-point standards and the KCRVs are shown, along with their expanded $(k=2)$ uncertainties. Here, the DoE values are also well within their expanded uncertainties. Note that the uncertainties in Table 3 are higher than those of Table 2 because the DoE has been established indirectly.

Table 3. Degree of equivalence between $T_{\mathrm{FP}}$ realized by NIST and the KCRV, $D_{\text {NIST/KCRV, and its expanded }}$ uncertainty $(k=2), U\left(D_{\mathrm{NIST} / \mathrm{KCRV}}\right)$, at $T_{\mathrm{FP}}$ values of $-30^{\circ} \mathrm{C}$ and $-50{ }^{\circ} \mathrm{C}$, as determined by the bilateral comparison CCT-K6.2 [23] between NIST and NMIJ/AIST (Japan).

\begin{tabular}{|c|c|c|}
\hline $\begin{array}{c}\text { Nominal } \\
T_{\mathrm{DP} / \mathrm{FP}} \\
\left({ }^{\circ} \mathrm{C}\right)\end{array}$ & $\begin{array}{c}D_{\mathrm{NIST} / \mathrm{KCRV}} \\
\left({ }^{\circ} \mathrm{C}\right)\end{array}$ & $\begin{array}{c}U\left(D_{\mathrm{NIST} / \mathrm{KCRV})}\right) \\
\left({ }^{\circ} \mathrm{C}\right)\end{array}$ \\
\hline-30 & -0.048 & 0.075 \\
\hline-50 & -0.012 & 0.142 \\
\hline
\end{tabular}


Although there are no CCT-K6 KCRVs at $-70{ }^{\circ} \mathrm{C}$ and $-80{ }^{\circ} \mathrm{C}$, it is nevertheless useful to show the DoE between the NIST HHG and NMIJ/AIST standards at those point for validation of their standards. The DoE values and their expanded uncertainties are shown in Table 4. The DoE values are well within the expanded uncertainties, showing agreement between the standards of NIST and NMIJ/AIST at these points.

Table 4. Degree of equivalence between $T_{\mathrm{FP}}$ realized by NMIJ/AIST (Japan) and that of NIST, and its expanded uncertainty $(k=2)$ at $-70{ }^{\circ} \mathrm{C}$ and $-80^{\circ} \mathrm{C}$.

\begin{tabular}{|c|c|c|}
\hline $\begin{array}{c}\text { Nominal } \\
T_{\mathrm{DP} / \mathrm{FP}} \\
\left({ }^{\circ} \mathrm{C}\right)\end{array}$ & $\begin{array}{c}D_{\mathrm{NIST} \text { NMIJ }} \\
\left({ }^{\circ} \mathrm{C}\right)\end{array}$ & $\begin{array}{c}U(D \text { NIST/NMIJ }) \\
\left({ }^{\circ} \mathrm{C}\right)\end{array}$ \\
\hline-70 & -0.045 & 0.466 \\
\hline-80 & 0.059 & 0.112 \\
\hline
\end{tabular}

In 2008, the CCT arranged for a multilateral key comparison of above-ambient dew-point standards, named CCT-K8 [24], with the Instituto Nacional de Técnica Aeroespacial (INTA, Spain) as its pilot and NIST as its co-pilot. The additional participants were KRISS (South Korea), (NMC-A*STAR (Singapore), NMIJ/AIST (Japan), VNIIFTRI (Russia), INRiM (Italy), NPL (UK), PTB (Germany), and BEV/E+E (Austria). Measurements were made in 2016 and 2017. The comparisons were made at dew point temperatures of $30^{\circ} \mathrm{C}, 50{ }^{\circ} \mathrm{C}, 65^{\circ} \mathrm{C}, 80^{\circ} \mathrm{C}, 85^{\circ} \mathrm{C}, 90{ }^{\circ} \mathrm{C}$, and $95{ }^{\circ} \mathrm{C}$. As the NIST HHG does not realize dew points above $85^{\circ} \mathrm{C}$, it did not perform comparison measurements at $90^{\circ} \mathrm{C}$ and $95^{\circ} \mathrm{C}$. At the time of this writing, Draft A of the CCT-K 8 report is still in progress.

\subsection{SIM Key Comparisons}

The NIST HHG has participated in a number of bilateral comparisons for the Inter-American Metrology System (SIM), the Regional Metrology Organization (RMO) for North, Central, and South America. It has performed comparisons with NRC (Canada) from $-25{ }^{\circ} \mathrm{C}$ to $20{ }^{\circ} \mathrm{C}$ (designated SIM.T-K6.1) [25], CENAM (Mexico) from $-20^{\circ} \mathrm{C}$ to $20^{\circ} \mathrm{C}$ (designated SIM.T-K6.2) [26], INMETRO (Brazil) from $-30{ }^{\circ} \mathrm{C}$ to $20^{\circ} \mathrm{C}$ (designated SIM.T-K6.3) [27], and LACOMET (Costa Rica) from $-30{ }^{\circ} \mathrm{C}$ to $20^{\circ} \mathrm{C}$ (designated SIM.T-K6.5) [28]. All comparisons have shown DoE's within the expanded uncertainties, showing agreement between the standards of NIST and the above-mentioned NMIs at these points. These comparisons have made it possible for these SIM NMIs to establish the DoE's between their dew/frost-point standards and the CCT-K6 KCRVs at several points. 


\section{Calibration of Chilled-Mirror Hygrometers and Cavity Ringdown Spectrometers}

\subsection{Initial Procedures}

Before connecting the hygrometers to the hybrid generator, they are checked for noticeable damage and for proper operation. Any damage or serious operation problems is grounds for rejecting the instrument for calibration. For the case of chilled-mirror hygrometers, we clean the hygrometer mirrors first with ethanol and afterwards with distilled water. Finally, tests are performed to ensure that calibration points requested for each hygrometer are within its measurement range.

\subsection{Connecting the Hygrometers to the Hybrid Generator}

The manifold connecting the hygrometers to the generator is shown in Fig. 27. A maximum of two customer hygrometers can be connected to the generator. Normally only one hygrometer is attached for a calibration, but if a customer sends two hygrometers and requests the same calibration points, the manifold can accommodate simultaneous calibrations. The manifold includes bypass tubes that lead out to the room. Each bypass tube has an adjustable valve that allows control of the flow rate of output gas entering the hygrometers. As shown in the figure, a pressure gauge is located near the input to the first customer hygrometer for measuring the pressure of the customer hygrometers and check standard.
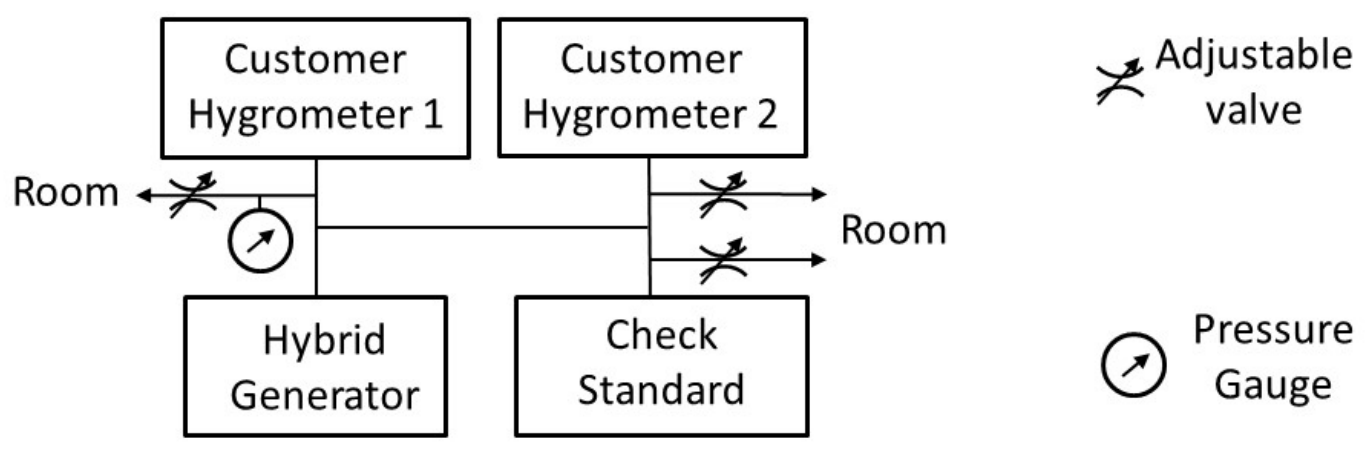

Figure 27. Connections of customer hygrometer and check standard to hybrid generator.

If the desired humidity values exceed a frost point of $-10.3^{\circ} \mathrm{C}\left(x=2.3 \times 10^{-3}\right)$, the hygrometers are connected directly to the output of the 2-P generator, at a point downstream of the expansion valve, as shown in Figure 1a. If the desired dew-point values are above ambient temperature, the tubes connecting the output of the generator to the hygrometers are wrapped with heater tape so that they can be heated to at least $30^{\circ} \mathrm{C}$ above the generated dew-point temperature.

If the desired humidity values are below a frost point of $-10.3^{\circ} \mathrm{C}$, the divided-flow system is used, with the multiplexer attached to the saturator. The hygrometers are attached to the output of the multiplexer, as shown in Fig. $1 \mathrm{~b}$.

The tubing used for connecting the generator to the hygrometers is made of electropolished stainless steel. The valves and fittings used in the manifold are also made of stainless steel. The fittings are almost always of the metal-gasket face-seal type. The exceptions are at the customer hygrometer input when it has a compression fitting and for the connections to the adjustable valves. 


\subsection{Calibration Measurements}

The calibrations are done at specific humidity points as requested by the customer. The order in which the calibration points are acquired is at the discretion of the operator. However, for highest efficiency we plan the order so that as many points as possible can be taken at one saturator temperature.

The hybrid generator temperature/pressure parameters are set to generate the desired humidity. The flow rate through each hygrometer is set to that recommended by the instrument manufacturer (typically $0.5 \mathrm{~L} / \mathrm{min}$ ). After setting the hybrid generator to produce the desired humidity, a computer application opens up a spreadsheet. For each nominal humidity point, a data-acquisition application commands the relevant instruments to measure the temperature and pressure of the saturator, the pressure of the air entering the hygrometers, and the wet-gas and dry-gas flows (if the divided flow method is used); these measurements are used to calculate $x$ and $T_{\mathrm{DP} / \mathrm{FP}}$ inside the hygrometers using Eqs. 1-3. For each set of measurements, the application also records the $x$ or $T_{\mathrm{DP} / \mathrm{FP}}$ measurement of the customer hygrometer and check standard hygrometer. All measurements are recorded in a spreadsheet at $30 \mathrm{~s}$ intervals for at least $30 \mathrm{~min}$ after all measurements reach a steady state. Finally, the application averages the measurements for the last $30 \mathrm{~min}$ to give the final values. If the readings never reach a steady state, efforts will be made to find and fix the source of the problem. The spreadsheet includes plots that monitor the saturator temperature and pressure, as well as the dew/frost point and molar fraction of the generator. It also includes plots that monitor the measurements of the check standard and customer hygrometers.

Once the data is acquired for all requested humidity points, the results are assembled into a workbook. The new check standard data is compared to previous check standard data to validate the performance of the generator during this set of measurements. The final results comparing the customer hygrometer humidity to the HHG humidity are placed in a calibration report similar to that shown in Appendix III. For calibrations of chilled-mirror hygrometers measuring relative humidity, dew-point calibrations are made using the generator while a comparison calibration is made of the temperature probe against a reference thermometer in a stirred bath [15]. The reference relative humidity is calculated using the generated value of $x$ and reference temperature values using Eq. 4.

If the stability and/or repeatability of the hygrometer are significantly worse than the values given by the hygrometer specifications and the sources of these problems cannot be corrected, the hygrometer is rejected for calibration and returned to the customer.

As a check on the consistency of the HHG, a check standard (a chilled-mirror hygrometer) is attached to the output of the generator as shown in Fig. 27 when performing calibrations. A measurement history of the check standard exists for dew/frost points at available multiples of $10{ }^{\circ} \mathrm{C}$ (i.e. $-70{ }^{\circ} \mathrm{C},-60^{\circ} \mathrm{C}, \ldots 70^{\circ} \mathrm{C}, 80^{\circ} \mathrm{C}$ ) as well as $85^{\circ} \mathrm{C}$. During a hygrometer calibration, comparisons are made of the check-standard points with their historical values. Data acquisition for the check standard is performed as described in section 9.4. If the new check standard measurements differ from the average of the old measurements by more than the expanded total uncertainty $(k=2)$ of the HHG and hygrometer, the new results are considered suspect, and further investigation must be made to determine the validity of these results. An example of a checkstandard history plot is shown in Fig. 28. The standard deviation of the points in the plot is $20 \mathrm{mK}$. 


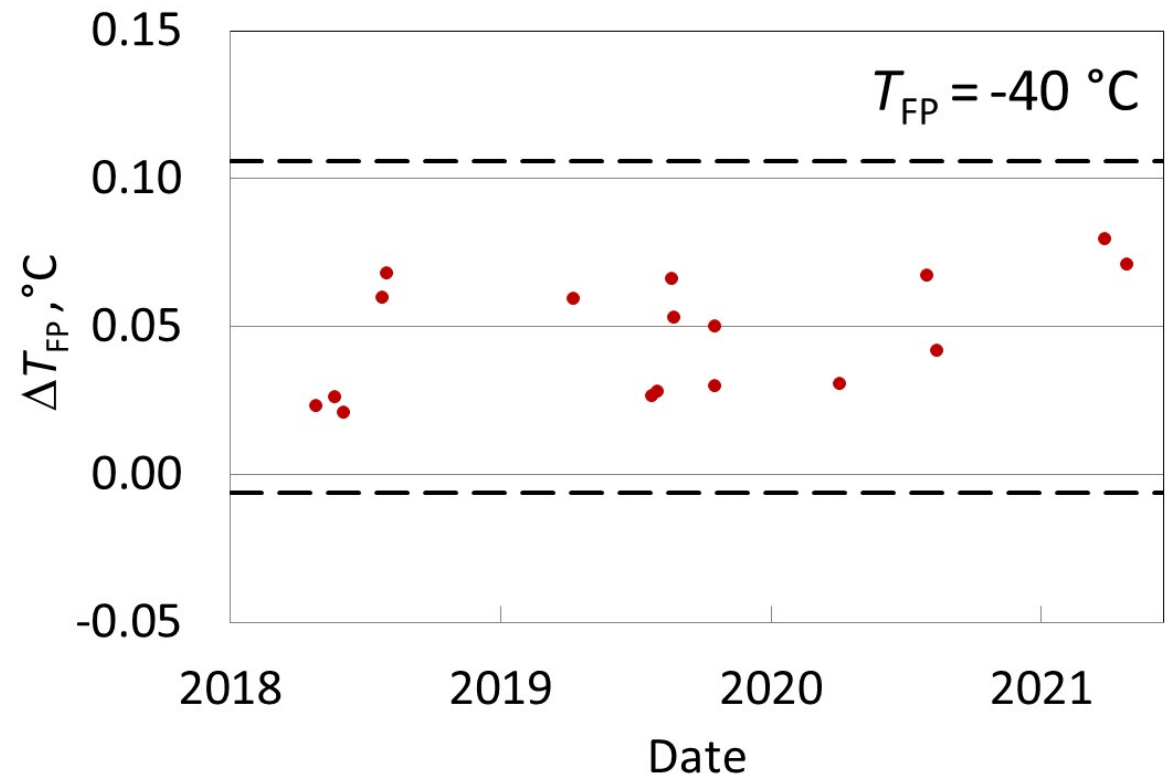

Figure 28. Check Standard history plot for a frost point of $-40{ }^{\circ} \mathrm{C}$. The plot shows the difference $\Delta T_{\mathrm{FP}}$ between the frost-point temperature measured by the check standard and that generated by the HHG as a function of date. The dashed lines represent the $k=2$ uncertainty limits for the hygrometer repeatability. The standard deviation of the points in the plot is $20 \mathrm{mK}$.

\section{Calibration of Thermohygrometers and Dataloggers}

\subsection{Initial Procedures}

Before beginning calibration of the thermohygrometers and dataloggers, they are checked for noticeable damage and for proper operation. Any sign of damage or serious operation problems is grounds for rejecting an instrument for calibration.

The instrument sensors are calibrated in the HHG test chamber (see section 6). For instruments with a cord between their sensor and controller, the sensor is placed inside the chamber while the controller is placed outside the environmental chamber. The cord enters the side of the environmental chamber between a square opening and a slightly compressible square cork block that seals the opening. The cord enters the test chamber from the environmental chamber through a circular port of diameter $2.2 \mathrm{~cm}$. A thermohygrometer with a sensor that has a diameter larger than $2.2 \mathrm{~cm}$ cannot be calibrated using this configuration; in this case the controller may need to be placed in the test chamber as well.

The test chamber does not have a window allowing visual observation of the items inside. Therefore, if the controller must be placed inside the chamber, it must provide some means for data communications with a computer located outside the environmental chamber (e.g. a RS-232 serial port). The communications need not be simultaneous with the instrument measurements. For 
example, with dataloggers, where the controller and sensors are together in one unit, the measurement values can be transmitted after the measurements are completed and the datalogger is taken out of the test chamber.

Instrument sensors are generally placed near the center of the chamber and as close to the test chamber reference thermometer as possible to minimize temperature differences between them. This arrangement is shown in Fig. 14; however, in this photograph the customer instrument (a datalogger) was placed further away than normal for ease of viewing. The sensors are usually mounted by attaching them to a vertical rod in the chamber using a cable tie, as shown in the lower photograph of Fig. 14. If multiple dataloggers are calibrated in the chamber simultaneously, they may be placed on a horizontal metal grill mounted in the chamber at about $1 / 3$ the height of the chamber.

Once the instrument sensors are placed in the test chamber, the environmental chamber is set to control at the desired temperature for the calibration measurement. Additionally, the heat exchanger between the HHG output and the environmental chamber (see section 6.2) is set to control at this same temperature. If the desired relative humidity value corresponds to a dew/frost point that exceeds $-10.3{ }^{\circ} \mathrm{C}\left(x=2.3 \times 10^{-3}\right)$, the heat exchanger is connected directly to the output of the 2-P generator, immediately downstream of the PID throttle valve shown in Fig. 1a. If the relative humidity corresponds to a dew point above ambient temperature, the tubes connecting the throttle valve to the heat exchanger are wrapped with heater tape so that they can be heated to at least $30{ }^{\circ} \mathrm{C}$ above the generated dew-point temperature. If the desired relative humidity value corresponds to a frost point at or below $-10.3{ }^{\circ} \mathrm{C}$, the divided-flow system is used, with the multiplexer attached to the saturator. The heat exchanger is attached to the output of the multiplexer shown in Fig. 1 b.

\subsection{Calibration Measurements}

The calibrations are done at specific temperature and relative humidity points as requested by the customer. The order in which the calibration points are acquired is at the discretion of the operator. However, for highest efficiency we plan the order so that as many points as possible can be taken at one saturator and/or chamber temperature.

The hybrid generator temperature/pressure parameters are set to generate the desired relative humidity for the given chamber temperature. The flow rate through the chamber is set to $150 \mathrm{~L} / \mathrm{min}$. Afterwards, a computer application opens up a spreadsheet. For each nominal relative humidity point, a data-acquisition application commands the relevant instruments to measure the temperature and pressure of the saturator, the pressure of the air entering the test chamber, the wetgas and dry-gas flows (if the divided-flow method is used), and the temperature inside the test chamber; these measurements are used to calculate $R H$ and $T_{\mathrm{DP} / \mathrm{FP}}$ inside the test chamber using Eqs. 2-4. For each set of measurements, the application also records $R H$ using a thermohygrometer check standard and $T_{\mathrm{DP} / \mathrm{FP}}$ using a chilled-mirror check standard. All measurements are recorded in a spreadsheet at $90 \mathrm{~s}$ intervals for at least $30 \mathrm{~min}$ after all measurements reach a steady state. Finally, the application averages the measurements for the last $30 \mathrm{~min}$ to give the final values. If the readings never reach a steady state, efforts will be made to find and fix the source of the problem. The spreadsheet includes plots that monitor the saturator temperature and pressure, as well as the relative humidity and dew/frost point in the test chamber. It also includes plots that monitor the measurements of the check standards and customer instruments. 
Once the data is acquired for all requested humidity points, the results are assembled into a workbook. The new check standard data is compared to previous check standard data to validate the performance of the generator during this set of measurements. The final results comparing the customer instrument's temperature and relative humidity measurements to the HHG test chamber temperature and relative humidity are placed in a calibration report similar to that shown in Appendix III.

\section{Quality Control}

The pressure gauges used for measuring the pressure in the saturator and the hygrometer are recalibrated against a piston gauge by the NIST Thermodynamic Metrology Group once every two years. The SPRT used for measuring the saturator temperature is checked yearly against the water triple point and the PRTs used for measuring the test chamber, environmental chamber, and heat exchanger temperatures are checked yearly against the ice point. The respective $R_{0}$ values of the SPRT and PRTs are adjusted to conform with the results of these measurements. For the SPRT and test chamber PRT, if the temperature measurement at this point differs by more than $10 \mathrm{mK}$ from that of the original calibration, the thermometer is recalibrated over its full range by the NIST Thermodynamic Metrology Group. The SPRT's bridge and resistance standard are also checked on a periodic basis. The laminar flow elements used for measuring the wet and dry flow in the divided flow system are also recalibrated periodically.

NIST is a self-accrediting body that conforms to ISO/IEC 17025 quality standards [29]. The NIST humidity calibration services undergo 17025 conformity assessments every two years by assessors within NIST but outside of the NIST Thermodynamic Metrology Group.

\section{Summary}

We have described here the design and performance of the NIST hybrid generator, which generates dew/frost points between $-90{ }^{\circ} \mathrm{C}$ and $85{ }^{\circ} \mathrm{C}$ (amount fractions between $0.1 \mu \mathrm{mol} / \mathrm{mol}$ and 0.57 $\mathrm{mol} / \mathrm{mol}$ ). This primary generator uses a novel design that incorporates both the two-pressure method and divided-flow method. Between $-70{ }^{\circ} \mathrm{C}$ and $85^{\circ} \mathrm{C}$, the dew/frost-point expanded uncertainty is always below $25 \mathrm{mK}$. As the frost point decreases from $-70{ }^{\circ} \mathrm{C}$ to $-90{ }^{\circ} \mathrm{C}$, the uncertainty increases from $25 \mathrm{mK}$ to $120 \mathrm{mK}$ due to the increasing influence of the uncertainty of $x_{\mathrm{p}}$, which we estimate to be $u\left(x_{\mathrm{p}}\right)=1 \mathrm{nmol} / \mathrm{mol}$. Over the low frost-point range, this uncertainty is considerably lower than the uncertainty of most 2-P generators. Comparison of the expected humidity generated by the HHG with that measured by the NIST gravimetric hygrometer shows agreement within the combined expanded uncertainties of the generator and hygrometer. Key comparisons of the humidity generated by the HHG with that of humidity generators of other major NMIs shows agreement within the expanded uncertainties of the generators and transfer standard. These comparisons provide a satisfactory validation of the performance of the HHG.

We have also described the design and performance of the NIST HHG test chamber. This chamber, when combined with the HHG, can calibrate thermohygrometers and dataloggers over the range $2 \%$ to $98 \%$ for temperatures between $-34{ }^{\circ} \mathrm{C}$ and $85{ }^{\circ} \mathrm{C}$. The expanded relative uncertainty of the relative humidity in this system is less than $0.3 \%$. 


\section{Acknowledgements}

The authors thank Dr. Joseph T. Hodges for conceiving the humidity generator described in this document, obtaining the funding to develop it, and performing preliminary calculations on its performance. The authors also thank Gregory E. Scace for his many contributions to the development of this generator, including the design of the HHG final saturator, test chamber, and the test chamber heat exchanger. 


\section{References}

[1] G.E. Scace et al., "An Overview of the NIST Hybrid Humidity Generator”, in Proceedings of the $5^{\text {th }}$ International Symposium on Humidity and Moisture (Rio de Janeiro, Brazil: INMETRO, 2007).

[2] C.W. Meyer et al, "Performance and Validation Tests on the NIST Hybrid Humidity Generator", in Proceedings of the 10th International Symposium on Temperature and Thermal Measurements in Industry and Science (TEMPMEKO 2007), Int. J. Thermophys. 29, 1606-1614 (2008).

[3] C.W. Meyer et al., "Uncertainty Budget for the NIST Hybrid Humidity Generator", in Proceedings of the 11th International Symposium on Temperature and Thermal Measurements in Industry and Science (TEMPMEKO 2010), Int. J. Thermophys. 33, 1488-1499 (2012).

[4] W. Wagner and A. Pruss, "International Equations for the Saturation Properties of Ordinary Water Substance--Revised According to the International Temperature Scale of 1990", J. Phys. Chem. Ref. Data 22, 783-787 (1993).

[5] R.W. Hyland and A. Wexler, "Formulations for the Thermodynamic Properties of Dry Air from 173.15 K to 473.15 K, and of Saturated Moist Air from 173.15 K to $372.15 \mathrm{~K}$, at Pressures to $5 \mathrm{MPa}$.", ASHRAE Trans. 89-IIa, 520-535 (1983).

[6] A. Wexler, "Humidity Standards", Tappi 44 (6), 180A -191A (1961).

[7] J. W. Lovell-Smith et al., "Metrological challenges for measurements of key climatological observables. Part 4: atmospheric relative humidity", Metrologia 53, R40R59, (2016).

[8] International Association for the Properties of Water and Steam, R14-08(2011), "Revised Release on the Pressure along the Melting and Sublimation Curves of Ordinary Water Substance" (2011), available at www.iapws.org.

[9] W. Wagner et al., "New Equations for the Melting Pressure and Sublimation Pressure of $\mathrm{H}_{2} \mathrm{O}$ Ice Ih", J. Phys. Chem. Ref. Data. 40, 043103 (2011).

[10] International Association for the Properties of Water and Steam, G5-01(2020), "Guideline on the Use of Fundamental Physical Constants and Basic Constants of Water" (2020), available at www.iapws.org.

[11] A. Picard et al., "Revised formula for the density of moist air (CIPM-2007)", Metrologia 45, 149 (2008).

[12] ASTM Standard E 1137/E 1137M - 08, "Standard Specification for Industrial Platinum Resistance Thermometers", Annual Book of ASTM Standards, vol. 14.03, ASTM International, Conshohocken, PA (2020). 
[13] BIPM, IEC, IFCC, ILAC, ISO, IUPAC, IUPAP and OIML, "Evaluation of measurement data--Guide to the expression of uncertainty in measurement", JCGM 100:2008, https://www.bipm.org/utils/common/documents/jcgm/JCGM_100_2008_E.pdf, (2008).

[14] B.N. Taylor and C.E. Kuyatt, "Guidelines for Evaluating and Expressing the Uncertainty of NIST Measurement Results”, NIST Technical Note 1297, National Institute of Standards and Technology, Gaithersburg (1994).

[15] C.D. Vaughn and G.F. Strouse, "The NIST Industrial Thermometer Calibration Laboratory", in Proceedings of TEMPMEKO 2001: the 8th International Symposium on Temperature and Thermal Measurements, B. Fellmuth, J. Seidel, G. Scholz, eds., VDE Verlag GMBH, Berlin (2002), 629-634.

[16] W. Wagner and A. Pruss, "The IAPWS Formulation 1995 for the Thermodynamic Properties of Ordinary Water Substance for General and Scientific Use", J. Phys. Chem. Ref. Data 31, 387 (2002).

[17] R.W. Hyland, "A Correlation for the Second Interaction Virial Coefficients and Enhancement Factors for Moist Air”, J. Res. NBS 79A, 551-560 (1975).

[18] C.W. Meyer et al., "Automated Continuous-Flow Gravimetric Hygrometer as a Primary Humidity Standard", in Proceedings of the $5^{\text {th }}$ International Symposium on Humidity and Moisture, (Rio de Janeiro, Brazil: INMETRO, 2007).

[19] C.W. Meyer, et al., "The Second-generation NIST Standard Hygrometer", Metrologia 47 $192(2010)$.

[20] CIPM MRA Documents, https://www.bipm.org/en/cipm-mra/cipm-mra-documents.

[21] S. Bell et al., CCT-K6 Final Report, NPL REPORT ENG 57, Metrologia 52, Tech. Suppl., 03005 (2015).

[22] G.E. Scace and J.T. Hodges, "Uncertainty of the NIST Low Frost-point Humidity Generator", in Proceedings of TEMPMEKO 2001: the 8th International Symposium on Temperature and Thermal Measurements, B. Fellmuth, J. Seidel, G. Scholz, eds., VDE Verlag GMBH, Berlin (2002), 597-602.

[23] C.W. Meyer and H. Abe, CCT-K6.2 Final Report, Metrologia 57 Tech. Suppl. 03007 (2020).

[24] CCT-K8 Technical Protocol, https://www.bipm.org/kcdb/comparison?id=1073.

[25] C.W. Meyer and K.D. Hill, SIM.T-K6.1 Final Report, Metrologia 52 Tech. Suppl., 03008 (2015). 
[26] P.H. Huang et al., SIM.T-K6.2 Final Report, Metrologia 51 Tech. Suppl., 03002 (2014)

[27] P. Huang, C. Meyer, and J.D. Brionizio, SIM.T-K6.3 Final Report, Metrologia 52 Tech. Suppl., 03001 (2015)

[28] C. W. Meyer, and A. Solano, SIM.T-K6.5 Final Report, Metrologia 53 Tech. Suppl., 03005 (2016)

[29] ISO/IEC, General Requirements for the Competence of Testing and Calibration Laboratories, ISO/IEC 17025:2017 (2017).

[30] J.W. Lovell-Smith, "On Correlation in the Water Vapour Pressure Formulation", Metrologia 43, 556 (2006). 


\section{Appendix I. Derivation of the Uncertainty Equations for the Hybrid Generator}

The total uncertainty of a quantity $z$ is related to the $n$ individual uncertainty components $y_{i}$ through the general law of error propagation [12]:

$$
u(z)^{2}=\sum_{i=1}^{n}\left(\frac{\partial z}{\partial y_{i}}\right) u\left(y_{i}\right)^{2}+2 \sum_{i=1}^{n-1} \sum_{j=i+1}^{n} r_{i, j} \frac{\partial z}{\partial y_{i}} \frac{\partial z}{\partial y_{j}} u\left(y_{i}\right) u\left(y_{j}\right)
$$

The relevant quantities and the derivatives $\partial z / \partial y_{i}$ may be found by expanding the differential $d z$ :

$$
d z=\sum_{i=1}^{n} \frac{\partial z}{\partial y_{i}} d y_{i}
$$

Below, the total uncertainty for humidity generated by the hybrid generator will be derived for four cases: 1) water amount fraction when the generator is used in 2-P mode or 1-P mode, 2) dew-point temperature when the generator is used in 2-P mode or 1-P mode, 3) water amount fraction when the generator is used in divided-flow mode, and 4) frost-point temperature when the generator is used in divided-flow mode.

\section{Water Amount Fraction When the Generator is Used in 2-P Mode or 1-P Mode}

The total uncertainty for this case is obtained by applying Eq. A2 to Eq. 1, which yields

$$
d x=\frac{f_{\mathrm{s}}}{P_{\mathrm{s}}} d e_{\mathrm{s}}+\frac{e_{\mathrm{s}}}{P_{\mathrm{s}}} d f_{\mathrm{s}}-\frac{e_{\mathrm{s}} f_{\mathrm{s}}}{P_{\mathrm{s}}^{2}} d P_{\mathrm{s}} .
$$

where $f_{\mathrm{s}} \equiv f\left(T_{\mathrm{s}}, P_{\mathrm{s}}\right)$ and $e_{\mathrm{s}} \equiv e\left(T_{\mathrm{s}}, P_{\mathrm{s}}\right)$. In $d e_{\mathrm{s}}$, we can separate out the differential relating to the uncertainty of its calculating equation $d e_{\mathrm{s}}^{\text {calc }}$ from that relating to the uncertainty of the temperature from which it is calculated:

$$
d e_{\mathrm{s}}=d e_{\mathrm{s}}^{\text {calc }}+\frac{d e_{\mathrm{s}}}{d T_{\mathrm{s}}} d T_{\mathrm{s}}
$$

Similarly, in $d f_{\mathrm{s}}$, we can separate out to the differential relating to the uncertainty of its calculating equation $d f_{s}^{\text {calc }}$ from that relating to the uncertainty of the temperature and pressure from which it is calculated:

$$
d f_{\mathrm{s}}=d f_{\mathrm{s}}^{\text {calc }}+\frac{d f_{\mathrm{s}}}{d T_{\mathrm{s}}} d T_{\mathrm{s}}+\frac{d f_{\mathrm{s}}}{d P_{\mathrm{s}}} d P_{\mathrm{s}}
$$

However, because $d f_{\mathrm{s}} / d T_{\mathrm{s}}$ and $d f_{\mathrm{s}} / d P_{\mathrm{s}}$ are very small, Eq. A5 may be approximated as $d f_{s} \approx d f_{s}^{\text {calc }}$. Using this approximation while combining Eqs. A3-A4 gives 


$$
d x=\frac{f_{\mathrm{s}}}{P_{\mathrm{s}}} \frac{d e_{\mathrm{s}}}{d T_{\mathrm{s}}} d T_{\mathrm{s}}-\frac{e_{\mathrm{s}} f_{\mathrm{s}}}{P_{\mathrm{s}}^{2}} d P_{\mathrm{s}}+\frac{f_{\mathrm{s}}}{P_{\mathrm{s}}} d e_{\mathrm{s}}^{\mathrm{calc}}+\frac{e_{\mathrm{s}}}{P_{\mathrm{s}}} d f_{\mathrm{s}}^{\mathrm{calc}}
$$

The uncertainty in the amount fraction may then be expressed as

$$
u(x)^{2}=\left(\frac{f_{\mathrm{s}}}{P_{\mathrm{s}}} \frac{d e_{\mathrm{s}}}{d T_{\mathrm{s}}}\right)^{2} u\left(T_{\mathrm{s}}\right)^{2}+\left(\frac{e_{\mathrm{s}} f_{\mathrm{s}}}{P_{\mathrm{s}}^{2}}\right)^{2} u\left(P_{\mathrm{s}}\right)^{2}+\left(\frac{f_{\mathrm{s}}}{P_{\mathrm{s}}}\right)^{2} u\left(e_{\mathrm{s}}^{\text {calc }}\right)^{2}+\left(\frac{e_{\mathrm{s}}}{P_{\mathrm{s}}}\right)^{2} u\left(f_{\mathrm{s}}^{\mathrm{calc}}\right)^{2},
$$

and the relative uncertainty $u_{\mathrm{r}}(x)$ is then given by

$$
u_{\mathrm{r}}(x)^{2}=\left[\frac{u(x)}{x}\right]^{2}=\left(\frac{1}{e_{\mathrm{s}}} \frac{d e_{\mathrm{s}}}{d T_{\mathrm{s}}}\right)^{2} u\left(T_{\mathrm{s}}\right)^{2}+\frac{u\left(P_{\mathrm{s}}\right)^{2}}{P_{\mathrm{s}}^{2}}+\frac{u\left(e_{\mathrm{s}}^{\mathrm{calc}}\right)^{2}}{e_{\mathrm{s}}}+\frac{u\left(f_{\mathrm{s}}^{\text {calc }}\right)^{2}}{f_{\mathrm{s}}}
$$

\section{Dew-point Temperature When the Generator is Used in 2-P Mode or 1-P Mode}

Here we consider the total uncertainty for the dew-point temperature $T_{\mathrm{DP}}$ in a chamber with temperature $T_{\mathrm{c}}=T_{\mathrm{DP}}$, pressure $P_{\mathrm{c}}$, and water vapor pressure $e_{\mathrm{c}}$. This uncertainty may be determined by inverting Eq. A4 to solve for $d T_{\mathrm{s}}$ and then substituting the saturator parameters with the chamber parameters ( $T_{\mathrm{s}}$ with $T_{\mathrm{DP}}, e_{\mathrm{s}}$ with $e_{\mathrm{c}}$, and $e_{\mathrm{s}}^{\text {calc }}$ with $\left.e_{\mathrm{c}}^{\text {calc }}\right)$ :

$$
d T_{\mathrm{DP}}=d T_{\mathrm{c}}=\frac{1}{\left[d e_{\mathrm{c}} / d T_{\mathrm{DP}}\right]}\left(d e_{\mathrm{c}}-d e_{\mathrm{c}}^{\mathrm{calc}}\right) .
$$

Letting $f_{\mathrm{c}} \equiv f\left(T_{\mathrm{c}}, P_{\mathrm{c}}\right)$, we can express $e_{\mathrm{c}}$ in terms of $x$ and $P_{\mathrm{c}}$ :

$$
e_{\mathrm{c}}=\frac{x P_{\mathrm{c}}}{f_{\mathrm{c}}} .
$$

Differentiating Eq. A10 and inserting the resulting expression for de in Eq. A9 gives

$$
d T_{\mathrm{DP}}=\frac{1}{\left[d e_{\mathrm{c}} / d T_{\mathrm{DP}}\right]}\left[\frac{P_{\mathrm{c}}}{f_{\mathrm{c}}} d x+\frac{x}{f_{\mathrm{c}}} d P_{\mathrm{c}}-\frac{x P_{\mathrm{c}}}{f_{\mathrm{c}}^{2}} d f_{\mathrm{c}}-d e_{\mathrm{c}}^{\mathrm{calc}}\right] .
$$

Using the approximation $d f_{\mathrm{c}} \cong d f_{\mathrm{c}}^{\mathrm{calc}}$ in Eq. A11 and combining it with Eqs. 1 and $\mathrm{A} 6$ and yields

$$
\begin{aligned}
d T_{\mathrm{DP}}=\frac{1}{\left[d e_{\mathrm{c}} / d T_{\mathrm{c}}\right]}[ & \frac{P_{\mathrm{c}} f_{\mathrm{s}}}{P_{\mathrm{s}} f_{\mathrm{c}}} \frac{d e_{\mathrm{s}}}{d T_{\mathrm{s}}} d T_{\mathrm{s}}-\frac{P_{\mathrm{c}} e_{\mathrm{s}} f_{\mathrm{s}}}{P_{\mathrm{s}}^{2} f_{\mathrm{c}}} d P_{\mathrm{s}}+\left(\frac{P_{\mathrm{c}} f_{\mathrm{s}}}{P_{\mathrm{s}} f_{\mathrm{c}}} d e_{\mathrm{s}}^{\mathrm{calc}}-d e_{\mathrm{c}}^{\mathrm{calc}}\right) \\
& \left.+e_{\mathrm{c}}\left(\frac{e_{\mathrm{s}} P_{\mathrm{c}}}{P_{\mathrm{s}} f_{\mathrm{c}}} d f_{\mathrm{s}}^{\text {calc }}-\frac{d f_{\mathrm{c}}^{\mathrm{calc}}}{f_{\mathrm{c}}}\right)+\frac{e_{\mathrm{c}}}{P_{\mathrm{c}}} d P_{\mathrm{c}}\right]
\end{aligned}
$$


Recognizing that $x$ is the same in both the saturator and chamber, $e_{\mathrm{s}} f_{\mathrm{s}} / P_{\mathrm{s}}=e_{\mathrm{c}} f_{\mathrm{c}} / P_{\mathrm{c}}$, and so A12 may be written

$$
\begin{aligned}
& d T_{\mathrm{DP}}=\frac{e_{\mathrm{c}}}{\left[d e_{\mathrm{c}} / d T_{\mathrm{DP}}\right]} {\left[\frac{1}{e_{\mathrm{s}}} \frac{d e_{\mathrm{s}}}{d T_{\mathrm{s}}} d T_{\mathrm{s}}-\frac{d P_{\mathrm{s}}}{P_{\mathrm{s}}}+\left(\frac{d e_{\mathrm{s}}^{\text {calc }}}{e_{\mathrm{s}}}-\frac{d e_{\mathrm{c}}^{\text {calc }}}{e_{\mathrm{c}}}\right)\right.} \\
&\left.+\left(\frac{d f_{\mathrm{s}}^{\text {calc }}}{f_{\mathrm{s}}}-\frac{d f_{\mathrm{c}}^{\text {calc }}}{f_{\mathrm{c}}}\right)+\frac{d P_{\mathrm{c}}}{P_{\mathrm{c}}}\right]
\end{aligned}
$$

This equation can be simplified by defining the differentials

$$
\begin{aligned}
& d \Delta e^{\mathrm{calc}} \equiv \frac{d e_{\mathrm{s}}^{\mathrm{calc}}}{e_{\mathrm{s}}}-\frac{d e_{\mathrm{c}}^{\mathrm{calc}}}{e_{\mathrm{c}}} \quad \text { and } \\
& d \Delta f^{\mathrm{calc}} \equiv \frac{d f_{\mathrm{s}}^{\mathrm{calc}}}{f_{\mathrm{s}}}-\frac{d f_{\mathrm{c}}^{\mathrm{calc}}}{f_{\mathrm{c}}} .
\end{aligned}
$$

Then Eq. A13 becomes

$$
d T_{\mathrm{DP}}=\frac{e_{\mathrm{c}}}{\left[d e_{\mathrm{c}} / d T_{\mathrm{DP}}\right]}\left[\frac{1}{e_{\mathrm{s}}} \frac{d e_{\mathrm{s}}}{d T_{\mathrm{s}}} d T_{\mathrm{s}}-\frac{d P_{\mathrm{s}}}{P_{\mathrm{s}}}+d \Delta e^{\mathrm{calc}}+d \Delta f^{\mathrm{calc}}+\frac{d P_{\mathrm{c}}}{P_{\mathrm{c}}}\right]
$$

And the uncertainty of the dew-point temperature is

$$
u\left(T_{\mathrm{DP}}\right)^{2}=\left(\frac{e_{\mathrm{c}}}{\left[d e_{\mathrm{c}} / d T_{\mathrm{DP}}\right]}\right)^{2}\left[\left(\frac{1}{e_{\mathrm{s}}} \frac{d e_{\mathrm{s}}}{d T_{\mathrm{s}}}\right)^{2} u\left(T_{\mathrm{s}}\right)^{2}+\frac{u\left(P_{\mathrm{s}}\right)^{2}}{P_{\mathrm{s}}^{2}}+\frac{u\left(P_{\mathrm{c}}\right)^{2}}{P_{\mathrm{c}}^{2}}+u_{\mathrm{r}}\left(\Delta e^{\mathrm{calc}}\right)^{2}+u_{\mathrm{r}}\left(\Delta f^{\mathrm{calc}}\right)^{2}\right]
$$

The relative uncertainties $u_{\mathrm{r}}\left(\Delta f^{\text {calc }}\right)$ and $u_{\mathrm{r}}\left(\Delta e^{\text {calc }}\right)$ have not been resolved by the humidity community, and it is currently an area of active work [30]. Because of this, we use in this document the conventional analysis [30]. When the generator is used in 1-P mode $\left(P_{\mathrm{s}} \cong P_{\mathrm{c}}\right)$, this method assumes that $e_{\mathrm{c}} \cong e_{\mathrm{s}}$ and $f_{\mathrm{c}} \cong f_{\mathrm{s}}$, and therefore

$$
u_{\mathrm{r}}\left(\Delta e^{\text {calc }}\right)=u_{\mathrm{r}}\left(\Delta f^{\text {calc }}\right)=0
$$

For the 2-P mode $\left(P_{\mathrm{s}} \neq P_{\mathrm{c}}\right)$, the method assumes that there are no correlations between $u\left(e_{\mathrm{s}}^{\text {calc }}\right)$ and $u\left(e_{\mathrm{c}}^{\text {calc }}\right)$ and between $u\left(f_{\mathrm{s}}^{\text {calc }}\right)$ and $u\left(f_{\mathrm{c}}^{\text {calc }}\right)$; therefore

$$
u_{\mathrm{r}}\left(\Delta e^{\mathrm{calc}}\right)^{2} \equiv \frac{u\left(e_{\mathrm{s}}^{\mathrm{calc}}\right)^{2}}{e_{\mathrm{s}}^{2}}+\frac{u\left(e_{\mathrm{c}}^{\mathrm{calc}}\right)^{2}}{e_{\mathrm{c}}^{2}} \text { and }
$$




$$
u_{\mathrm{r}}\left(\Delta f^{\mathrm{calc}}\right)^{2} \equiv \frac{u\left(f_{\mathrm{s}}^{\mathrm{calc}}\right)^{2}}{f_{\mathrm{s}}^{2}}+\frac{u\left(f_{\mathrm{c}}^{\mathrm{calc}}\right)^{2}}{f_{\mathrm{c}}^{2}}
$$

\section{Relative Humidity When the Generator is Used in 2-P Mode or 1-P Mode}

Here we consider the total uncertainty for the relative humidity $R H$ in a chamber with temperature $T_{\mathrm{c}}$, pressure $P_{\mathrm{c}}$ when the generator is used in 2-P or 1-P mode. By the WMO definition, the relative humidity is defined as

$$
R H \equiv \frac{x}{x_{\mathrm{c}}}=\frac{e_{\mathrm{p}}}{e_{\mathrm{c}} f_{\mathrm{c}}}
$$

where $x_{\mathrm{c}}$ is the water amount fraction in the chamber at saturation and the partial water vapor pressure $e_{\mathrm{p}}$ in the chamber is given by

$$
e_{\mathrm{p}}=x P_{\mathrm{c}}
$$

and $e_{\mathrm{c}}$ is the saturated water vapor pressure at temperature $T_{\mathrm{c}}$. Note that $e_{\mathrm{c}}$ is a function of $T_{\mathrm{c}}$, while $e_{\mathrm{p}}$ is an independent variable. Placing Eq. A22 into Eq. A21,

$$
R H \equiv \frac{x P_{\mathrm{c}}}{e_{\mathrm{c}} f_{\mathrm{c}}}=\frac{e_{\mathrm{s}} f_{\mathrm{s}} P_{\mathrm{c}}}{e_{\mathrm{c}} f_{\mathrm{c}} P_{\mathrm{s}}}
$$

The total uncertainty for this case is obtained by applying Eq. A2 to Eq. A22, which yields

$$
d(R H)=\frac{f_{\mathrm{s}} P_{\mathrm{c}}}{e_{\mathrm{c}} f_{\mathrm{c}} P_{\mathrm{s}}} d e_{\mathrm{s}}+\frac{e_{\mathrm{s}} P_{\mathrm{c}}}{e_{\mathrm{c}} f_{\mathrm{c}} P_{\mathrm{s}}} d f_{\mathrm{s}}+\frac{e_{\mathrm{s}} f_{\mathrm{s}}}{e_{\mathrm{c}} f_{\mathrm{c}} P_{\mathrm{s}}} d P_{\mathrm{c}}-\frac{e_{\mathrm{s}} f_{\mathrm{s}} P_{\mathrm{c}}}{e_{\mathrm{c}} f_{\mathrm{c}}^{2} P_{\mathrm{s}}} d f_{\mathrm{c}}-\frac{e_{\mathrm{s}} f_{\mathrm{s}} P_{\mathrm{c}}}{e_{\mathrm{c}} f_{\mathrm{c}} P_{\mathrm{s}}^{2}} d P_{\mathrm{s}}-\frac{e_{\mathrm{s}} f_{\mathrm{s}} P_{\mathrm{c}}}{e_{\mathrm{c}}{ }^{2} f_{\mathrm{c}} P_{\mathrm{s}}} d e_{\mathrm{c}} .
$$

Recognizing that

$$
d e=d e^{\mathrm{calc}}+\frac{d e}{d T} d T
$$

A24 becomes

$$
\begin{aligned}
d(R H)= & \frac{P_{\mathrm{c}} f_{\mathrm{s}}}{P_{\mathrm{s}} e_{\mathrm{c}} f_{\mathrm{c}}}\left[d e_{\mathrm{s}}^{\mathrm{calc}}+\frac{d e_{\mathrm{s}}}{d T_{\mathrm{s}}} d T_{\mathrm{s}}\right]+\frac{e_{\mathrm{s}} P_{\mathrm{c}}}{P_{\mathrm{s}} e_{\mathrm{c}} f_{\mathrm{c}}} d f_{\mathrm{s}}+\frac{e_{\mathrm{s}} f_{\mathrm{s}}}{P_{\mathrm{s}} e_{\mathrm{c}} f_{\mathrm{c}}} d P_{\mathrm{c}} \\
& -\frac{e_{\mathrm{s}} P_{\mathrm{c}} f_{\mathrm{s}}}{e_{\mathrm{c}} P_{\mathrm{s}} f_{\mathrm{c}}^{2}} d f_{\mathrm{c}}-\frac{e_{\mathrm{s}} P_{\mathrm{c}} f_{\mathrm{s}}}{e_{\mathrm{c}} P_{\mathrm{s}}^{2} f_{\mathrm{c}}} d P_{\mathrm{s}}-\frac{e_{\mathrm{s}} P_{\mathrm{c}} f_{\mathrm{s}}}{e_{\mathrm{c}}^{2} P_{\mathrm{s}} f_{\mathrm{c}}}\left[d e_{\mathrm{c}}^{\mathrm{calc}}+\frac{d e_{\mathrm{c}}}{d T_{\mathrm{c}}} d T_{\mathrm{c}}\right]
\end{aligned}
$$


Inserting Eqs. A14 and A15 yields:

$$
\begin{aligned}
d(R H)= & \frac{P_{\mathrm{c}} f_{\mathrm{s}}}{P_{\mathrm{s}} e_{\mathrm{c}} f_{\mathrm{c}}} \frac{d e_{\mathrm{s}}}{d T_{\mathrm{s}}} d T_{\mathrm{s}}+\frac{e_{\mathrm{s}} f_{\mathrm{s}}}{P_{\mathrm{s}} f_{\mathrm{c}} f_{\mathrm{c}}} d P_{\mathrm{c}}-\frac{e_{\mathrm{s}} f_{\mathrm{s}} P_{\mathrm{c}}}{e_{\mathrm{c}} f_{\mathrm{c}} P_{\mathrm{s}}^{2}} d P_{\mathrm{s}}-\frac{e_{\mathrm{s}} f_{\mathrm{s}} P_{\mathrm{c}}}{e_{\mathrm{c}}^{2} f_{\mathrm{c}} P_{\mathrm{s}}} \frac{d e_{\mathrm{c}}}{d T_{\mathrm{c}}} d T_{\mathrm{c}} \\
& +\frac{e_{\mathrm{s}} f_{\mathrm{s}} P_{\mathrm{c}}}{e_{\mathrm{c}} f_{\mathrm{c}} P_{\mathrm{s}}} \frac{d e_{\mathrm{c}}}{d T_{\mathrm{c}}} d \Delta e^{\text {calc }}+\frac{e_{\mathrm{s}} f_{\mathrm{s}} P_{\mathrm{c}}}{e_{\mathrm{c}} f_{\mathrm{c}} P_{\mathrm{s}}} d \Delta f \\
= & \frac{P_{\mathrm{c}} e_{\mathrm{s}} f_{\mathrm{s}}}{P_{\mathrm{s}} e_{\mathrm{c}} f_{\mathrm{c}}}\left[\frac{1}{e_{\mathrm{s}}} \frac{d e_{\mathrm{s}}}{d T_{\mathrm{s}}} d T_{\mathrm{s}}+\frac{d P_{\mathrm{c}}}{P_{\mathrm{c}}}-\frac{d P_{\mathrm{s}}}{P_{\mathrm{s}}}-\frac{1}{e_{\mathrm{c}}} \frac{d e_{\mathrm{c}}}{d T_{\mathrm{c}}} d T_{\mathrm{c}}+d \Delta e^{\text {calc }}+d \Delta f\right]
\end{aligned}
$$

Noting Eq. A23, the standard relative uncertainty for the relative humidity is then

$$
\begin{aligned}
u_{r}(R H)^{2}=\left[\frac{u(R H)}{R H}\right]^{2}= & {\left[\left(\frac{1}{e_{\mathrm{s}}} \frac{d e_{\mathrm{s}}}{d T_{\mathrm{s}}}\right)^{2} u\left(T_{\mathrm{s}}\right)^{2}+\frac{1}{P_{\mathrm{s}}^{2}} u\left(P_{\mathrm{s}}\right)^{2}+\left(\frac{1}{e_{\mathrm{c}}} \frac{d e_{\mathrm{c}}}{d T_{\mathrm{c}}}\right)^{2} u\left(T_{\mathrm{c}}\right)^{2}+\frac{1}{P_{\mathrm{c}}^{2}} u\left(P_{\mathrm{c}}\right)^{2}\right.} \\
& \left.+u_{\mathrm{r}}\left(\Delta e^{\text {calc }}\right)+u_{\mathrm{r}}\left(\Delta f^{\text {calc }}\right)\right]
\end{aligned}
$$

Once again, the values of $u_{\mathrm{r}}\left(\Delta e^{\text {calc }}\right)$ and $u_{\mathrm{r}}\left(\Delta f^{\text {calc }}\right)$ are best estimated by Eq. A16 when the generator is used in 1-P mode and by Eq. A17 and Eq. A18 when the generator is used in 2-P mode.

\section{Water Amount Fraction When the Generator is Used in Divided-flow Mode}

For the generator used with the divided-flow method, the differential for the amount fraction may be expanded as

$$
d x=\frac{\dot{n}_{\mathrm{s}} d x_{\mathrm{s}}+\dot{n}_{\mathrm{p}} d x_{\mathrm{p}}}{\dot{N}}+\frac{\dot{n}_{\mathrm{p}}\left(x_{\mathrm{s}}-x_{\mathrm{p}}\right)}{\dot{N}^{2}} d \dot{n}_{\mathrm{s}}-\frac{\dot{n}_{\mathrm{s}}\left(x_{\mathrm{s}}-x_{\mathrm{p}}\right)}{\dot{N}^{2}} d \dot{n}_{\mathrm{p}}
$$

Since $x_{\mathrm{p}} \ll x_{\mathrm{s}}$, this reduces to

$$
d x \cong \frac{\dot{n}_{\mathrm{s}}}{\dot{N}} d x_{\mathrm{s}}+\frac{\dot{n}_{\mathrm{p}}}{\dot{N}} d x_{\mathrm{p}}+\frac{\dot{n}_{\mathrm{p}} x_{\mathrm{s}}}{\dot{N}^{2}} d \dot{n}_{\mathrm{s}}-\frac{\dot{n}_{\mathrm{s}} x_{\mathrm{s}}}{\dot{N}^{2}} d \dot{n}_{\mathrm{p}}
$$

Using the result of Eq. A6 as $d x_{\mathrm{s}}$, and noting $x_{\mathrm{s}}=e_{\mathrm{s}} f_{\mathrm{s}} / P_{\mathrm{s}}$, this becomes

$$
d x \cong \frac{\dot{n}_{\mathrm{s}} f_{\mathrm{s}}}{\dot{N} P_{\mathrm{s}}} \frac{d e_{\mathrm{s}}}{d T_{\mathrm{s}}} d T_{\mathrm{s}}-\frac{\dot{n}_{\mathrm{s}} e_{\mathrm{s}} f_{\mathrm{s}}}{\dot{N} P_{\mathrm{s}}^{2}} d P_{\mathrm{s}}+\frac{\dot{n}_{\mathrm{s}} f_{\mathrm{s}}}{\dot{N} P_{\mathrm{s}}} d e_{\mathrm{s}}^{\text {calc }}+\frac{\dot{n}_{\mathrm{s}} e_{\mathrm{s}}}{\dot{N} P_{\mathrm{s}}} d f_{\mathrm{s}}^{\text {calc }}+\frac{\dot{n}_{\mathrm{p}}}{\dot{N}} d x_{\mathrm{p}}+\frac{\dot{n}_{\mathrm{p}} e_{\mathrm{s}} f_{\mathrm{s}}}{\dot{N}^{2} P_{\mathrm{s}}} d \dot{n}_{\mathrm{s}}-\frac{\dot{n}_{\mathrm{s}} e_{\mathrm{s}} f_{\mathrm{s}}}{\dot{N}^{2} P_{\mathrm{s}}} d \dot{n}_{\mathrm{p}}
$$

Noting that $x \cong \dot{n}_{\mathrm{s}} e_{\mathrm{s}} f_{\mathrm{s}} / \dot{N} P_{\mathrm{s}}$ and $x_{\mathrm{s}}=e_{\mathrm{s}} f_{\mathrm{s}} / P_{\mathrm{s}}$, the amount fraction standard relative uncertainty $u_{\mathrm{r}}(x)$ is then given by 


$$
\begin{aligned}
u_{\mathrm{r}}(x)^{2}=\left[\frac{u(x)}{x}\right]^{2} \cong & \cong\left(\frac{1}{e_{\mathrm{s}}} \frac{d e_{\mathrm{s}}}{d T_{\mathrm{s}}}\right)^{2} u\left(T_{\mathrm{s}}\right)^{2}+\frac{u\left(P_{\mathrm{s}}\right)^{2}}{P_{\mathrm{s}}^{2}}+\frac{u\left(e_{\mathrm{s}}^{\mathrm{calc}}\right)^{2}}{e_{\mathrm{s}}^{2}}+\frac{u\left(f_{\mathrm{s}}^{\text {calc }}\right)^{2}}{f_{\mathrm{s}}} \\
& +\frac{u\left(\dot{n}_{\mathrm{p}}\right)^{2}}{\dot{N}^{2}}+\left(\frac{x_{\mathrm{s}}}{x}-1\right)^{2}\left(\frac{u\left(x_{\mathrm{p}}\right)^{2}}{x_{\mathrm{s}}^{2}}+\frac{u\left(\dot{n}_{\mathrm{s}}\right)^{2}}{\dot{N}^{2}}\right)
\end{aligned}
$$

\section{Frost-point Temperature When the Generator is Used in Divided-flow Mode}

In the hybrid generator, the divided-flow method will only be used for generating frost points. We expand the frost-point temperature differential by combining Eqs. A11 and A31, which yields

$$
\begin{aligned}
& d T_{\mathrm{FP}}=\frac{P_{\mathrm{c}}}{\left[d e_{\mathrm{c}} / d T_{\mathrm{c}}\right] f_{\mathrm{c}}} {\left[\frac{\dot{n}_{\mathrm{s}} f_{\mathrm{s}}}{\dot{N} P_{\mathrm{s}}} \frac{d e_{\mathrm{s}}}{d T_{\mathrm{s}}} d T_{\mathrm{s}}-\frac{\dot{n}_{\mathrm{s}} e_{\mathrm{s}} f_{\mathrm{s}}}{\dot{N} P_{\mathrm{s}}^{2}} d P_{\mathrm{s}}+\frac{\dot{n}_{\mathrm{s}} f_{\mathrm{s}}}{\dot{N} P_{\mathrm{s}}} d e_{\mathrm{s}}^{\text {calc }}+\frac{\dot{n}_{\mathrm{s}} e_{\mathrm{s}}}{\dot{N} P_{\mathrm{s}}} d f_{\mathrm{s}}^{\text {calc }}\right.} \\
&\left.+\frac{\dot{n}_{\mathrm{p}}}{\dot{N}} d x_{\mathrm{p}}+\frac{\dot{n}_{\mathrm{p}} e_{\mathrm{s}} f_{\mathrm{s}}}{\dot{N}^{2} P_{\mathrm{s}}} d \dot{n}_{\mathrm{s}}+\frac{\dot{n}_{\mathrm{s}} e_{\mathrm{s}} f_{\mathrm{s}}}{\dot{N}^{2} P_{\mathrm{s}}} d \dot{n}_{\mathrm{p}}+\frac{x}{P_{\mathrm{c}}} d P_{\mathrm{c}}-\frac{x}{f_{\mathrm{c}}} d f_{\mathrm{c}}^{\text {calc }}-\frac{f_{\mathrm{c}}}{P_{\mathrm{c}}} d e_{\mathrm{c}}^{\text {calc }}\right]
\end{aligned}
$$

Here $e_{\mathrm{c}}$ is the saturated vapor pressure for ice. Because of this, we assume no correlation between the uncertainties of $e_{\mathrm{c}}^{\text {calc }}$ and $e_{\mathrm{s}}^{\text {calc }}$, since $e_{\mathrm{s}}^{\text {calc }}$ is the calculation of the saturated vapor pressure for water and is different for that of ice. Using the definitions for $d \Delta e^{\text {calc }}$ and $d \Delta f^{\text {calc }}$ in Eqs. A14-A15, and noting that $x=\dot{n}_{\mathrm{s}} e_{\mathrm{s}} f_{\mathrm{s}} / \dot{N} P_{\mathrm{s}}=e_{\mathrm{c}} f_{\mathrm{c}} / P_{\mathrm{c}}$ and $x_{\mathrm{s}}=e_{\mathrm{s}} f_{\mathrm{s}} / P_{\mathrm{s}}$, Eq. A33 becomes

$$
\begin{aligned}
d T_{\mathrm{FP}}=\frac{e_{\mathrm{c}}}{\left[d e_{\mathrm{c}} / d T_{\mathrm{c}}\right]} & {\left[\frac{1}{e_{\mathrm{s}}} \frac{d e_{\mathrm{s}}}{d T_{\mathrm{s}}} d T_{\mathrm{s}}-\frac{d P_{\mathrm{s}}}{P_{\mathrm{s}}}+\frac{d P_{\mathrm{c}}}{P_{\mathrm{c}}}+d \Delta e^{\text {calc }}+d \Delta f^{\text {calc }}\right.} \\
& \left.+\left(\frac{x_{\mathrm{s}}}{x}-1\right)\left(\frac{d x_{\mathrm{p}}}{x_{\mathrm{s}}}+\frac{d \dot{n}_{\mathrm{s}}}{\dot{N}}\right)+\frac{d \dot{n}_{\mathrm{p}}}{\dot{N}}\right]
\end{aligned}
$$

The frost-point temperature uncertainty then becomes

$$
\begin{aligned}
& u\left(T_{\mathrm{FP}}\right)^{2}=\frac{e_{\mathrm{c}}}{\left[d e_{\mathrm{c}} / d T_{\mathrm{c}}\right]^{2}} {\left[\left(\frac{1}{e_{\mathrm{s}}} \frac{d e_{\mathrm{s}}}{d T_{\mathrm{s}}}\right)^{2} u\left(T_{\mathrm{s}}\right)^{2}+\frac{u\left(P_{\mathrm{s}}\right)^{2}}{P_{\mathrm{s}}^{2}}+\frac{u\left(P_{\mathrm{c}}\right)^{2}}{P_{\mathrm{c}}^{2}}+u_{\mathrm{r}}\left(\Delta e^{\text {calc }}\right)^{2}+u_{\mathrm{r}}\left(\Delta f^{\text {calc }}\right)^{2}\right.} \\
&\left.+\left(\frac{x_{\mathrm{s}}}{x}-1\right)^{2}\left(\frac{u\left(x_{\mathrm{p}}\right)^{2}}{x_{\mathrm{s}}^{2}}+\frac{u\left(\dot{n}_{\mathrm{s}}\right)^{2}}{\dot{N}^{2}}\right)+\frac{u\left(\dot{n}_{\mathrm{p}}\right)^{2}}{\dot{N}^{2}}\right]
\end{aligned}
$$


Here, we once again use the conventional method for estimating $u_{\mathrm{r}}\left(\Delta e^{\text {calc }}\right)^{2}$ and $u_{\mathrm{r}}\left(\Delta f^{\text {calc }}\right)^{2}$, which employs Eq. A19-A20.

\section{Relative Humidity When the Generator is Used in Divided-flow Mode}

Here we consider the total uncertainty for the relative humidity $R H$ in a chamber with temperature $T_{\mathrm{c}}$ and pressure $P_{\mathrm{c}}$ when the generator is used in divided-flow mode. From Eqs. A21-A23, the relative humidity is

$$
R H \equiv \frac{x P_{\mathrm{c}}}{e_{\mathrm{c}} f_{\mathrm{c}}}
$$

and so

$$
d(R H)=\frac{P_{\mathrm{c}}}{e_{\mathrm{c}} f_{\mathrm{c}}} d x+\frac{x}{e_{\mathrm{c}} f_{\mathrm{c}}} d P_{\mathrm{c}}-\frac{x P_{\mathrm{c}}}{e_{\mathrm{c}}^{2} f_{\mathrm{c}}} d e_{\mathrm{c}}-\frac{x P_{\mathrm{c}}}{e_{\mathrm{c}} f_{\mathrm{c}}^{2}} d f_{\mathrm{c}}
$$

Inserting Eq. 6, Eq. A25, and Eq. A31 and into Eq. A37 yields:

$$
\begin{aligned}
d(R H)= & \frac{x P_{\mathrm{c}}}{e_{\mathrm{c}} f_{\mathrm{c}}}\left[\frac{1}{e_{\mathrm{s}}} \frac{d e_{\mathrm{s}}}{d T_{\mathrm{s}}} d T_{\mathrm{s}}-\frac{d P_{\mathrm{s}}}{P_{\mathrm{s}}}+\frac{d e_{\mathrm{s}}^{\text {calc }}}{e_{\mathrm{s}}}+\frac{d f_{\mathrm{s}}^{\text {calc }}}{f_{\mathrm{s}}}+\left(\frac{x_{\mathrm{s}}}{x}-1\right)\left(\frac{d x_{\mathrm{p}}}{x_{\mathrm{s}}}+\frac{d \dot{n}_{\mathrm{s}}}{\dot{N}}\right)-\frac{d \dot{n}_{\mathrm{p}}}{\dot{N}}\right] \\
& +\left(\frac{P_{\mathrm{c}}}{e_{\mathrm{c}} f_{\mathrm{c}}}\right)\left(x+\frac{\dot{n}_{\mathrm{p}}}{\dot{N}} x_{\mathrm{p}}\right)\left(\frac{d P_{\mathrm{c}}}{P_{\mathrm{c}}}-\frac{1}{e_{\mathrm{c}}} \frac{d e_{\mathrm{c}}}{d T_{\mathrm{c}}} d T_{\mathrm{c}}-\frac{d e_{\mathrm{c}}^{\text {calc }}}{e_{\mathrm{c}}}-\frac{d f_{\mathrm{c}}^{\text {calc }}}{f_{\mathrm{c}}}\right)
\end{aligned}
$$

Noting that $x_{\mathrm{p}} \cong 0$ and using Eqs. A14 and A15, this can be arranged to be

$$
\begin{aligned}
d(R H)= & \frac{x P_{\mathrm{c}}}{e_{\mathrm{c}} f_{\mathrm{c}}}\left[\frac{1}{e_{\mathrm{s}}} \frac{d e_{\mathrm{s}}}{d T_{\mathrm{s}}} d T_{\mathrm{s}}-\frac{d P_{\mathrm{s}}}{P_{\mathrm{s}}}-\frac{1}{e_{\mathrm{c}}} \frac{d e_{\mathrm{c}}}{d T_{\mathrm{c}}} d T_{\mathrm{c}}+\frac{d P_{\mathrm{c}}}{P_{\mathrm{c}}}+d \Delta e^{\text {calc }}+d \Delta f^{\text {calc }}\right. \\
& \left.+\left(\frac{x_{\mathrm{s}}}{x}-1\right)\left(\frac{d x_{\mathrm{p}}}{x_{\mathrm{s}}}+\frac{d \dot{n}_{\mathrm{s}}}{\dot{N}}\right)-\frac{d \dot{n}_{\mathrm{p}}}{\dot{N}}\right]
\end{aligned}
$$

The relative uncertainty for the relative humidity is then: 


$$
\begin{aligned}
u_{\mathrm{r}}(R H)=\left[\frac{u(R H)}{R H}\right]^{2}= & {\left[\left(\frac{1}{e_{\mathrm{s}}} \frac{d e_{\mathrm{s}}}{d T_{\mathrm{s}}}\right)^{2} u\left(T_{\mathrm{s}}\right)^{2}+\frac{u\left(P_{\mathrm{s}}\right)^{2}}{P_{\mathrm{s}}^{2}}+\left(\frac{1}{e_{\mathrm{c}}} \frac{d e_{\mathrm{c}}}{d T_{\mathrm{c}}}\right)^{2} u\left(T_{\mathrm{c}}\right)^{2}+\frac{u\left(P_{\mathrm{c}}\right)^{2}}{P_{\mathrm{c}}^{2}}\right.} \\
& \left.+u_{\mathrm{r}}\left(\Delta e^{\text {calc }}\right)+u_{\mathrm{r}}\left(\Delta f^{\text {calc }}\right)+\left(\frac{x_{\mathrm{s}}}{x}-1\right)^{2}\left(\frac{u\left(x_{\mathrm{p}}\right)^{2}}{x_{\mathrm{s}}^{2}}+\frac{u\left(\dot{n}_{\mathrm{s}}\right)^{2}}{\dot{N}^{2}}\right)+\frac{u\left(\dot{n}_{\mathrm{p}}\right)^{2}}{\dot{N}^{2}}\right],
\end{aligned}
$$

where $u_{\mathrm{r}}\left(\Delta e^{\text {calc }}\right)^{2}$ and $u_{\mathrm{r}}\left(\Delta f^{\text {calc }}\right)^{2}$ are given by Eq. A19-A20. Note that in the limit of $x=x_{\mathrm{s}}$, Eq. A39 is equivalent to Eq. A28. 


\section{Appendix II. Uncertainty Element Subcomponents for the HHG and its Test Chamber}

Table 5. Subcomponents for the uncertainty elements $T_{\mathrm{s}}, T_{\mathrm{c}}, P_{\mathrm{s}}$, and $P_{\mathrm{c}}$ for the Hybrid Generator and its Test Chamber. Note that saturation efficiency, air contamination, and water contamination have been assigned to be subcomponents of $T_{\mathrm{s}}$ for simplicity.

\begin{tabular}{|c|c|c|c|c|}
\hline & Source of & certainty & Standard Uncertainty & Unit \\
\hline \multirow{10}{*}{$\begin{array}{l}\text { Saturator } \\
\text { Temperature } \\
T_{\mathrm{s}}\end{array}$} & \multirow{3}{*}{$S P R T$} & Calibration & 0.5 & $\mathrm{mK}$ \\
\hline & & \begin{tabular}{|l|} 
Drift \\
\end{tabular} & 0.3 & $\mathrm{mK}$ \\
\hline & & \begin{tabular}{|l} 
Self-heating \\
\end{tabular} & 0.1 & $\mathrm{mK}$ \\
\hline & \multirow{2}{*}{ Bridge } & Calibration & 0.1 & $\mathrm{mK}$ \\
\hline & & \begin{tabular}{|l|} 
Resolution \\
\end{tabular} & 0.1 & $\mathrm{mK}$ \\
\hline & \multirow[t]{2}{*}{ Saturator } & $\begin{array}{l}\text { Temperature } \\
\text { gradients }\end{array}$ & \begin{tabular}{|ll}
1 & $\left(T \leq 40^{\circ} \mathrm{C}\right)$ \\
$0.16 T /{ }^{\circ} \mathrm{C}-5.4$ & $\left(T>40^{\circ} \mathrm{C}\right)$ \\
\end{tabular} & $\mathrm{mK}$ \\
\hline & & Temperature Stability & 1 & $\mathrm{mK}$ \\
\hline & \multirow{3}{*}{ Other } & Saturation efficiency & 0.5 & $\mathrm{mK}$ \\
\hline & & Air contamination & $<0.2$ & $\mathrm{mK}$ \\
\hline & & Water contamination & $<0.2$ & $\mathrm{mK}$ \\
\hline \multirow{6}{*}{$\begin{array}{l}\text { Chamber } \\
\text { Temperature } \\
T_{\mathrm{c}}\end{array}$} & \multirow{3}{*}{$P R T$} & Calibration & 10 & $\mathrm{mK}$ \\
\hline & & \begin{tabular}{|l|} 
Drift \\
\end{tabular} & 0.3 & $\mathrm{mK}$ \\
\hline & & \begin{tabular}{|l} 
Self-heating \\
\end{tabular} & 0.1 & $\mathrm{mK}$ \\
\hline & \multirow{2}{*}{ Bridge } & Calibration & 0.1 & $\mathrm{mK}$ \\
\hline & & Resolution & 0.1 & $\mathrm{mK}$ \\
\hline & Chamber & Temperature Nonuniformity & 10 & $\mathrm{mK}$ \\
\hline \multirow{7}{*}{$\begin{array}{l}\text { Saturator } \\
\text { Pressure } \\
P_{\mathrm{s}}\end{array}$} & \multirow{6}{*}{$\begin{array}{l}\text { Pressure } \\
\text { gauge }\end{array}$} & Calibration & 7 & $\mathrm{~Pa}$ \\
\hline & & Drift & $10+0.0001 P_{\mathrm{s}} / \mathrm{Pa}$ & $\mathrm{Pa}$ \\
\hline & & Resolution & 7 & $\mathrm{~Pa}$ \\
\hline & & Hydrostatic head & 1 & $\mathrm{~Pa}$ \\
\hline & & Flow effect & 2 & $\mathrm{~Pa}$ \\
\hline & & Repeatability & 7 & $\mathrm{~Pa}$ \\
\hline & Saturator & $\begin{array}{l}P_{\mathrm{s}} \\
\text { stability }\end{array}$ & \begin{tabular}{|ll}
7 & $\left(P_{\mathrm{s}} \approx\right.$ ambient pressure $)$ \\
20 & $\left(P_{\mathrm{s}}>\right.$ ambient pressure $)$
\end{tabular} & $\mathrm{Pa}$ \\
\hline \multirow{7}{*}{$\begin{array}{l}\text { Chamber } \\
\text { Pressure } \\
P_{c}\end{array}$} & \multirow{6}{*}{$\begin{array}{l}\text { Pressure } \\
\text { gauge }\end{array}$} & Calibration & 7 & $\mathrm{~Pa}$ \\
\hline & & Drift & 5 & $\mathrm{~Pa}$ \\
\hline & & Resolution & 7 & $\mathrm{~Pa}$ \\
\hline & & Hydrostatic head & 1 & $\mathrm{~Pa}$ \\
\hline & & Flow effect & 2 & $\mathrm{~Pa}$ \\
\hline & & Repeatability & 7 & $\mathrm{~Pa}$ \\
\hline & Chamber & $P_{\mathrm{c}}$ stability & 7 & $\mathrm{~Pa}$ \\
\hline
\end{tabular}


Appendix III. Sample Calibration Reports

Page 65 of 75 


\title{
墖 \\ UNITED STATES DEPARTMENT OF COMMERCE National Institute of Standards and Technology Gaithersburg, Maryland 20899-8361 \\ Sample Calibration Report REPORT OF CALIBRATION CHILLED-MIRROR HYGROMETER
}

\author{
Michell Instruments, Model S4000 TRS, S/N 12345 \\ Submitted \\ by \\ DPM, Inc. \\ Somewhere, NC 98765
}

\begin{abstract}
The chilled-mirror hygrometer was calibrated by comparison against air of known water vapor content, generated by the NIST Hybrid Humidity Generator (HHG). The hygrometer mirror was cleaned using distilled water before the calibration. Subsequently, the outlet from the generator was connected to the inlet of the hygrometer using stainless steel tubing. The frost / dew points generated during the calibration ranged from $-90^{\circ} \mathrm{C}$ to $20^{\circ} \mathrm{C}$. For each calibration point, the following procedure was used. The generator was set to produce humidified air with a flow rate of 30 standard liters per minute (SLM), and approximately 0.7 SLM of this air was set to pass through the hygrometer. For the frost points, the hygrometer sensor body temperature was set to $20{ }^{\circ} \mathrm{C}$ above the frost point temperature. Once the flow started, humidity measurements were made with the hygrometer to determine when the readings reached a steady state. Once a steady state was reached, the determined values of the generated humidity were averaged over a minimum of 30 minutes, as were the values of the humidity from the hygrometer display. These average values are presented below in Table 1 for all calibration points. The dew/frostpoint standards generated by the HHG are traceable to the International System of Units (SI) through NIST pressure and temperature standards. The generator and the complete calibration procedure are described in NIST SP250-83r1, entitled "Calibration of Hygrometers with the Hybrid Humidity Generator", which may be found at https://nvlpubs.nist.gov/nistpubs/Legacy/SP/nistspecialpublication250-83r1.pdf. The results in this report pertain only to the item tested.
\end{abstract}

In Table 1, three uncertainty values are provided for each calibration point. $U_{\mathrm{HHG}}$ is the expanded uncertainty of the dew/frost point generated by the NIST Hybrid Humidity Generator. $U_{\text {DUT }}$ is the expanded uncertainty of the device under test due to reproducibility, estimated by the manufacturer. Finally, $U_{\text {Tot }}$ is the total expanded uncertainty of the calibration, obtained by adding $U_{\mathrm{HHG}}$ and $U_{\mathrm{DUT}}$ in quadrature. An expanded uncertainty is expressed as $U=k u_{\mathrm{c}}$, with $U$ determined from a combined standard uncertainty $u_{\mathrm{c}}$ and a coverage factor $k=2$. The values of $U_{\mathrm{HHG}}$ are dependent on the uncertainties of individual generator parameters. A discussion and presentation of the total HHG uncertainties and their components as a function of the generator parameters are provided in NIST SP 250-83r1.

For the Director

National Institute of Standards and Technology

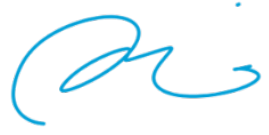

Julia Scherschligt

Leader, Thermodynamic Metrology Group

Sensor Science Division

Measurement and analysis performed by Christopher Meyer

Order Number: O-0000009876

Service ID: $36070 \mathrm{~S}$

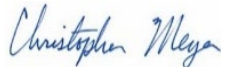

P.O. Number: 12345

Measurements performed: 7/27/21-8/01/21

Report Date: August 6, 2021

Page 1 of 2 
Order No: O-0000009876

Service ID: $36070 \mathrm{C}$

Date: August 6, 2021

Table 1

Michell Instruments, Model S4000 TRS, S/N 155515

\begin{tabular}{|c|c|}
\hline \multicolumn{2}{|c|}{ Calibration Values } \\
\hline $\begin{array}{c}\text { NIST HHG } \\
T_{\mathrm{DP}}, T_{\mathrm{FP}} \\
\left({ }^{\circ} \mathrm{C}\right)\end{array}$ & $\begin{array}{c}\text { DUT } \\
T_{\mathrm{DP}}, T_{\mathrm{FP}} \\
\left({ }^{\circ} \mathrm{C}\right)\end{array}$ \\
\hline 20.01 & 20.00 \\
1.01 & 1.02 \\
-20.01 & -20.09 \\
-40.04 & -40.11 \\
-59.99 & -60.08 \\
-80.05 & -80.15 \\
-90.27 & -90.38 \\
\hline
\end{tabular}

\begin{tabular}{|c|c|c|}
\hline \multicolumn{3}{|c|}{ Calibration Uncertainties } \\
\hline $\begin{array}{c}U_{\text {HHG }} \\
(k=2) \\
\left({ }^{\circ} \mathrm{C}\right)\end{array}$ & $\begin{array}{c}U_{\text {DUT }} \\
(k=2) \\
\left({ }^{\circ} \mathrm{C}\right)\end{array}$ & $\begin{array}{c}U_{\text {Tot }} \\
(k=2) \\
\left({ }^{\circ} \mathrm{C}\right)\end{array}$ \\
\hline 0.02 & 0.1 & 0.1 \\
0.02 & 0.1 & 0.1 \\
0.02 & 0.1 & 0.1 \\
0.02 & 0.1 & 0.1 \\
0.02 & 0.1 & 0.1 \\
0.03 & 0.1 & 0.1 \\
0.12 & 0.1 & 0.2 \\
\hline
\end{tabular}

In this table,

NIST HHG $T_{\mathrm{DP}}$ is the dew point temperature generated by the NIST hybrid humidity generator, NIST HHG $T_{\mathrm{FP}}$ is the frost point temperature generated by the NIST hybrid humidity generator,

DUT $T_{\mathrm{DP}}$ is the dew point temperature measured by the device under test, DUT $T_{\mathrm{FP}}$ is the frost point temperature measured by the device under test,

$U_{\mathrm{HHG}}$ is the expanded uncertainty $(k=2)$ of the hybrid humidity generator,

$U_{\text {DUT }}$ is the estimated expanded uncertainty $(k=2)$ of the device under test, based on its specifications, and $U_{\text {Tot }}$ is the total expanded uncertainty $(k=2)$ of the calibration, as calculated from $U_{\mathrm{HHG}}$ and $U_{\text {DUT. }}$.

Note: the values above $0{ }^{\circ} \mathrm{C}$ are dew point temperatures and the values below $0{ }^{\circ} \mathrm{C}$ are frost point temperatures.

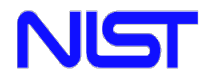

National Institute of Standards and Technology

Technology Administration, U.S. Department of Commerce

Page 2 of 2 


$$
\begin{gathered}
\text { UNITED STATES } \\
\text { National Institut } \\
\text { Gaithersburg, Marylat } \\
\text { REPORT OF CATIBRATION } \\
\text { CHILLED-MIRROR HYGROMETER } \\
\text { (with external thermometer) } \\
\text { SH Systems Dew Point Mirror RH-473-RP2, S/N 12-3456 } \\
\text { Submitted } \\
\text { by }
\end{gathered}
$$

\section{Sample Calibration Report REPORT OF CALIBRATION CHILLED-MIRROR HYGROMETER (with external thermometer)}

\author{
Submitted \\ by \\ DPM, Inc. \\ Somewhere, NC 98765
}

\begin{abstract}
The dew/frost-point temperature measurements made by the device under test (DUT) were calibrated by comparison against known dew-point values in air generated by the NIST Hybrid Humidity Generator (HHG). Before calibration, the DUT mirror was cleaned using distilled water. Subsequently, the outlet from the generator was connected to the inlet of the DUT using stainless steel tubing. For the relative-humidity calibrations, the external thermometer of the DUT was placed in a temperature controlled bath next to a NIST-calibrated thermometer. The relative-humidity value displayed by the DUT, $R H_{\text {DUT, }}$ determined from the measured dew point and measured external thermometer temperature, was compared to the relative humidity $R H_{\mathrm{HHG}}$ from the HHG. Specifically, $R H_{\mathrm{HHG}}$ is the calculated relative humidity of a sample of air with a known dew point generated by the HHG for the temperature measured by the NIST thermometer. The dew point, temperature, and relative humidity measurements were determined simultaneously. For all calibration points, the average values of the dew point temperature, external thermometer temperature, and relative humidity are presented in Table 1, Table 2, and Table 3 , respectively.
\end{abstract}

The frost / dew points generated during the calibration ranged from $-8.4{ }^{\circ} \mathrm{C}$ to $20{ }^{\circ} \mathrm{C}$ and the thermometers were controlled at temperatures between $20^{\circ} \mathrm{C}$ and $25^{\circ} \mathrm{C}$. For each calibration point, the following procedure was used. The generator was set to produce humidified air with a flow rate of 30 standard liters per minute (SLM), and approximately 0.5 SLM of this air was set to pass through the DUT. Once the flow started, humidity measurements were made with the DUT to determine when the readings reached a steady state. Once a steady state was reached, the values of the generated and DUT dew point temperature, the NIST and DUT thermometer temperature, and the generated and DUT relative humidity were averaged over a minimum of 30 minutes. The DUT values were automatically acquired by computer using the DUT serial port. The dew/frost-point and relative humidity standards generated by the HHG are traceable to the International System of Units (SI) through NIST pressure and temperature standards. The generator and the complete calibration procedure are described in NIST SP250 83r1, entitled "Calibration of Hygrometers with the Hybrid Humidity Generator", which may be found at

https://nvlpubs.nist.gov/nistpubs/Legacy/SP/nistspecialpublication250-83r1.pdf. The results in this report pertain only to the item tested.

In Tables 1-3, expanded uncertainty values are provided for each calibration point. An expanded uncertainty is expressed as $U=k u_{\mathrm{c}}$, with $U$ determined from a combined standard uncertainty $u_{\mathrm{c}}$ and a coverage factor $k=2$. The uncertainty of the HHG is dependent on the uncertainties of individual generator parameters, which are discussed and presented in NIST SP $250-83$.

For the Director

National Institute of Standards and Technology

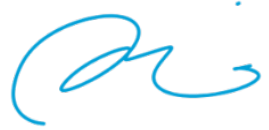

Julia Scherschligt

Leader, Thermodynamic Metrology Group

Sensor Science Division

Measurement and analysis performed by Christopher Meyer

Order Number: O-0000009876

Service ID: $36070 \mathrm{~S}$

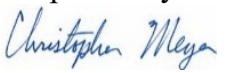

P.O. Number: 12345

Measurements performed: 7/27/21-8/01/21

Report Date: August 6, 2021

Page 1 of 4 
Order No: O-0000009876

Service ID: $36070 \mathrm{~S}$

Date: August 6, 2021

RH Systems Dew Point Mirror RH-473-RP2, S/N 12-3456

Table 1

Dew/Frost Point Temperature

\begin{tabular}{|c|c|c|}
\hline Pt. & \multicolumn{2}{|c|}{ Calibration Values } \\
\hline & $\begin{array}{c}\text { NIST } \\
T_{\mathrm{DP},} T_{\mathrm{FP}} \\
\left({ }^{\circ} \mathrm{C}\right)\end{array}$ & $\begin{array}{c}\text { DUT } \\
T_{\mathrm{DP},} T_{\mathrm{FP}} \\
\left({ }^{\circ} \mathrm{C}\right)\end{array}$ \\
\hline 1 & 20.72 & 20.63 \\
2 & 17.79 & 17.73 \\
3 & 13.02 & 12.95 \\
4 & 6.20 & 6.19 \\
5 & -8.38 & -8.36 \\
6 & 15.38 & 15.32 \\
7 & 10.65 & 10.61 \\
\hline
\end{tabular}

\begin{tabular}{|c|c|c|}
\hline \multicolumn{2}{|c|}{ Calibration Uncertainties } \\
\hline $\begin{array}{c}\text { NIST } \\
\left(T_{\mathrm{DP},} T_{\mathrm{FP}}\right) \\
\left({ }^{\circ} \mathrm{C}\right)\end{array}$ & $\begin{array}{c}\text { DUT } \\
U\left(T_{\mathrm{DP}}, T_{\mathrm{FP}}\right) \\
\left({ }^{\circ} \mathrm{C}\right)\end{array}$ & $\begin{array}{c}U_{\mathrm{Tot}} \\
(k=2) \\
\left({ }^{\circ} \mathrm{C}\right)\end{array}$ \\
\hline 0.02 & 0.05 & 0.05 \\
0.02 & 0.05 & 0.05 \\
0.02 & 0.05 & 0.05 \\
0.02 & 0.05 & 0.05 \\
0.02 & 0.05 & 0.05 \\
0.02 & 0.05 & 0.05 \\
0.02 & 0.05 & 0.05 \\
\hline
\end{tabular}

In this table,

NIST $T_{\mathrm{DP}}$ is the dew point temperature generated by the NIST hybrid humidity generator, NIST $T_{\mathrm{FP}}$ is the frost point temperature generated by the NIST hybrid humidity generator

DUT $T_{\mathrm{DP}}$ is the dew point temperature measured by the device under test, DUT $T_{\mathrm{FP}}$ is the frost point temperature measured by the device under test,

NIST $U\left(T_{\mathrm{DP}}, T_{\mathrm{FP}}\right)$ is the expanded uncertainty $(k=2)$ of the hybrid humidity generator,

DUT $U\left(T_{\mathrm{DP}}, T_{\mathrm{FP}}\right)$ is the estimated expanded uncertainty $(k=2)$ of the device under test, based on its specifications, and

$U_{\text {Tot }}$ is the total expanded uncertainty $(k=2)$ of the calibration, as calculated from $U\left(T_{\mathrm{DP}, \mathrm{NIST}}\right)$ and $U\left(T_{\mathrm{DP}, \mathrm{DUT}}\right)$.

Note: the values above $0^{\circ} \mathrm{C}$ are dew point temperatures and the values below $0{ }^{\circ} \mathrm{C}$ are frost point temperatures. 
Order No: O-0000009876

Service ID: $36070 \mathrm{~S}$

Date: August 6, 2021

RH Systems Dew Point Mirror RH-473-RP2, S/N 12-3456

Table 2

External Thermometer Temperature $T$

\begin{tabular}{|c|c|c|}
\hline Pt. & \multicolumn{2}{|c|}{ Calibration Values } \\
\hline & $\begin{array}{c}T_{\text {NIST }} \\
\left({ }^{\circ} \mathrm{C}\right)\end{array}$ & $\begin{array}{r}T_{\text {DUT }} \\
\left({ }^{\circ} \mathrm{C}\right)\end{array}$ \\
\hline 1 & 22.41 & 22.42 \\
2 & 22.30 & 22.31 \\
3 & 22.41 & 22.42 \\
4 & 22.39 & 22.40 \\
5 & 23.23 & 23.25 \\
6 & 24.85 & 24.86 \\
7 & 19.94 & 19.95 \\
\hline
\end{tabular}

\begin{tabular}{|c|c|c|}
\hline \multicolumn{3}{|c|}{ Calibration Uncertainties } \\
\hline $\begin{array}{c}U\left(T_{\mathrm{NIST}}\right) \\
(k=2) \\
\left({ }^{\circ} \mathrm{C}\right)\end{array}$ & $\begin{array}{c}U\left(T_{\mathrm{DUT}}\right) \\
(k=2) \\
\left({ }^{\circ} \mathrm{C}\right)\end{array}$ & $\begin{array}{c}U_{\mathrm{Tot}}(T) \\
(k=2) \\
\left({ }^{\circ} \mathrm{C}\right)\end{array}$ \\
\hline 0.01 & 0.01 & 0.01 \\
0.01 & 0.01 & 0.01 \\
0.01 & 0.01 & 0.01 \\
0.01 & 0.01 & 0.01 \\
0.01 & 0.01 & 0.01 \\
0.01 & 0.01 & 0.01 \\
0.01 & 0.01 & 0.01 \\
\hline
\end{tabular}

In this table,

$T_{\mathrm{NIST}}$ is the bath temperature as measured by the NIST reference thermometer,

$T_{\text {DUT }}$ is the bath temperature as measured by the DUT external thermometer,

$U\left(T_{\mathrm{NIST}}\right)$ is the expanded uncertainty $(k=2)$ of the NIST calibration,

$U\left(T_{\text {DUT }}\right)$ is the estimated expanded uncertainty $(k=2)$ of $T_{\text {DUT }}$, based on the reproducibility of similar probes, and

$U_{\mathrm{Tot}}$ is the total expanded uncertainty $(k=2)$ of the external thermometer calibration, as calculated from $U\left(T_{\mathrm{NIST}}\right)$ and $U\left(T_{\text {DUT }}\right)$. 
Order No: O-0000009876

Service ID: $36070 \mathrm{~S}$

Date: August 6, 2021

RH Systems Dew Point Mirror RH-473-RP2, S/N 12-3456

Table 3

Relative Humidity

\begin{tabular}{|c|c|c|}
\hline Pt. & \multicolumn{2}{|c|}{ Calibration Values } \\
\hline $\begin{array}{c}R H_{\text {NIST }} \\
(\%)\end{array}$ & $\begin{array}{c}R H_{\text {DUT }} \\
(\%)\end{array}$ \\
\hline 1 & 90.2 & 89.6 \\
3 & 75.6 & 75.3 \\
4 & 55.3 & 55.0 \\
5 & 35.0 & 34.9 \\
6 & 55.6 & 10.5 \\
7 & 55.0 & 55.4 \\
\hline
\end{tabular}

\begin{tabular}{|c|c|c|}
\hline \multicolumn{3}{|c|}{ Calibration Uncertainties } \\
\hline $\begin{array}{c}U\left(R H_{\text {NIST }}\right) \\
(k=2) \\
(\%)\end{array}$ & $\begin{array}{c}U\left(R H_{\text {DUT }}\right) \\
(k=2) \\
(\%)\end{array}$ & $\begin{array}{c}U_{\text {Tot }}(R H) \\
k=2) \\
(\%)\end{array}$ \\
\hline 0.1 & 0.2 & 0.2 \\
0.1 & 0.2 & 0.2 \\
0.1 & 0.1 & 0.1 \\
0.1 & 0.1 & 0.1 \\
0.1 & 0.1 & 0.1 \\
0.1 & 0.1 & 0.1 \\
0.1 & 0.1 & 0.1 \\
\hline
\end{tabular}

For each point in this table,

$R H_{\text {NIST }}$ is the is the calculated relative humidity of a sample of air with the dew point generated by the HHG (given for this point in Table 1) and at the temperature measured by the NIST thermometer (given for this point in Table 2),

$R H_{\text {DUT }}$ is the relative humidity measured by the DUT, determined from the measured dew point (given for this point in table 1) and measured external thermometer temperature (given for this point in Table 2),

$U\left(R H_{\mathrm{NIST}}\right)$ is the expanded uncertainty $(k=2)$ of the NIST calibration, excluding DUT uncertainties,

$U\left(R H_{\text {DUT }}\right)$ is the estimated expanded uncertainty $(k=2)$ of $R H_{\text {DUT }}$ due to reproducibility, based on its specifications, and

$U\left(R H_{\mathrm{Tot}}\right)$ is the total expanded uncertainty $(k=2)$ of the relative-humidity calibration, as calculated from $U\left(R H_{\mathrm{NIST}}\right)$ and $U\left(R H_{\text {DUT }}\right)$.

$U_{\text {Tot }}$ is the total expanded uncertainty $(k=2)$ of the relative humidity calibration, as calculated from $U\left(R H_{\text {NIST }}\right)$ and $U\left(R H_{\text {DUT }}\right)$.

\section{NIST}




\title{
Sample Calibration Report REPORT OF CALIBRATION THERMOHYGROMETER
}

\author{
Fluke Model 1620 "DewK" Thermohygrometer, S/N 12345 with \\ Fluke Thermo-hygrometer Sensor 2626-S, S/N 98765 \\ Submitted \\ by \\ DPM, Inc. \\ Somewhere, NC 98765
}

\begin{abstract}
The thermohygrometer was calibrated by comparison against air of known water vapor content, pressure and temperature. The moist air was generated by the NIST Hybrid Humidity Generator (HHG) and channeled through stainless-steel tubes into a temperature-controlled stainless-steel test chamber. Before entering the chamber, the moist air was directed through a heat exchanger to bring it to the temperature of the chamber. The flowing air exited the test chamber through a $122 \mathrm{~cm}$ long stainlesssteel tube. The following procedure was used for the calibration of the device under test (DUT). The generator was set to produce humidified air with a flow rate of 150 standard liters per minute (SLM) through the chamber. The moisture content in the chamber was measured by a NIST dew-point hygrometer. Once the flow started, humidity measurements were made with the hygrometers to determine when the readings reached a steady state. For each calibration point, once a steady state was reached, the determined values of the generated relative humidity were averaged over a minimum of 30 minutes, as were the values of the humidity from the customer hygrometer. These average values are presented below in Table 1 for all calibration points. The relative humidity standards generated by the HHG are traceable to the International System of Units (SI) through NIST pressure and temperature standards. The generator and the complete calibration procedure are described in NIST SP250-83r1, entitled "Calibration of Hygrometers with the Hybrid Humidity Generator", which may be found at https://nvlpubs.nist.gov/nistpubs/Legacy/SP/nistspecialpublication250-83r1.pdf. The results in this report pertain only to the item tested.
\end{abstract}

In Table 1, three uncertainty values are provided for each calibration point. $U\left(T_{\mathrm{NIST}}\right)$ and $U\left(R H_{\mathrm{NIST}}\right)$ are the expanded uncertainties of the NIST-determined values of the temperature and relative humidity, respectively. $U\left(T_{\mathrm{DUT}}\right)$ and $U\left(R H_{\mathrm{DUT}}\right)$ are the expanded reproducibility-related uncertainties of the DUT measurements of the temperature and relative humidity, respectively; these uncertainties are estimated using the manufacturer specifications of the hygrometer. Finally, $U_{\text {Tot }}(T)$ and $U_{\mathrm{Tot}}(R H)$ are the total expanded uncertainties of the temperature and relative-humidity calibrations, respectively, obtained by adding $U_{\mathrm{HHG}}$ and $U_{\mathrm{DUT}}$ in quadrature. An expanded uncertainty is expressed as $U=k u_{\mathrm{c}}$, with $U$ determined from a combined standard uncertainty $u_{\mathrm{c}}$ and a coverage factor $k=2$. The values of $U\left(T_{\mathrm{NIST}}\right)$ and $U\left(R H_{\mathrm{NIST}}\right)$ are dependent on the uncertainties of individual parameters for the HHG and test chamber. A discussion of the uncertainty components for the HHG uncertainties as a function of the generator parameters is provided in NIST SP 250-83r1.

For the Director

National Institute of Standards and Technology

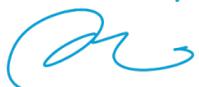

Julia Scherschligt

Leader, Thermodynamic Metrology Group

Sensor Science Division

Measurement and analysis performed by Christopher Meyer

Test Number: 0000009876

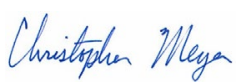

Service ID: 36070 S

Purchase Order Number: 12345

Measurements performed: 7/27/21-8/01/21

Report Date: August 6, 2021

Page 1 of 2

Page 72 of 75 
Test No: 0000009876

Service ID: $36070 \mathrm{~S}$

Date: August 6, 2021

Table 1

Fluke Model 1620 "DewK" Thermohygrometer, S/N 12345 with

Fluke Thermo-hygrometer Sensor 2626-S, S/N 98765

a. Test Chamber Temperature $T$

\begin{tabular}{|c|c|c|}
\hline Pt. & \multicolumn{2}{|c|}{ Calibration Values } \\
\hline & $\begin{array}{r}T_{\text {NIST }} \\
\left({ }^{\circ} \mathrm{C}\right)\end{array}$ & $\begin{array}{r}T_{\text {DUT }} \\
\left({ }^{\circ} \mathrm{C}\right)\end{array}$ \\
\hline 1 & 22.96 & 22.87 \\
2 & 22.99 & 22.91 \\
3 & 22.98 & 22.89 \\
4 & 19.04 & 18.95 \\
5 & 29.00 & 28.91 \\
\hline
\end{tabular}

\begin{tabular}{|c|c|c|}
\hline \multicolumn{3}{|c|}{ Calibration Uncertainties } \\
\hline $\begin{array}{c}U\left(T_{\text {NIST }}\right) \\
(k=2) \\
\left({ }^{\circ} \mathrm{C}\right)\end{array}$ & $\begin{array}{c}U\left(T_{\text {DUT }}\right) \\
(k=2) \\
\left({ }^{\circ} \mathrm{C}\right)\end{array}$ & $\begin{array}{c}U_{\text {Tot }}(T) \\
(k=2) \\
\left({ }^{\circ} \mathrm{C}\right)\end{array}$ \\
\hline 0.03 & 0.025 & 0.04 \\
0.03 & 0.025 & 0.04 \\
0.03 & 0.025 & 0.04 \\
0.03 & 0.025 & 0.04 \\
0.03 & 0.025 & 0.04 \\
\hline
\end{tabular}

b. Test Chamber Relative Humidity $R H$

\begin{tabular}{|c|c|c|}
\hline Pt. & \multicolumn{2}{|c|}{ Calibration Values } \\
\hline & $\begin{array}{c}R H_{\text {NIST }} \\
(\%)\end{array}$ & $\begin{array}{c}R H_{\text {DUT }} \\
(\%)\end{array}$ \\
\hline 1 & 84.0 & 84.5 \\
2 & 50.0 & 50.4 \\
3 & 17.6 & 18.8 \\
4 & 49.6 & 50.7 \\
5 & 49.9 & 50.1 \\
\hline
\end{tabular}

\begin{tabular}{|c|c|c|}
\hline \multicolumn{3}{|c|}{ Calibration Uncertainties } \\
\hline $\begin{array}{c}U\left(R H_{\text {NIST }}\right) \\
(k=2) \\
(\%)\end{array}$ & $\begin{array}{c}U\left(R H_{\text {DUT }}\right) \\
(k=2) \\
(\%)\end{array}$ & $\begin{array}{c}U_{\text {Tot }}(R H) \\
(k=2) \\
(\%)\end{array}$ \\
\hline 0.4 & 1.0 & 1.1 \\
0.4 & 1.0 & 1.1 \\
0.4 & 1.0 & 1.1 \\
0.4 & 1.0 & 1.1 \\
0.4 & 1.0 & 1.1 \\
\hline
\end{tabular}

In this table,

$T_{\text {NIST }}$ is the test chamber temperature, as measured by the NIST reference thermometer,

$T_{\text {DUT }}$ is the test chamber temperature, as measured by the device under test,

$U\left(T_{\mathrm{NIST}}\right)$ is the expanded uncertainty $(k=2)$ of temperature inside the test chamber,

$U\left(T_{\text {DUT }}\right)$ is the estimated expanded uncertainty $(k=2)$ of the DUT for temperature measurement due to reproducibility, based on its specifications, and

$U\left(T_{\text {Tot }}\right)$ is the total expanded uncertainty $(k=2)$ of the temperature calibration, as calculated from $U\left(T_{\mathrm{NIST}}\right)$ and $U\left(T_{\mathrm{DUT}}\right)$.

$R H_{\text {NIST }}$ is the relative humidity in the HHG test chamber, calculated using the chamber temperature and the known moisture content generated by the HHG into the chamber

$R H_{\text {DUT }}$ is the relative humidity in the HHG test chamber, as measured by the device under test

$U\left(R H_{\mathrm{NIST}}\right)$ is the expanded uncertainty $(k=2)$ of relative humidity inside the test chamber,

$U\left(R H_{\text {DUT }}\right)$ is the estimated expanded uncertainty $(k=2)$ of the DUT for relative-humidity measurement due to reproducibility, based on its specifications, and

$U\left(R H_{\mathrm{Tot}}\right)$ is the total expanded uncertainty $(k=2)$ of the relative-humidity calibration, as calculated from $U\left(R H_{\mathrm{NIST}}\right)$ and $U\left(R H_{\text {DUT }}\right)$.

\section{NLT}




\title{
圈 \\ Sample Calibration Report REPORT OF CALIBRATION CAVITY RING DOWN HYGROMETER
}

\author{
Tiger Optics, Model LaserTrace $3 \mathrm{H}_{2} \mathrm{O}$ \\ $\mathrm{S} / \mathrm{N} 12345$ \\ Submitted \\ by \\ DPM, Inc. \\ Somewhere, NC 98765
}

\begin{abstract}
The cavity ring down hygrometer was calibrated by comparison against air of known water vapor content, generated by the NIST Hybrid Humidity Generator (HHG). The outlet from the generator was connected to the inlet of the hygrometer using stainless steel tubing. The pressure at the inlet of the hygrometer was slightly above ambient pressure. The outlet of the hygrometer was attached to a diaphragm pump. The water amount fraction generated during the calibration ranged from $0.5 \mathrm{micromol} / \mathrm{mol}$ to $5.0 \mathrm{micromol} / \mathrm{mol}$. For each calibration point, the following procedure was used. The generator was set to produce humidified air with a flow rate of 17 standard liters per minute (SLM), this air passed in parallel through the test hygrometer, a check hygrometer, and a bypass port. Before measurements were made, the hygrometer was configured for air as the carrier gas and the hygrometer was autotuned. Once the flow started, humidity measurements were made with the hygrometer to determine when the readings reached a steady state. Once a steady state was reached, the determined values of the generated humidity were averaged over a minimum of 30 minutes, as were the values of the humidity from the hygrometer. The hygrometer values were read and recorded from the display. These average values are presented below in Table 1 for all calibration points. The relative humidity standards generated by the HHG are traceable to the International System of Units (SI) through NIST pressure and temperature standards. The generator and the complete calibration procedure are described in NIST SP250-83r1, entitled "Calibration of Hygrometers with the Hybrid Humidity Generator", which may be found at

https://nvlpubs.nist.gov/nistpubs/Legacy/SP/nistspecialpublication250-83r1.pdf. The results in this report pertain only to the item tested.

In Table 1, three uncertainty values are provided for each calibration point. $U_{\mathrm{HHG}}$ is the expanded uncertainty of the water amount fraction generated by the NIST Hybrid Humidity Generator. $U_{\text {DUT }}$ is the expanded uncertainty of the device under test due to reproducibility, estimated by the manufacturer. Finally, $U_{\mathrm{Tot}}$ is the total expanded uncertainty of the calibration, obtained by adding $U_{\mathrm{HHG}}$ and $U_{\mathrm{DUT}}$ in quadrature. An expanded uncertainty is expressed as $U=k u_{\mathrm{c}}$, with $U$ determined from a combined standard uncertainty $u_{\mathrm{c}}$ and a coverage factor $k=2$. The values of $U_{\mathrm{HHG}}$ are dependent on the uncertainties of individual generator parameters. A discussion and presentation of the total HHG uncertainties and their components as a function of the generator parameters are provided in NIST SP 250-83rl.
\end{abstract}

For the Director

National Institute of Standards and Technology

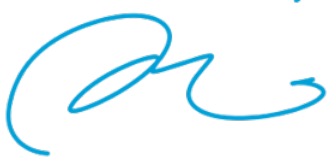

Julia Scherschligt

Group Leader, Thermodynamic Metrology

Sensor Science Division

Measurement and analysis performed by Christopher Meyer

Order Number: 0000009876

Service ID: 36070 S

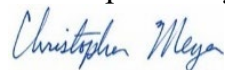

Measurements performed: August 4, 2021

Report Date: August 6, 2021

Page 1 of 2 
Order No: 0000009876

Service ID: $36070 \mathrm{~S}$

Date: August 6, 2021

Table 1

Tiger Optics Cavity Ring Down Hygrometer

LaserTrace $3 \mathrm{H}_{2} \mathrm{O}$; S/N 12345

\begin{tabular}{|c|c|}
\hline \multicolumn{2}{|c|}{ Calibration Values } \\
\hline NIST HHG & DUT \\
$x$ & $x$ \\
(micromol $/ \mathrm{mol})$ & $($ micromol $/ \mathrm{mol})$ \\
\hline 5.059 & 5.149 \\
1.039 & 1.048 \\
0.511 & 0.517 \\
\hline
\end{tabular}

\begin{tabular}{|c|c|c|}
\hline \multicolumn{3}{|c|}{ Calibration Uncertainties } \\
\hline $\begin{array}{c}U_{\mathrm{HHG}} \\
(k=2) \\
(\mathrm{micromol} / \mathrm{mol})\end{array}$ & $\begin{array}{c}U_{\text {DUT }} \\
(k=2) \\
(\mathrm{micromol} / \mathrm{mol})\end{array}$ & $\begin{array}{c}U_{\text {Tot }} \\
(k=2) \\
(\mathrm{micromol} / \mathrm{mol})\end{array}$ \\
\hline 0.01 & 0.05 & 0.05 \\
0.003 & 0.01 & 0.01 \\
0.002 & 0.005 & 0.005 \\
\hline
\end{tabular}

In this table,

NIST HHG $x$ is the water amount fraction generated by the NIST hybrid humidity generator,

DUT $x$ is the water amount fraction measured by the device under test,

$U_{\mathrm{HHG}}$ is the expanded uncertainty $(k=2)$ of the hybrid humidity generator,

$U_{\text {DUT }}$ is the estimated expanded uncertainty $(k=2)$ of the device under test, based on its specifications, and

$U_{\text {Tot }}$ is the total expanded uncertainty $(k=2)$ of the calibration, as calculated from $U_{\mathrm{HHG}}$ and $U_{\text {DUT }}$.

\section{NاكT}

National Institute of Standards and Technology

Technology Administration, U.S. Department of Commerce

Page 2 of 2 